HIGH RISK STUDENTS ON TRACK TO GRADUATION:

A QUALITATIVE CASE STUDY OF STUDENT SUCCESS

A Dissertation
presented to
the Faculty of the Graduate School
at the University of Missouri-Columbia
In Partial Fulfillment
of the Requirements for the Degree
Doctor of Education
by
DREW BURKEYBILE
Dr. Sandy Hutchinson, Dissertation Supervisor
December 2020


(C) Copyright by Drew M. Burkeybile 2020

All Rights Reserved 
The undersigned, appointed by the dean of the Graduate School, have examined the thesis or dissertation entitled

HIGH RISK STUDENTS ON TRACK TO GRADUATION:

A QUALITATIVE CASE STUDY OF STUDENT SUCCESS

presented by Drew M. Burkeybile, a candidate for the degree of Doctor of Education in Educational Leadership and Policy Analysis, and hereby certify that, in their opinion, it is worthy of acceptance.

Dr. Sandy Hutchinson

Dr. Barbara N. Martin

Dr. Bryan McDonald

Dr. Brenda Moeder 


\section{DEDICATION}

This dissertation is dedicated to my wonderful wife and terrific kids. It is with their love and support I am able to complete this degree. Thank you, thank you! I appreciate all the sacrifices you made during this time and am truly grateful for all the help along the way. It has been a journey that I could not have completed without my significant other. Thank you for being there during the good times and the challenging times. Thank you for pushing me when it was needed and helping me focus on the ultimate goal. Furthermore, this is dedicated to all my family members who have supported me in achieving my goals. Education is a priority in our family, and I am thankful to have the family support and encouragement complete this degree. 


\section{ACKNOWLEDGEMENTS}

Completion of this degree has been a process influenced by many individuals. I would like to thank my dissertation committee members for their contributions to the research. I would like to thank Dr. Sandy Hutchinson, my advisor and dissertation chair, for the endless support, encouragement, and guidance. I am very grateful for your assistance in getting me into and through this program.

I would also like to recognize and thank all the other individuals in Cohort 10. With extra special acknowledgement for the UCM-Warrensburg cohort who supported me countless times, in countless way, since the beginning of the program. Some wonderful memories were made on Wednesday nights in Lovinger 4000.

I would also like to extend appreciation to the administration at the University of Central Missouri for allowing me to conduct this research. Furthermore, I want to acknowledge the students from the University of Central Missouri who participated in this study. Thank you for your time and for sharing your voice. This research would not be possible without the support from the campus community. 


\section{TABLE OF CONTENTS}

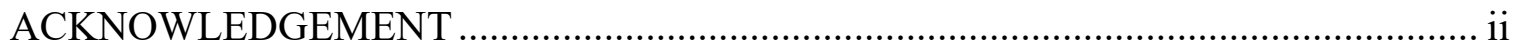

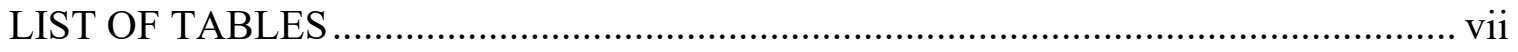

LIST OF ABBREVIATIONS ............................................................................ viii

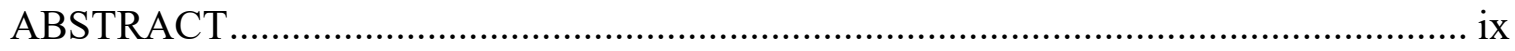

Section

1. INTRODUCTION TO THE DISSERTATION IN PRACTICE ...........................

BACKGROUND OF THE STUDY …..............................................................

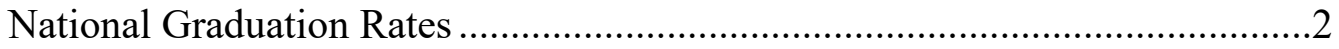

Graduation Rates at the University of Central Missouri .................................3

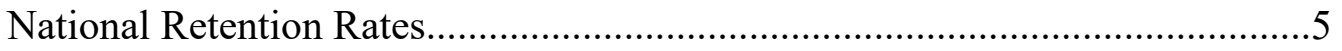

Retention Rates at the University of Central Missouri ..................................5

STATEMENT OF THE PROBLEM ..............................................................6

Gap in the Literature ............................................................................ 10

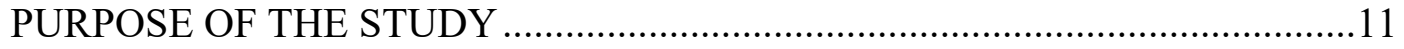

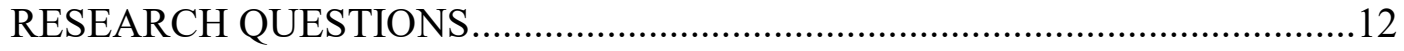

CONCEPTUAL/THEORETICAL FRAMEWORK........................................... 12

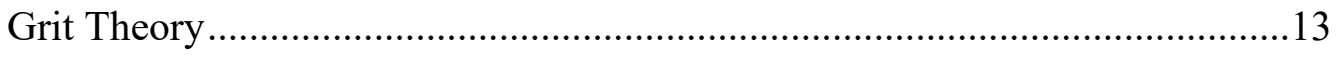

DESIGN OF THE STUDY ........................................................................... 14

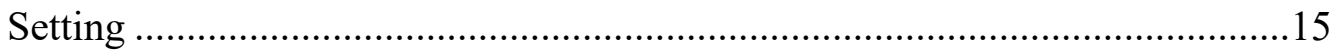

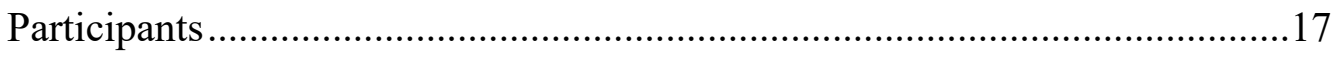

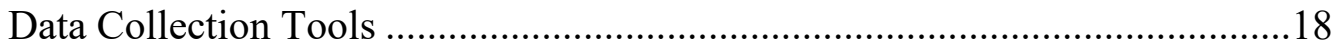

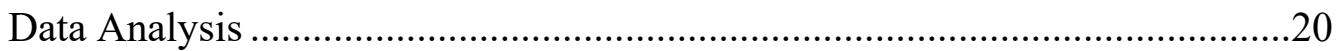

LIMITATIONS, ASSUMPTIONS, AND DESIGN CONTROLS .......................22

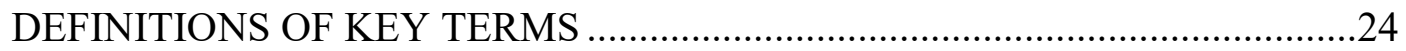


RESEARCH QUESTIONS ANSWERED

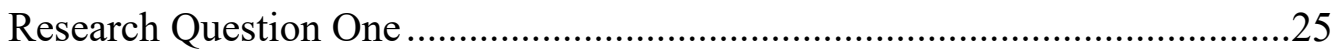

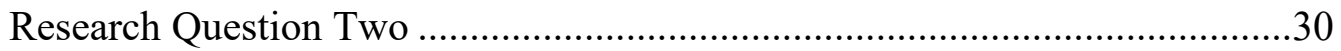

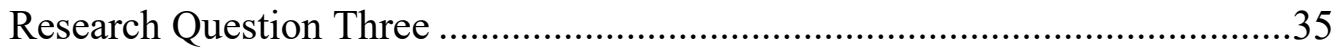

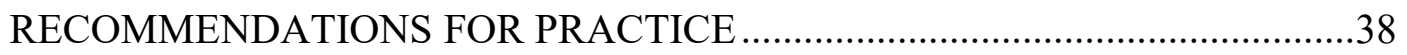

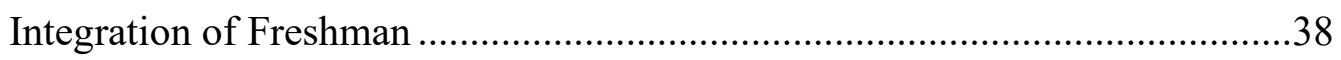

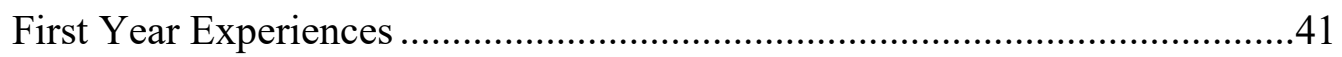

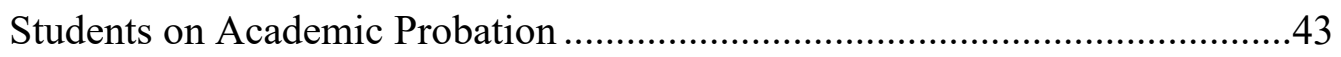

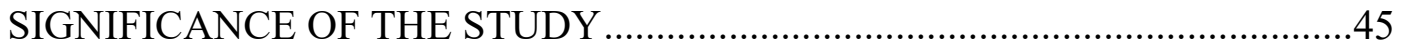

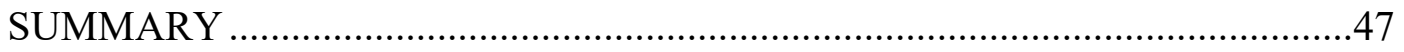

2. PRACTITIONER SETTING FOR THE STUDY ……………………...............49

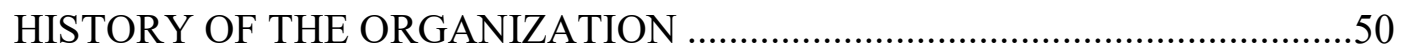

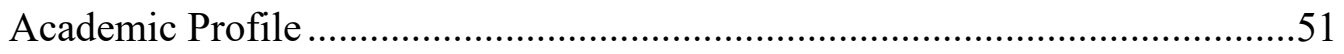

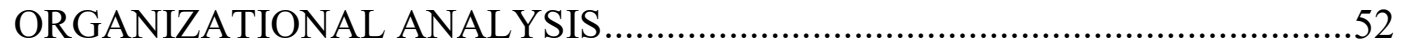

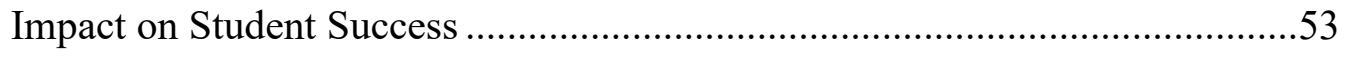

Structural Frame Analysis .............................................................................54

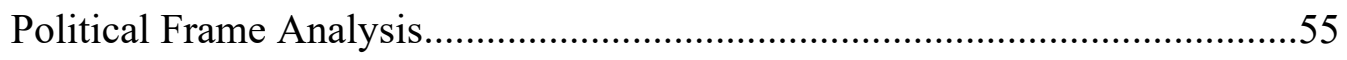

LEADERSHIP ANALYSIS OF UCM..............................................................56

IMPLICATIONS FOR RESEARCH IN THE PRACTITIONER SETTING.........59

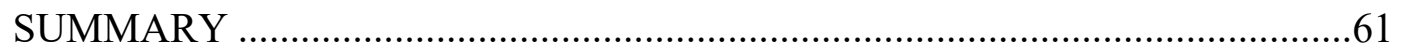

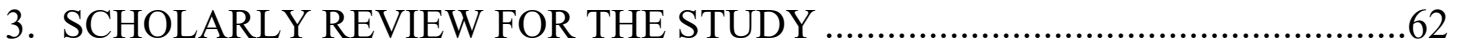

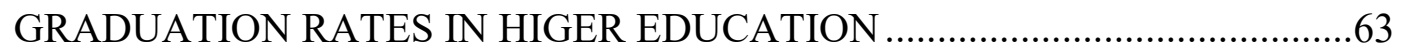

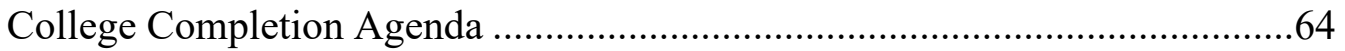

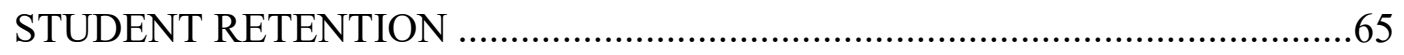




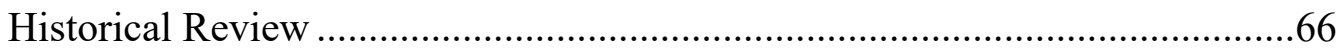

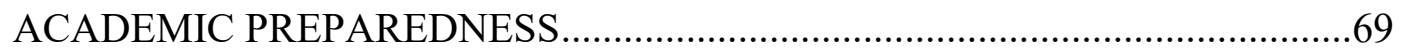

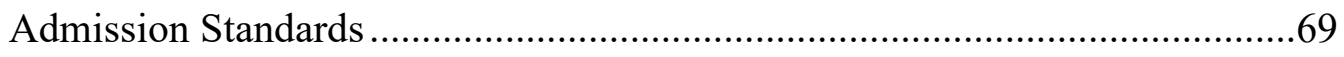

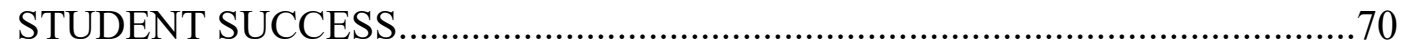

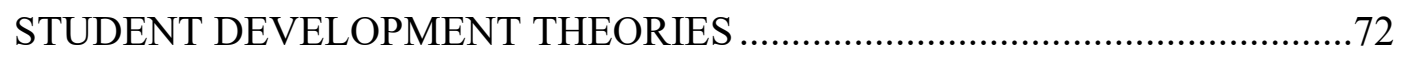

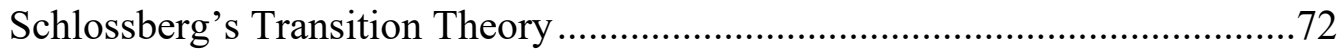

Chickering Theory of Identity Development ……………...............................73

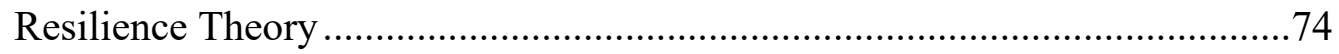

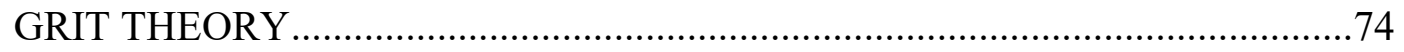

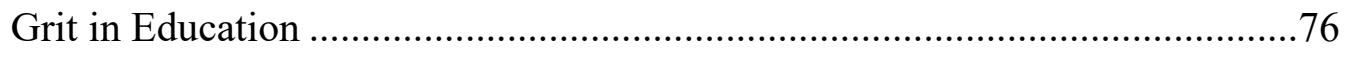

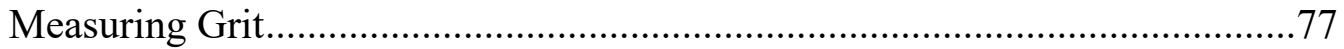

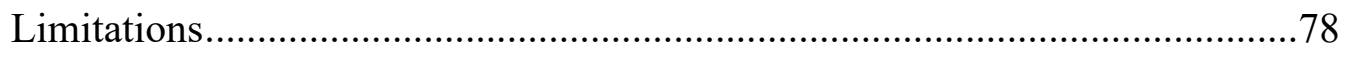

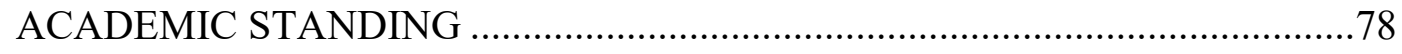

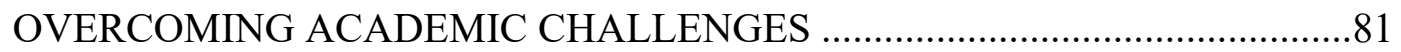

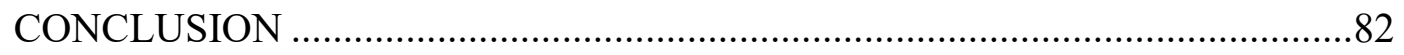

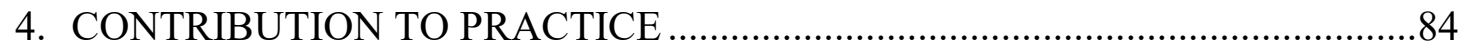

DISSEMINATION OF PRACTITIONER CONTRIBUTION …............................85

PRESENTATION FOR UNIVERSITY LEADERSHIP ......................................86

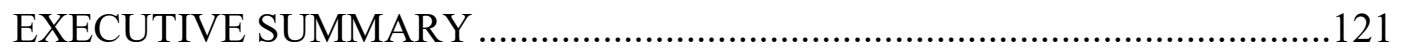

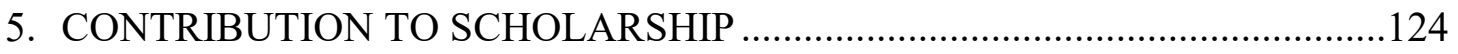

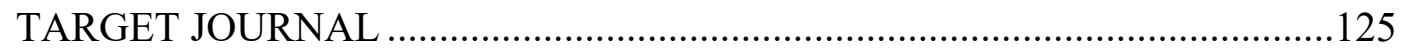

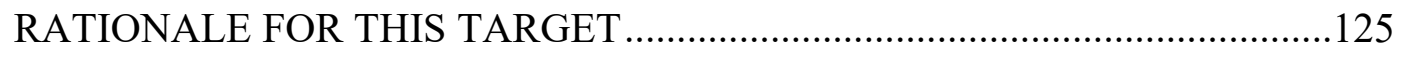

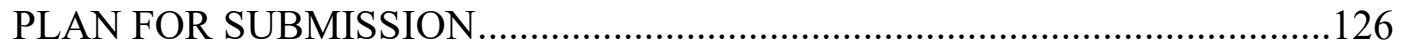


JOURNAL ARTICLE

6. SCHOLARLY PRACTITIONER REFLECTION .........................................150

INFLUENCE ON PRACTICE AS EDUCATIONAL LEADER ........................152

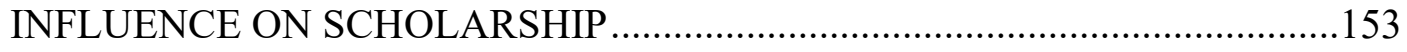

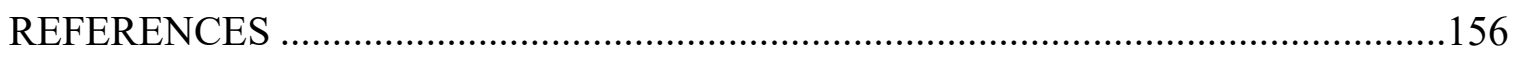

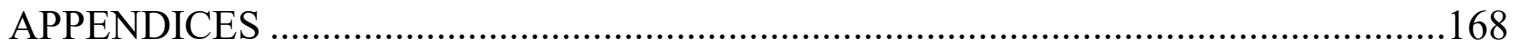

Appendix A: Participant Interview Questions and Format..............................168

Appendix B: Email to UCM Students Requesting Participation in Study..........171

Appendix C: Interview Consent Form to Participate in a Research Study .. 172

Appendix D: Statement of the Problem Charts ................................. 175

Appendix E: Findings .............................................................. 177

Appendix F: Research Questions Answered ...................................... 199

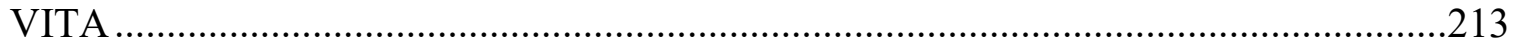




\section{LIST OF TABLES}

Table 1: University of Central Missouri graduation and retention rates, first-time, fulltime freshman 


\section{LIST OF ABBREVIATIONS}

ACT: $\quad$ American College Testing

GPA: Grade Point Average

IRB: Institutional Review Board

RQ: $\quad$ Research Question

SAT: $\quad$ Scholastic Assessment Test

UCM: University of Central Missouri 


\begin{abstract}
This qualitative case study was designed to investigate how first-time, full-time undergraduate students who met standard admissions requirements ended up on academic probation after their first semester. Furthermore, this study explores how these students were able to overcome the academic adversity, return to good academic standing, and be on track to graduation. The theoretical framework of grit was used to during the research, since the research participants were able to overcome academic adversity.

A high percentage of the regularly admitted first-time, full-time freshman at UCM who struggle academically during their first semester and are subsequently placed on academic probation, end up leaving the university with no degree. This study focuses on the minority of students in this population who stay enrolled, persisted, are in good academic standing, and are on track to complete a degree. Data collection for this research included individual interviews with students and document analysis.

Findings indicate three major themes that impact student success: "fit" in an academic program, student mental health, and utilization of student resources. The research can provide university leadership with insight on how to improve student success, retain students on probation, and improve graduation rates for this population of students.
\end{abstract}




\section{SECTION ONE}

\section{INTRODUCTION TO THE DISSERTATION}




\section{Background of the Study}

Starting college for a new student is a monumental occasion that is typically filled with a range of emotions. For many freshmen, college is the first time to live independently and start making significant personal decisions (Dawson \& Pooley, 2013; Siegel, 2003). College is filled with new people, places and opportunities, as students possess new freedoms and responsibilities (Pascarella \& Terenzini, 2005). In addition, students are excited to focus on their education and future career goals (Keup \& Young, 2018). However, this excitement can be neutralized with poor academic performance in a student's first semester of college (Balduf, 2009; Sriram \& Vetter, 2012). Every year students are admitted to college by meeting the admission standards set by the institution (Westrick, Le, Robbins, Radunzel, \& Schmidt, 2015). The expectation is that students will be academically successful throughout their studies, earning a college degree (York, Gibson, \& Rankin, 2015). However, research has shown not all students who start college will finish college, and institutions are unable to keep the students enrolled through degree completion (Choy, 2009; Pascarella \& Terenzini, 1980).

\section{National Graduation Rates}

According to the National Student Clearinghouse Research Center (2019), the four-year graduation rate for first-time, full-time students starting in the fall 2012 semester at a four-year public institution was $41 \%$. For various reasons many students require additional time than the traditional four-year graduation timeline. According to the U.S. Department of Education, National Center for Education Statistics (2019), the six-year graduation rate for undergraduate students who started in the fall 2011 semester is $60 \%$. With a higher calculation, the National Student Clearinghouse Research Center 
(2019) reported 65\% of first-time, full-time students starting in the fall 2012 graduated in six years. Research has shown there is not a significant increase in the graduation rate after six years (U.S. Department of Education, National Center for Education Statistics, 2017) therefore graduation data are not collected beyond the six-year time frame (National Student Clearinghouse Research Center, 2017b). The statistics do account for the students who are currently enrolled and continuing to work towards a degree; however, it is estimated $20.5 \%$ of this population has left college completely without earning a degree (National Student Clearinghouse Research Center, 2019).

\section{Graduation Rates at the University of Central Missouri}

In comparison, the University of Central Missouri (UCM) is behind the national averages for four-year and six-year graduation rates. According to the UCM (2018) Fact Book, the four-year graduation rate for first-time, full-time freshmen starting in the fall 2014 semester is $32.4 \%$. This rate is the highest since graduation rates were formally tracked by the institution in 1993 (University of Central Missouri, 2018). According to the Fact Book (University of Central Missouri, 2018) the next highest four-year graduation rate for first-time, full-time freshman was in 2010 at 32.1\%. The following year, 2011, the four-year graduation rate for this student population dropped to $28.6 \%$ (University of Central Missouri, 2018). After this dip, four-year graduation rates have been on the incline for UCM at $28.9 \%$ for 2012 and 30\% for 2013 (University of Central Missouri, 2018). The average four-year graduation rate for first-time, full-time UCM freshmen from 1993 to 2014 is 26\% (University of Central Missouri, 2018). (See Table 1.) 
The average six-year graduation rate for first-time, full-time UCM freshmen from 1993 to 2012 is $49.6 \%$ (University of Central Missouri, 2018). For full-time, first-time freshmen starting the fall 2012 the six-year graduation rate is $49.4 \%$ (University of Central Missouri, 2018). This rate is below the institutional high mark of 53.5\% in 2007 (University of Central Missouri, 2018). (See Table 1.) The first step in graduating more students is retaining the students from year to year.

Table 1

University of Central Missouri graduation and retention rates, first-time, full-time freshman

\begin{tabular}{|c|c|c|c|c|c|c|c|c|c|}
\hline \multirow{2}{*}{$\begin{array}{c}\text { Cohort } \\
\text { year }\end{array}$} & & \multicolumn{3}{|c|}{ Retention } & \multicolumn{3}{|c|}{ Graduation } \\
\cline { 2 - 9 } & Number & Year & Two & Three & Four & Five & Six & Seven & Eight \\
1993 & 1,454 & $64.0 \%$ & $52.6 \%$ & $49.7 \%$ & $15.9 \%$ & $34.2 \%$ & $40.6 \%$ & $42.8 \%$ & $43.7 \%$ \\
1994 & 1,358 & $63.6 \%$ & $53.0 \%$ & $49.5 \%$ & $16.6 \%$ & $36.2 \%$ & $41.9 \%$ & $43.2 \%$ & $44.5 \%$ \\
1995 & 1,439 & $67.7 \%$ & $55.5 \%$ & $52.1 \%$ & $17.9 \%$ & $39.1 \%$ & $43.4 \%$ & $44.8 \%$ & $45.7 \%$ \\
1996 & 1,271 & $73.6 \%$ & $60.9 \%$ & $56.7 \%$ & $18.7 \%$ & $40.9 \%$ & $46.7 \%$ & $48.5 \%$ & $49.5 \%$ \\
1997 & 1,348 & $72.5 \%$ & $61.2 \%$ & $57.6 \%$ & $22.8 \%$ & $43.8 \%$ & $50.7 \%$ & $52.1 \%$ & $53.2 \%$ \\
1998 & 1,414 & $73.5 \%$ & $63.6 \%$ & $59.5 \%$ & $23.4 \%$ & $47.2 \%$ & $52.6 \%$ & $54.2 \%$ & $55.1 \%$ \\
1999 & 1,341 & $74.2 \%$ & $63.4 \%$ & $59.2 \%$ & $22.7 \%$ & $44.5 \%$ & $50.6 \%$ & $52.4 \%$ & $53.3 \%$ \\
2000 & 1,461 & $72.4 \%$ & $63.5 \%$ & $58.2 \%$ & $26.6 \%$ & $46.1 \%$ & $51.1 \%$ & $53.1 \%$ & $53.9 \%$ \\
2001 & 1,442 & $72.8 \%$ & $63.0 \%$ & $60.3 \%$ & $26.2 \%$ & $47.9 \%$ & $53.1 \%$ & $54.8 \%$ & $55.8 \%$ \\
2002 & 1,252 & $72.8 \%$ & $63.7 \%$ & $60.4 \%$ & $27.2 \%$ & $46.7 \%$ & $51.9 \%$ & $53.8 \%$ & $54.2 \%$ \\
2003 & 1,358 & $69.9 \%$ & $60.6 \%$ & $57.6 \%$ & $24.2 \%$ & $43.8 \%$ & $48.4 \%$ & $50.7 \%$ & $51.6 \%$ \\
2004 & 1,436 & $71.0 \%$ & $64.3 \%$ & $59.2 \%$ & $26.4 \%$ & $45.4 \%$ & $51.0 \%$ & $53.3 \%$ & $53.9 \%$ \\
2005 & 1,485 & $68.9 \%$ & $60.5 \%$ & $55.8 \%$ & $28.2 \%$ & $46.3 \%$ & $50.4 \%$ & $52.0 \%$ & $52.3 \%$ \\
2006 & 1,507 & $70.7 \%$ & $60.7 \%$ & $56.7 \%$ & $27.6 \%$ & $45.3 \%$ & $49.3 \%$ & $51.3 \%$ & $52.0 \%$ \\
2007 & 1,427 & $71.9 \%$ & $64.7 \%$ & $60.4 \%$ & $30.0 \%$ & $49.8 \%$ & $53.5 \%$ & $54.8 \%$ & $55.4 \%$ \\
2008 & 1,586 & $72.8 \%$ & $64.3 \%$ & $60.5 \%$ & $29.2 \%$ & $47.6 \%$ & $52.9 \%$ & $54.2 \%$ & $55.3 \%$ \\
2009 & 1,479 & $72.6 \%$ & $63.6 \%$ & $58.9 \%$ & $30.6 \%$ & $47.9 \%$ & $52.1 \%$ & $53.6 \%$ & $54.2 \%$ \\
2010 & 1,547 & $72.5 \%$ & $64.8 \%$ & $60.4 \%$ & $32.1 \%$ & $48.7 \%$ & $52.8 \%$ & $53.9 \%$ & $54.6 \%$ \\
2011 & 1,649 & $68.7 \%$ & $59.6 \%$ & $56.1 \%$ & $28.6 \%$ & $45.5 \%$ & $49.1 \%$ & $50.5 \%$ & \\
2012 & 1,762 & $68.8 \%$ & $59.1 \%$ & $55.6 \%$ & $28.9 \%$ & $45.1 \%$ & $49.4 \%$ & & \\
2013 & 1,746 & $69.7 \%$ & $60.8 \%$ & $57.5 \%$ & $30.0 \%$ & $47.5 \%$ & & & \\
2014 & 1,687 & $70.8 \%$ & $61.7 \%$ & $56.3 \%$ & $32.4 \%$ & & & & \\
2015 & 1,641 & $70.8 \%$ & $63.7 \%$ & $58.6 \%$ & & & & & \\
2016 & 1,578 & $71.9 \%$ & $62.3 \%$ & & & & & & \\
2017 & 1,665 & $69.9 \%$ & & & & & & & \\
Average & 1,493 & $70.7 \%$ & $61.3 \%$ & $57.2 \%$ & $26.0 \%$ & $44.8 \%$ & $49.6 \%$ & $51.3 \%$ & $52.2 \%$ \\
\hline
\end{tabular}




\section{National Retention Rates}

The overall retention rate for students who started college at four-year public institutions in fall 2017 was $71.2 \%$ (National Student Clearinghouse Research Center, 2019). Depending on the definition of retention or how retention is calculated, rates may differ. According to the U.S. Department of Education National Center for Education Statistics (2019), the retention rate for first-time, full-time undergraduate degree-seeking students who enrolled at a four-year public institution in fall 2016 was $81 \%$. Institutions of higher education expend time, money, effort, and research to improve retention rates (Berger \& Lyon, 2005; Tinto, 2007).

\section{Retention Rates at the University of Central Missouri}

Like other institutions, UCM tracks student retention. According to the UCM (2018) Fact Book, the average one-year retention rate for first-time, full-time UCM freshmen from 1993 to 2017 is $70.7 \%$. The average retention rate for the same student population at two-years and three-years is $61.3 \%$ and $57.2 \%$, respectively (University of Central Missouri, 2018). For full-time, first-time freshmen starting the fall 2017 the oneyear retention rate is $69.9 \%$ (University of Central Missouri, 2018). The highest one-year retention rate for first-time, full-time UCM freshmen is $72.8 \%$, most recently set in 2008 (University of Central Missouri, 2018) (See Table 1.).

As the research shows, there is room for improvement in retaining students to degree completion both nationally and at UCM. Even more interesting is retention and graduation data specific to student populations. To gain a better understanding of retention and graduation rates for special populations of students, campus-wide data need to be disaggregated. Special populations of students include first-generation, 
underrepresented minorities, low socioeconomic status or Pell eligible, and military or veteran, to name a few. Furthermore, students can be divided based upon gender, age, academic program, grade level, and academic standing, to name a few. Improving the retention rate in each specific population will increase the overall institution retention rate.

\section{Statement of the Problem}

Typical research on retention is quantitative in nature and focuses on predicting retention based upon student characteristics (Braxton, Sullivan, \& Johnson, 1997; Tinto, 2007). Students are regularly admitted to universities across the country by fulfilling the admission standards, but do not progress to graduate with a degree. Every year students are regularly admitted to institutions based upon ACT score and high school GPA with the expectation of being successful (Westrick, Le, Robbins, Radunzel, \& Schmidt, 2015). Universities, such as UCM, use the same information in admission formulas generating percentile index scores for applicants to determine who is admitted. However, every semester, students who were admitted to college with the expectation of being successful find themselves with poor grades and end up with academic problems. Many students continue the academic decline and are eventually suspended from the institution or drop out (Tinto, 1993). Historically, students who earn low first semester GPA's are retained at a lower rate (Tinto, 1993).

Some students, however, recover from academic distress, go on to improve academically, and complete a college degree. Little is known how these students end up in academic struggles, even though the students met the standards for admissions (Balduf, 2009). Furthermore, it is important to investigate how these students are able to recover 
academically and return to good academic standing. Rather than focusing institutional resources on student attrition, Tinto (1987) recommended a focus on student persistence in order to promote student success. At the end of each semester, UCM gives students their academic standing based upon the student's academic performance. This results in students possibly being placed on academic probation. Academic performance has a strong correlation to student retention and degree completion (Bean, 2005; Pascarella \& Terenzini, 2005; Tinto, 2007).

After the fall 2014 semester, 637 students from the entire UCM undergraduate student population were given an academic status of academic probation. Disaggregating the population revealed 266 students $(41.8 \%)$ who were placed on probation after the fall 2014 semester were first-time, full-time freshman regularly admitted to the university, starting the fall 2014 semester. As of the spring 2020 semester, 22 of the 266 students $(8.3 \%)$, who were first-time, full-time freshman regularly admitted to the university, starting the fall 2014 semester, and placed on academic probation after the fall 2014 semester were retained, continued their academic progress at UCM, and graduated. Most of the 266 students (who were first-time, full-time freshman regularly admitted to the university, starting the fall 2014 semester, and placed on academic probation after the fall 2014 semester), 82.3\%, left UCM with a GPA below 2.00 and no degree completed. Another group of students, $8.6 \%$, left UCM in good academic standing, but no degree completed. And two students (0.8\%) were still currently enrolled surpassing the six-year graduation timeline. (See charts in Appendix D.)

After the fall 2015 semester, 655 students from the entire UCM undergraduate student population were given an academic status of academic probation. Disaggregating 
the population revealed 230 students $(35 \%)$ who were placed on probation after the fall 2015 semester were first-time, full-time freshman regularly admitted to the university, starting the fall 2015 semester. As of the spring 2020 semester, 7 of the 230 students (3\%), who were first-time, full-time freshman regularly admitted to the university, starting the fall 2015 semester, and placed on academic probation after the fall 2015 semester were retained, continued their academic progress at UCM, and graduated. Most of the 230 students (who were first-time, full-time freshman regularly admitted to the university, starting the fall 2015 semester, and placed on academic probation after the fall 2015 semester), 85.2\%, left UCM with a GPA below 2.00 and no degree completed. Another group of students, 5.7\%, left UCM in good academic standing, but no degree completed. Another 14 students (4.8\%) were still enrolled for their sixth academic year at UCM. (See charts in Appendix D.)

After the fall 2016 semester, 538 students from the entire UCM undergraduate student population were given an academic status of academic probation. Disaggregating the population revealed 228 students $(42.3 \%)$ who were placed on probation after the fall 2016 semester were first-time, full-time freshman regularly admitted to the university, starting the fall 2016 semester. As of the spring 2020 semester, 24 of the 228 students (10.5\%), who were first-time, full-time freshman regularly admitted to the university, starting the fall 2016 semester, and placed on academic probation after the fall 2016 semester, were retained and still enrolled, continuing their academic progress towards a degree during a fifth academic year. Most of the 228 students (who were first-time, fulltime freshman regularly admitted to the university, starting the fall 2016 semester, and placed on academic probation after the fall 2016 semester), 81.1\%, left UCM with a GPA 
below 2.00 and no degree completed. Another group of students, 8.3\%, left UCM in good academic standing, but no degree completed. (See charts in Appendix D.)

After the fall 2017 semester, 532 UCM students were given an academic status of academic probation. This population included all undergraduate students, including new, returning, full-time, part-time, domestic, international, transfer, freshman through senior, etc. For this study the focus was undergraduate students who were regularly admitted to UCM as first-time, full-time freshmen. Narrowing down the population reveals 230 students (43.2\%) who were placed on probation after the fall 2017 semester were firsttime, full-time freshman regularly admitted to the university, starting the fall 2017 semester. As of the spring 2020 semester, 23 of the 230 students (10\%), who were firsttime, full-time freshman regularly admitted to the university, starting the fall 2017 semester, and placed on academic probation after the fall 2017 semester, were retained and still enrolled, continuing their academic progress towards a degree as seniors. Most of the 230 students (first-time, full-time freshman regularly admitted to the university, starting the fall 2017 semester, and place on academic probation after the fall 2017 semester), 86.1\%, left UCM with a GPA below 2.00 and no degree completed. Another group of students, $3.9 \%$, left UCM in good academic standing, but no degree completed. (See charts in Appendix D.)

The problem is the large number of first-time, full time freshman, regularly admitted to the university, being placed on academic probation after their first semester at UCM. Furthermore, the problem is the high percentage (consistently over $80 \%$ ) of regularly admitted first-time, full-time freshman at UCM who struggle academically during their first semester, are placed on academic probation, and end up leaving the 
university with a poor GPA and no degree. Following the admission standards set by the university, these students should be successful (Balduf, 2009). The small percentage of students who were placed on academic probation after their first semester, however, were able to recover academically, stay enrolled at UCM, and continue their academic progress towards graduation are an important population to study.

\section{Gap in the Literature}

Research completed by Sriram and Vetter (2012) investigated students who were considered "high-risk" but were able to persist towards degree completion. The study consisted of interviewing students who were conditionally admitted as freshmen but were able to successfully progress to seniors in college (Sriram \& Vetter, 2012). Though this study provided insight into student strategies to overcome academic adversity, the population of students were admitted to the institution with exception of the regular admission standards.

Balduf (2009) interviewed first-time college students who experienced academic challenges during their first semester. These students were admitted to the institution based upon the regular admissions standards, with the expectation of being academically successful. However, due to poor grades in their coursework, they were placed on academic probation after their first semester (Balduf, 2009). The study revealed common themes to explain why these students failed to be successful in their first semester (Balduf, 2009). This research provided a good basis to determine what led this particular group of students to be placed on academic probation; however, the research did not follow the students past their first semester to study if they were able to overcome the academic setback and progress towards degree completion. 
Only a small percentage of regularly admitted students are able to overcome academic probation after their first semester of attendance and continue to be successful. Little is known about how these students are able to recover from academic challenge and progress towards graduation. This research will help institutions improve retention, academic progression, and graduation rates of college students by focusing on students who were able to recover from academic peril and go on to successfully complete a college degree. There is a need to research how these students "flip the switch" or "turn the corner".

\section{Purpose of the Study}

The purpose of this study was to research students who were regularly admitted to UCM as first-time, full-time freshmen, who were subsequently placed on academic probation after their first semester, but were able to recover from the academic setback, persist and be on track to complete a baccalaureate degree. According to the UCM admission standards, students who are regularly admitted based upon high school GPA and ACT test scores should possess the academic capacity to successfully complete a degree. Too frequently students experience issues having a negative effect on their academics, resulting in the student earning poor grades and subsequently being placed on academic probation (Balduf, 2009; Bell \& Short, 2003; Keup \& Young, 2018). Specific emphasis of this study included researching what caused these students to be placed on academic probation and how these students were able to recover academically after experiencing a large academic setback. This investigation into student success contributes to improving the retention and graduation rates at UCM, in addition to the first-year 
experiences of freshmen students at UCM. The study also adds to the discussion of including non-cognitive factors to the standard admission formula.

\section{Research Questions}

The research questions guiding this study are:

RQ1: What contributed to the students being placed on academic probation?

RQ2: How did the students recover academically, return to good standing, and be on track to degree completion?

RQ3: What concepts of Grit Theory (self-motivation, persistence, overcoming adversity) were demonstrated by the student participants of this study?

\section{Conceptual/Theoretical Framework}

A review of the literature on academic success in higher education shows there are several theories which attempt to determine what makes a college student successful. Research by Duckworth (2006) recommended identifying the personality traits or influences which make a student successful. Research has revealed concepts such as grit theory, student development theory, and resilience theory explain why some students are more academically successful than their peers (Bashant, 2014; Dawson, \& Pooley, 2013, Duckworth, 2006). Schlossberg's student development theory has been applied to a student's transition and adjustment to college and the factors that affect their transition (Dawson, \& Pooley, 2013; Schlossberg, 2011). Chickering and Reisser (1993) created a psychosocial development theory identifying seven vectors of development a college student may experience. Factors such as motivation, cognitive skills, family support, and environmental influence are connected to the theory of resilience and impact how individuals overcome stress and obstacles in their lives (Garmexy, 1991). 
Furthermore, psychological models such as self-efficacy, persistence, and having a growth mindset aim to predict which student will be academically successful (Garza, Bain, \& Kupczynski, 2014; Hochanadel, 2015). The student success theories and models are applied to students who are high achievers, to determine why one student or group of students is academically superior when compared to other students. Current resources also examine specific groups of students, such as underrepresented minorities, first-year students, low socioeconomic status, or other specific demographics, to determine why some disadvantaged students, or high-risk students, persevere to academic success (González-Torres, \& Garde, 2014; Morales, 2014).

\section{Grit Theory}

The ability to sustain interest and effort over an extended period of time to achieve a long-term goal is referred to as 'grit' (Crede, Tynan, \& Harms, 2017). Components of grit include self-motivation, persistence, and overcoming adversity (Duckworth, Peterson, Matthews, \& Kelly, 2007; Perkins-Gough, 2013; Wolters \& Hussain, 2015). Duckworth, Peterson, Matthews, and Kelly (2007) defined grit as "perseverance and passion for long-term goals" (p. 1087). Further explained, "grit entails working strenuously toward challenges, maintaining effort and interest over years despite failure, adversity, and plateaus in progress" (Duckworth, Peterson, Matthews, \& Kelly, 2007, p. 1088).

According to Crede, Tynan, and Harms (2017), grit has been found to be a crucial characteristic in predicting the success and academic performance of students. To determine if the personality trait of grit is a better indicator of future success than intelligence alone, Duckworth $(2006,2009)$ researched students at all levels of education. 
Research is focused on ways to identify students with grit in addition to focusing on ways to foster grit within students in order to increase the opportunities for students to be successful (Duckworth et al., 2007; Crede, Tynan \& Harms, 2017). This framework is consistent with research on college students who overcome academic challenges such as academic probation early in their academic career.

Duckworth et al. (2007) developed a grit measuring tool in order to quantify the personality trait. Huang and Lin (2013) used a similar instrument to measure the resilience of college students. Studies by Wolters and Hussain (2015) and Hogan and Wong (2013) were able to successfully test and measure the characteristic of grit in individuals.

In the academic setting, college students with more grit are more likely to be retained, to be academically successful, and to graduate (Duckworth \& Quinn, 2009). Students with high levels of grit work harder and can overcome setbacks or challenges (Hogan \& Wong, 2013; Wolters \& Hussain, 2014). The tools are available to identify students who hold a great probability of academic success (Duckworth \& Quinn, 2009), and it is more than high school GPA and ACT test scores. Completing a college degree is a long-term goal which takes perseverance. In addition, students who are placed on academic probation are faced with a significant academic challenge that must be overcome to achieve this goal. Considering the components of grit, the theoretical framework of Grit Theory was used for this study.

\section{Design of the Study}

The methodology for this research was qualitative in nature, where the researcher was the primary instrument for data collection (Merriam \& Tisdell, 2016). The qualitative 
approach seeks to understand the meaning of an experience (Merriam \& Tisdell, 2016), in this case, the academic success of high-risk students. A qualitative investigation of the student participants allowed these individuals to convey their experiences relating to academic struggles and success (Creswell, 2014). This case study focused on the specific phenomenon as described, bound by setting and time. The methods of data collection included one-on-one interviews and document analysis.

To support the qualitative case study, this research was conducted under a constructionist paradigm or worldview (Creswell, 2014). Creswell (2014) described the constructionist worldview as "the belief that individuals seek understanding of the world in which they live and work. The goal of the research is to rely as much as possible on the participants' view of the subject being studied" (p. 8).

\section{Setting}

The setting of this study was the University of Central Missouri, in Warrensburg, Missouri. The University is located approximately 50 miles east of a major metropolitan city, located in a Midwest town of 19,000 residents (University of Central Missouri, 2018). Academically, UCM offers nearly 200 undergraduate degree program to approximately 9,000 undergraduate students (University of Central Missouri, 2018). Nearly $70 \%$ of the student population is considered full-time with a majority of the students residing on campus or in the local community (University of Central Missouri, 2018). With a student-to-faculty ratio of $17: 1, \mathrm{UCM}$ has 463 full-time faculty members (University of Central Missouri, 2018). UCM is a state leader in program-specific accreditations through national associations and is fully accredited by the North Central 
Association of Colleges and Schools (University of Central Missouri, 2018). This research was conducted during the summer and fall 2020 semesters.

UCM is considered a moderately selective institution for admission standards (University of Central Missouri, 2018). According to the University of Central Missouri Incoming Freshman Admission Requirements website (2019), to be admitted to UCM, a student must complete the 24-unit Missouri college-preparatory curriculum. In addition, a student needs either a score of 21 or higher on the ACT and $2.0 \mathrm{GPA}$; or a score of 20 on the ACT and $2.85 \mathrm{GPA}$; or a score of 19 on the ACT and $2.95 \mathrm{GPA}$; or a score of 18 on the ACT and $3.25 \mathrm{GPA}$; or a score of 17 on the ACT and $3.45 \mathrm{GPA}$; or a percentile index score, combining class rank, class size, and $\mathrm{ACT}$ score, to equal or exceed 100 (University of Central Missouri Incoming Freshman Admission Requirements, 2019). In the fall 2016 semester, 1,605 first-time, degree-seeking freshmen were enrolled at UCM (University of Central Missouri, 2018). In the fall 2017 semester, 1,681 first-time, degree-seeking freshmen were enrolled at UCM (University of Central Missouri, 2018). In the fall 2018 semester, 1,493 first-time, degree-seeking, freshmen were enrolled at UCM (University of Central Missouri, 2018). These enrollment numbers included all students admitted to UCM as first-time, degree seeking freshman for the given semester.

In addition to University measurements, the state governing body of the institution, the Missouri Department of Higher Education, requires reporting of graduation and retention rates on an annual basis (University of Central Missouri, 2018). The graduation rate and retention rate are key performance indicators for the University, with continual effort to improve these rates. In addition, for full disclosure, the researcher 
of this study is also an employee of UCM. Permission to complete this study was requested from and granted by Vice Provost of Academic Programs \& Services at UCM.

\section{Participants}

The participants of the study were undergraduate students who were regularly admitted to UCM as first-time, full-time freshmen, were subsequently placed on academic probation following their first semester, but were able to return to good academic standing and were currently on track to complete their college degree from UCM. These students had persisted after their early struggles, staying at UCM and being continually enrolled since their first semester to be on track to graduate from UCM within six years of their first enrollment. Furthermore, these students have improved their GPA to 2.40 or above, showing their improved academic abilities. These parameters provide a population of students who faced academic adversity early in their academic careers but have persevered to complete their degree or who were currently in good academic standing and on track to degree completion. The participant sample was purposeful, selected specific to this study (Merriam \& Tisdell, 2016).

This population does not include students who were conditionally admitted outside of the institution's regular admission standards. Every semester students are admitted conditionally, but are considered high-risk; therefore, the students receive special academic intervention and advising. This study also excluded students who participated in the TRIO Student Support Services Program, student-athletes, transfer students, students with prior military experience, post-baccalaureate students, international students, and students who have earned more than 21 credit hours of college credit before starting at UCM. This study focused on students who, based on admissions 
scores, were regularly admitted and were not required to complete special academic programming or requirements, and did not receive any special academic intervention or attention during their first semester and subsequent semesters.

For the fall 2015, 6 students meet the definition provided to be included in this study. For the fall 2016 semester cohort, 16 students meet the definition provided to be included in this study. And for the fall 2017 cohort, 14 students meet the definition provided to be included in this study. All 36 students were invited to participate in the study.

Students were invited to participate in the study via electronic communication to the student's university issued email account or personal email account (Appendix B). Effort was made to explain the rarity of their academic success and the benefit of their participation in the study. No additional incentives were provided to the students for participating. Once approval was received from the Institutional Review Board (IRB) from the University of Missouri- Columbia and UCM data collection commenced.

\section{Data Collection Tools}

The research methods were primarily semi-structured interviews with individual student participants following an interview question protocol (Appendix A) (Merriam \&

Tisdell, 2016). Consent was obtained from each participant and copy of the consent form (Appendix C) was provided to each participant, before the interview started. The interviews and discussion between the research and participant lasted between 30 and 90 minutes. Due the governmental stay at home orders and social distancing precautions related to the COVID-19 virus, interviews were conducted via electronic video conferencing and telephone. The participants were asked open-ended questions during 
the interview. According to Seidman (2013), "an open-ended question, unlike a leading question, establishes the territory to be explored while allowing the participant to take any direction he or she wants" (p. 87). The nature of the interview questions focused on the how and the why of the student experiences (Merriam \& Tisdell, 2016). In an attempt to produce data to answer the research questions, the interviews were conversational, exploring the participants lived experiences (Merriam, 2009; Seidman, 2013). Interview questions and interview structure was piloted with students similar to the target population to ensure they are appropriate for this research (Locke, Waneen, Spirduso, \& Silverman, 2000; Seidman, 2013). If needed, additional questions were asked to follow up on the answers provided and to ask the participant to expand upon their answer (Merriam, 2009; Seidman, 2013). Data was collected until saturation was reached (Creswell, 2014). All interviews were electronically recorded and then transcribed verbatim for analysis (Seidman, 2013). The recordings and transcriptions were reviewed on multiple occasions. Merriam and Tisdell (2016) recommended spending adequate time collecting the data, in addition to purposeful investigation for variation in the understanding of the phenomenon.

Another qualitative data collection strategy used was analysis of documents and artifacts (Merriam \& Tisdell, 2016). Documents are a ready-made source of data easily available to the researcher in the form of written, visual, digital and physical materials (Merriam \& Tisdell, 2016). Prior to completing the participant interviews, data were collected from appropriate documents. For this research, the participant's admissions record, degree audit, and college transcript were reviewed. Since the researcher is employed at UCM, these records were available electronically. All documents and 
records were held confidential and protected during the review. These documents were used first to determine if the student meets the parameters of the study, in addition to providing support for this research. Specifically, transcripts provided a student participant's semester GPA, cumulative GPA, and academic standing. Transcripts also showed a student participant's retention and enrollment history. Similarly, a student participant's degree audit provided specific details on degree progression and an expected degree completion date. These documents were also be used to generate interview questions for specific participants.

Demographic information and descriptive statistics were collected from the participants (Creswell, 2014). Informed consent was received from all participants and IRB approval received from the University of Missouri-Columbia, as well as UCM. Participants were allowed to stop participation in the study at any time. Following the steps outlined by Seidman (2013), a participant's identity was kept confidential. All identifying information of participants was removed and pseudonyms were used.

\section{Data Analysis}

Data analysis commenced once data were collected. Data collected from the participant interviews and document reviews were analyzed. In addition to listening to the recorded interviews, data analysis included reading and rereading the transcribed interviews to look for common themes in the data (Creswell, 2016). Open coding was utilized for individual analysis of the data (Kuckartz, 2014). The coding process involved assigning categories or labels to the various points of data, looking for themes (Creswell, 2016; Merriam \& Tisdell, 2016). From the open coding and collapsed coding, the categories were condensed, and themes were further defined, data analysis memos were 
created (Creswell, 2016). Data analysis memos allow the researcher to define and track the coding process (Merriam \& Tisdell, 2016). The process of coding turns individual pieces of data into meaningful information (Creswell, 2016).

In order to maintain reliability in the data analysis process, Yin (2014) recommended maintaining a chain of evidence. This was completed by tracking all steps in the data analysis process and documenting each step (Yin, 2014). This documentation was part of the data analysis memos created during the data analysis process. In addition, all data collected during the research process was retained and used during the data analysis process.

To increase trustworthiness in the research, member checking was utilized when possible (Creswell, 2016; Seidman, 2013). Merriam and Tisdell (2016) recommended the strategy of member checking, or respondent validation to ensure internal validity and credibility. Once transcription was completed, participants were asked to review and confirm specific quotes from the interview. Data pulled from document analysis was confirmed with the research participants. As preliminary findings emerged during the data analysis process, feedback was solicited from the participating students. Data triangulation was used to strengthen construct validity (Yin, 2014).

Recurring answers and responses from the participants were reviewed for potential patterns. The responses which were most commonly provided reveal themes in the data (Creswell, 2014). The resulting concepts and general themes revealed were used to answer the research questions of this study (Creswell, 2014; Merriam \& Tisdell, 2016; Seidman, 2013). 
In order to increase validity in the research, the researcher recognized and disclosed any possible bias during the data collection and data analysis process. Creswell (2014) recommended researchers disclose possible bias to appear authentic and credible. Furthermore, Creswell (2014) recommended the inclusion of data that are supportive of the general themes identified, as well as information that is conflicting, to increase validity of the research. The goal of this research was to provide an accurate and truthful account of the participants' experiences. The researcher's assumptions and limitations of the study while collecting and analyzing the data can influence the findings of the research (Creswell, 2014), therefore this information is provided next.

\section{Limitations, Assumptions, and Design Controls}

Due to the limited scope and qualitative nature of this study, there are limitations. The study was limited to a purposeful and specific sample of UCM students, in a given time period; therefore, the results may not be transferable or generalizable (Creswell, 2014). However, the information gathered can be used in part to improve student success at UCM and provide some contribution to the field of study. The study also relied on data reported by the students, which requires accurate recollection and memory.

"Good qualitative research contains comments by the researches about how their interpretation of the findings is shaped by their background, such as their gender, culture, history, and socioeconomic origin" (Creswell, 2014, p. 202). This research is no different. This study is potentially biased by the researcher's employment at UCM and experience working with numerous students in the academic environment.

In addition, assumptions were made regarding the research participants used for this study. The study assumed all students who agreed to serve as participants have all 
experienced the same or similar phenomenon during their time at UCM. Specific parameters regarding a student's admission indicators and academic status were used to select participants to control for this assumption. However, the participants' experiences prior to their time at UCM are uncontrollable and can influence this study.

Similarly, the study assumed all participants understood the questions they were asked and were honest during the interview process, providing truthful responses. Confidentiality was preserved to support students providing candid and honest answers. It is assumed the recorded interviews were transcribed accurately for analysis. Member checking or respondent validation was used when possible to control for accuracy in the transcribed responses (Creswell, 2014; Merriam \& Tisdell, 2016; Seidman, 2013).

The design controls used in this study included purposeful sampling of participants to meet the needs of the study (Merriam \& Tisdell, 2016). Case studies are based on the research strategy of identifying a group of individuals who share a similar experience bound in time (Creswell, 2014; Merriam \& Tisdell, 2016). Also, a semistructured interview protocol was used as a design control to highlight specific research questions, but also allow the participants to describe their experience (Merriam \& Tisdell, 2016).

Additional actions were taken to increase the reliability and validity of this study. Data were collected in a secure fashion in order for all data to be analyzed, along with maintaining a chain of evidence during the data analysis process (Yin, 2014), and member checking was utilized (Creswell, 2014; Merriam \& Tisdell, 2016; Seidman, 2013). Participants were asked to review transcripted interview responses and specific 
quotes from interviews for accuracy (Creswell, 2014; Merriam \& Tisdell, 2016; Seidman, 2013).

\section{Definitions of Key Terms}

The following definitions were used for this study:

Academic probation: A student whose cumulative GPA or total UCM GPA drops below 2.00 will be placed on academic probation (University of Central Missouri, 2019).

Academic standing: Student academic standing is determined by both the cumulative GPA and the UCM GPA (University of Central Missouri, 2019).

Good academic standing: Undergraduate students who have both a 2.00 cumulative and UCM grade point average are in good academic standing and are eligible to enroll for classes (University of Central Missouri, 2019).

Grade point average (GPA): A grade point average is a number representing the average value of the accumulated final grades earned in courses over time. More commonly called a GPA, a student's grade point average is calculated by adding up all accumulated final grades and dividing this figure by the number of grades awarded. This calculation results in a mathematical mean — or average — of all final grades. The most common form of GPA is based on a 0 to 4.0 scale $(A=4.0, B=3.0, C=2.0, D=1.0$, and $\mathrm{F}=0$ ), with a 4.0 representing a "perfect" GPA—or a student having earned straight A's in every course (Glossary of Education Reform, 2013).

Grit: Perseverance and passion for long-term goals (Duckworth, Peterson, Matthews, \& Kelly, 2007); the ability to sustain interest and effort over an extended period of time to achieve a long-term goal (Crede, Tynan, \& Harms, 2017). 


\section{Research Questions Answered}

The purpose of this qualitative case study was to examine students who were regularly admitted to UCM as first-time, full-time freshmen, who were subsequently placed on academic probation after their first semester, but were able to recover from the academic setback, persist and be on track to complete a baccalaureate degree and understand their experiences. The research questions guiding this inquiry include:

RQ1: What contributed to the students being placed on academic probation?

RQ2: How did the students recover academically, return to good standing, and be on track to degree completion?

RQ3: What concepts of Grit Theory (self-motivation, persistence, overcoming adversity) were demonstrated by the student participants of this study?

Research Question One: What contributed to the students being placed on academic probation?

This question was answered through analyzing data collected from participant interviews and through document analysis. In the end, there were several factors that contributed to the participants of this study being place on academic probation after their first semester at UCM. The four primary factors found in this study include poor class attendance, students not fitting in the right academic program, poor mental health, and not knowing how to utilize the campus resources.

Class attendance. The first factor that contributed to the students earning poor grades and being placed on academic probation was not attending class regularly. At some point during all the interviews, all of the participants mentioned the importance of going to class. Based upon the answers to the interview questions, the participants had 
poor attendance during their first semester which resulted in poor grades. Subsequently, their class attendance improved, which resulted in improve class grades and GPA.

When asked what advice you would give yourself your freshman year, most of the participants responded with, go to class. Milo's specific advice was, "If you are not going to attend an 8 am class, then do not sign up for 8 am classes." Jennifer also stated, "Wake up and go to class." Bill thoughtful response included, "Go to class. Everyone says, 'you have to go to class to do well', but it is so true." When comparing their current academic success with their past academic failures, most of the participants contributed the success, at least in part, to attending class. When reflecting upon his first semester, Jack stated, “...I stopped going to class." Silas stated, "Missing class makes a different. I got behind and could not catch up."

Finding the right "fit". The second factor that contributed to the students earning poor grades and being placed on academic probation after their first semester was a poor fit academically. Based upon the answers to the interview questions, the participants were happy with their choice to attend, and stay at UCM, however, most of the participants changed their major after their first semester. Nineteen out of the 24 participants (79\%) changed their academic major at least once after their first semester. This does include one student participant who was an undeclared major, also known as open option degree seeking student, who planned to select a major after their first semester.

When asked why he changed his major, Silas stated, Nursing not going the way I wanted it to. It made me depressed. After the first semester I tried harder, but I still struggled. I was watching peers who were doing 
better, and I was not. The information was not sticking in my head even if studied. The more thought about it, less I wanted to do it.

Some students divulged struggling in a particular major or subject and needed to change. Ava stated, "The math requirement was hard, too hard for me." Similarly, Charlie admitted, “... I realized I don’t like science and could not do it.” When asked why he changed his major, Liam simply stated, "It was not for me." Some students had a change in career aspirations. Marcus stated,

I knew I wanted to do therapy with children, but I also like to create, and be an artist. So, I learned I can do art therapy, which is popular with kids. And kind of combine the two. This resulted in my changing my major but also adding a minor. Whatever the reason was, the students did not fit in their academic major and the result was poor grades.

Poor mental health. The third factor that contributed to the students earning poor grades and being placed on academic probation after their first semester was a poor mental health and wellbeing. During the interviews the participants described their mental and physical wellbeing and how it impacted their academic performance. Many of the students described a challenging adjustment period during their first semester. Grace stated,

I did not need to study that much in high school to do alright. I found out that my study habits from high school would not work in college. It was very different and challenging the first semester, trying to figure out how to handle all the homework and assignments. 
Several students described their first semester as feeling "overwhelmed" with lots of "stress." When asked about his first semester classes, Zack stated, "My class schedule first semester was kind of weird. I remember all my classes spread out throughout the day. I was not use to all the free time between classes during the day." When asked about her class during the first semester, Evelyn stated, "It kind of snow balled on me. I could not keep up with the work. I remember feeling stressed out." When asked about what she remembers the most about her first semester, Emma stated, "I remember feeling very homesick after moving in. College was a new experience for me and initially it was a lot to handle."

While other students directly reported feeling depressed or suffering from depression. Matthew stated, It was really weird, I have never struggled before [academically], but I got into a funk. And kind of sent me into a depression for a little bit, had a couple of days where I did not get out of bed."

When asked what she remembers most about her first semester, Mia bluntly stated, "Depression." For the same question, Bill recalled, It was 2016, and a lot was happening in the world that year. After the election, some friends committed suicide. It was messy. That was when everything culminated up to the election and that was a big part of everything for me. I just stopped going to class. I was not on my anti-depressants; I was very depressed. I did not know what to do.

Utilization of campus resources. The fourth factor that contributed to the students earning poor grades and being placed on academic probation was not utilizing or 
not knowing how to utilize the resources available to students on campus. Based upon the participant responses, they rarely or never utilized their faculty teaching the courses, their assigned academic advisor, nor the tutoring services provided on campus. When directly asked about using these resources during the interviews, most participants replied, "No." When asked about how he reacted to failing a test, Chris stated, "I was not sure what to do. In high school it always worked itself out." Similarly, Ben stated, "Even though I knew I was doing bad in my classes, I did not know what to do about it."

The opportunities provided by UCM to inform these students of the resources available to them did work. The single day orientation during the summer months before the semester started as well as the multiple first year experience activities did not provide beneficial results for these students. Based upon the participants answers, these students either did not know about the resources available to them or were not comfortable using the resources. As first semester freshman, these students did not feel comfortable asking for help from their course faculty or advisors. When asked who she contacted regarding her academic troubles during her first semester, Emma stated, "No one really. I did not reach out to my faculty. I never went to tutoring. I knew I had to get it together, so I tried harder." When asked what contributed most to him underperformance, Axel stated, “...lack of understanding how to interact with my professors. I was not sure how they could help me. I was not sure the best way to ask for help given my situation. I had some much going on my first semester, I was kind of over loaded, and I was not sure where to go.

Rather than reaching out to his professors, Aaron stated, "I worked with friends who were in my major, but not in the same class. I did not have a good connection with my teachers 
at that time. And no tutoring." When asked who he contacted regarding his academic troubles during his first semester, Charlie stated,

I did reach out to math teacher. He was one of my favorite teachers that semester. He was always open to work with students and helped me as much as he could. I don't think I was ready to listen. I had my own mental block that stopped me. And I worked with other students in major on other classes.

Research Question Two: How did the students recover academically, return to good standing, and be on track to degree completion?

This question was answered through analyzing data collected from participant interviews and through document analysis. Simply stated, the students were able to recover academically by addressing the factors that contributed to their poor academic performance during their first semester. The same four factors from research question one were also involved in the academy recovery, but conversely. The four primary reasons the participants were able to recover academically, return to good standing, and be on track to degree completion include improved class attendance, students finding the right fit academically, improved mental health, and utilizing the campus resources available to them.

Improved class attendance. When asked what advice you would give yourself as a freshman, the most common response from all participants was, "go to class." Axel stated, "It's not that hard, you have to go to class." Sophia added to the advice and said, "Go to class and sit up front." Sophia added, “...try to schedule your classes that work for your personal schedule. I like all my classes back-to-back, which makes it easier for me 
to go to all my classes." Grace stated, "With the exception of being sick, I go to all my classes now."

Finding the right "fit". Considering that 19 out of the 24 participants (79\%) changed their academic major at least once after their first semester, there appears to be a relationship between a student's fit in their academic program of study and their academic success. Silas stated, “...staying motivated has not been too much of a challenge since I changed my major.” When discussing changing his major, Ben stated, “... So I thought back to what I really enjoyed, which was acting and performing. I did band in high school, and I enjoyed performing. I had fun then, and still had a desire to perform, so I chose theater. I am happy I changed. No regrets.

Ava, who changed her major four times stated, I am glad I did not quit, early on. Even though I will be a fifth year, I am glad to be here. I really enjoy my classes and the teachers now. They [faculty] have been supportive and really, I can’t say enough good things about my program.

During the interviews, three students also mentioned their plans to seek a graduate degree after finishing their bachelor's degree. Taylor stated, "I will finish my psychology degree in December, and then I am planning to stay [at UCM] and start my master's degree the next semester. I hope to do some work in the biomedical lab." Similarly, Liam talked about the connection between his classes and his future. Liam said,

The classes were much more interesting. There was a direct connection to my future job. At least what I hope to be doing as a job. My teachers do a good job of using real world examples and real problems that we have to solve in class. 
Sophia stated, "I have really enjoyed my student teaching experiences, so I am looking forward to having my own class after graduation."

A change in academic major also meant a change in peers, friends, or social network. Milo stated, "Another big change after my freshman year was joining LAE, which is the student group for all CJ [criminal justice] students. I am involved with them and participate in some of the competitions. Similarly, Matthew stated, "After my freshman year I moved into an apartment with four other guys from the rugby team. That is who I live with now. We have more in common that I did with my first roommate." When asked what advice you would give yourself as a freshman, Jack recommended, Don't go home every weekend. Stay on campus but get out of your dorm room. Get involved in the campus community and the organizations on campus. Get into the clubs and organizations earlier. Make new friends. College is more than just going to class. You can learn new things outside of class too.

Taylor said, "I am really involved in my sorority, it was great way to meet new people and to learn about other organizations." Evelyn said, "My sorority sisters have been very supportive." When asked about what changes occurred after his freshman year, Marcus stated,

I joined a fraternity my junior year. It was a new one and I was asked to join. When you join a fraternity there are certain rules you have to follow. One of those is your GPA, you have to keep your GPA up to stay in the chapter.

Several students discussed how their living arrangements impacted their success. Emma stated, “... I have lived by myself, it so much better for me.” Grace stated, "Since I left 
the Ellis I have lived in the same apartment. I am more comfortable in my apartment. It feels more like home for me."

Improved mental health. To conclude the interview, Chris was asked if there was anything else, he would like to add or be included in this interview about your experience at UCM since your first semester, and he stated,

There needs to be more counselors at UCM. There are a lot of new students in a new area and they don't know anyone, and they get all depressed. Add more people to help with mental health needs and offer more free counseling to students. A lot of people are not able to pull themselves up.

When asked what changed the most since your first semester, many of the participants stated their mental health, specifically an improvement in their mental health. Several participants stated they had visited the UCM Counseling Center to talk with a counselor since their freshman year. Milo stated,

The Counseling Center helped me learn about taking care of yourself. Or taking care of myself during times of stress. Talking through some of my worries helped reduce my anxiety.

When asked what has changed the most since her first semester, Taylor stated, I did go to the counseling center on campus and was able to get back on my medication. I went to see my doctor back home as well. Now, I am feeling much better and I am in a better place.

Axel stated,

I figured out my way of doing things, so time management, and how to handle the workload of college classes. After this my stress went down. Some semesters 
have been more stressful than others, but my first semester was the toughest, mentally.

When asked to provide the biggest misconception about attending college, Charlie stated, "No one in my family went to college, so I did not know what to expect. I was not prepared for the pressure. It is easy to get overwhelmed." Charlie added, "You have to stay organized and keep up to reduce the anxiety; that helped me." Bill recommended, Talk to your friends or who you live with. Knowing you are not alone helps. There are other students who might feel worried or stressed out, like you do. This will help during your first couple semesters as you adjust to college.

Utilizing campus resources. When asked what advice you would give yourself as a freshman, Amy state, "Get help earlier, when you see the signs of failing." A common theme from the participants as they approach graduation was an increase level of comfort utilizing the resources that are available to them. Many of the participants discussed working with their class teachers, outside of the regular class time, and communicating with their faculty via email or through attending office hours. Mia stated, "It is now easier to ask for help when I am having issues. I feel comfortable talking to my teachers. I email all my teachers now."

Many of the participants were able to name their assigned advisor showing they knew who to contact for questions relating to their academic progress. When asked what resources you use now compared to your first semester, Jennifer explained,

I started seeing my academic advisor more. To sign up for classes, and I needed help with technology. I then thought, I might as well keep doing this, it is easier. And it feels better to have someone who knows what they are doing help me, 
rather than me trying to do it by myself. After I changed my major I got transferred to Christine. She is the best. She is actually now a reference for me on my resume.

Aaron stated, "I have met with my teachers several times, when I need to, and meet with my advisor at least once per semester. Usually to make sure I get enrolled." Jennifer stated, "I am in constant communication with my faculty members and my advisor. And the OAS [Office of Accessibility Services] office." Regarding who to contact if he is having academic difficulties, Ben stated, "Now, it is easier for me, if I am having issues, I feel very comfortable talking to teachers. And have gotten help from them. I will email teachers now. Marcus stated,

My sophomore year, I believe, for one of my first social work classes, the instructor required our final paper be reviewed at the writing center. This was the first time I went there. I have went there for other classes since then. I do not use it all the time, but it is helpful.

Furthermore, Marcus explained, "I now see my advisor at least once per semester. And visit the counseling center if I need to.”

Research Question Three: What concepts of Grit Theory (self-motivation, persistence, overcoming adversity) were demonstrated by the student participants of this study?

This question was answered through analyzing data collected from participant interviews. A consensus from the participants was none of them considered leaving UCM after being placed on academic probation after their first semester. This shows the concept of persistence and the personal characteristic of resiliency demonstrated by the participants. This is especially evident considering statistics surrounding the student's 
academic situation. Since 2014 , a high percentage (consistently over $80 \%$ ) of the regularly admitted first-time, full-time freshman at UCM who struggle academically during their first semester and are subsequently placed on academic probation, end up leaving the university no degree. The participants of this study are in the minority compared to their peers in a similar situation.

Sophia stated, "Leaving was not an option for me, staying in college was the only option." Similarly, Mia stated,

I wanted to finish what I started. Leaving never crossed my mind. I knew I had to make changes and was eager to make changes after my first semester. I didn't think it could get any worse after that semester, so I was kind of looking forward. When asked if he ever considered leaving UCM, Chris stated, No, it was never a consideration, at all. I had a come to terms at the moment, and I need to just do this. I had to do it, I had no other options, besides going to college. There was nothing else for me to do. Leaving was not an option. Similarly, Aaron said, "I never considered leaving, but in my head, I was worried about suspension and trying to think what would I do if I get suspended."

When asked why she stayed at UCM, Jennifer stated, "It was only one semester. I just couldn't give up after one semester and because of a few teachers." Sam gave a very similar response by stating, "It was only one semester. I knew I could try again the next semester. And do better. I also found out I could repeat courses, and I did." Another commonality among the participants related to self-motivation was goal setting. Milo stated, 
Setting goals helps me get through the semester. It gives me something to look forward to each semester. I have to have goals in mind and have something to work towards. This semester, it is to get all A's.

Similarly, when asked about setting goals, Charlie stated, "Yes, I always set goals for grades." Ava answered, "Yes, I always like to know what the end goal is. I am big on planning. I have GPA goals every semester.” Amy specifically stated, "I hope I can bring up my overall GPA to above a 3.0." Zack explained,

Starting about my sophomore year, I started setting goals. This was the year I joined a fraternity. It really helped to have guys with the same focus. Our fraternity has GPA standards, to join and to say in. Being in the fraternity has helped me set goals now, especially for grades and GPA.

Goal setting, more for the short term, rather than long term, is an activity demonstrated by many of the student participants. Other participants talked about their motivation to improve their grades and stay on track to graduation. Heather described, My motivation is to not go back to where I was my freshman year. I have come so far now, compared to where I was. I want to get good grades now. I want to do my best in each class.

Amy commented,

My advisor has been a big part of my motivation to finish. She is very supportive. She helps me stay on track with my requirements and make sure I follow the degree plan now. She knows how much I have struggled and how much work it has been. 
Axel stated, "My motivation now is to get a good job. I started looking recently." Similarly, Matthew advised, "I am nervous about getting a job now. I need to finish this semester with good grades." Taylor stated, "If I go on to a $\mathrm{PhD}$ program, I will need a really good GPA."

Many participants in this study did exhibit concepts of Grit Theory, such as selfmotivation and persistence. And many participants set personal short-term goals. Furthermore, from an academic perspective the participants were able to overcome the adversity of being place on academic probation after their first semester. However, all the participants had distinct personal experiences that contributed to their academic success. It was not grit alone that propelled them through this adversity.

\section{Recommendations for Practice}

Based upon the research findings, several recommendations for practice were developed. These recommendations should be considered in the context of current practices at UCM and considered in an ideal situation. With the current climate and environment under COVID-19 precautions some recommendations may not be feasible at this time. The recommendations include ways to integrate freshman to college life, changes to the first-year experience program, and implementation of a freshman academic probation plan.

\section{Integration of Freshman}

There are a few matters to consider when integrating first-time, full-time freshman to the academic environment and college life at UCM. A student's first semester schedule is very important. The information used to create first semester freshman schedules should be reviewed. Not only should academic program requirements 
be considered but also personal preferences. Furthermore, communication between the student and the academic advisor is key. Once the schedule is set, feedback from the student should be gathered. Discussing the specific classes and schedule of classes with the student may result in changes to the schedule that ultimately benefit the student.

Many freshman schedules include classes for the general education requirements of a degree. In order to support new students, especially first-generation students, freshman only sections of general education classes should be offered. These sections can be taught by instructors that focus on teaching freshman students. These sections can include or be connected with other first year experience activities across campus. This will also allow specific assignments and activities geared towards freshman students to support successful integration to academic and UCM.

Specifically, the special assignments or activities could connect freshman with student resources on campus. To connect freshman to the UCM Writing Center, freshman English composition instructors could require all or some of the papers assigned in the class to be reviewed by Writing Center. A step in the writing process, or a requirement for the assignment, is review by the Writing Center. This will essentially force the student, to receive full points on the assignment, to utilize the Writing Center. Similarly, class instructors could require students to visit the UCM Tutoring Center. This could be tied to a specific class assignment(s) or if the student is performing poorly during the semester, the instructor could require regular visits to the Tutoring Center as part of the classwork. Typically, students are more likely to access these resources if they are tied to a specific course assignment, which in turn, would provide an opportunity for these student to become more familiar with and become more comfortable with these 
resources. A student having a positive experience and increased comfort level, may contribute to increased future utilizing of these resources. According to a few student participants this practice has happened, however, expanding and encouraging more faculty to involve these types of assignments would support the utilization of student recourses on campus.

An initiative to encourage students to access additional support from their faculty, and to improve the faculty/student relationship is to require the attendance of, or utilization of, faculty office hours. Asking a faculty member for help or merely asking a question can be intimidating especially for a freshman student. To get students more comfortable approaching their teachers, attending office hours could be required as part of the coursework. If utilization of office hours is tied to a specific course assignment or tied to the student's ability to earn points in the class, students are more likely do it. Initial meetings with faculty could be informal and perceived as low stress, with the hopes that students have a positive experience and improved comfort level to continue utilizing faculty office hours, or improved faculty/student relationship that results in the student seeking support from the faculty.

The importance of class attendance on student success, especially for freshman students, is highlighted in this research as well as many other studies. Therefore, it is important for UCM to inform and educate freshmen on the importance of attending class regularly in order to be successful. The importance of class attendance should be highlighted during freshman orientation and other events before the semester begins. Every class should put some emphasize on attendance. Faculty should be encouraged to report poor attendance via the early alert system after each class. This would allow 
students who are not regularly attending multiple classes, and possibly suffering from other issues, such as poor mental health or personal issues, to be identified in a timely manner. UCM can then intervene early and provide the needed support to the student.

Another key to integration of freshman is a focus on mental health. Mental health has a significant impact on student success. Therefore, mental health and student wellbeing should be incorporated into the integration of new students early and often, through various means. With the help of the UCM Counseling Center, mental health and student wellbeing should be incorporated into freshman orientation, week of welcome events, and first year experience activities. Furthermore, mental health awareness and resources could be provided to students in the residence halls and through individual classes. Making students more comfortable accessing counseling services and making is easier to access counseling services is key. The University Foundations course must have significant time devoted to student wellbeing, self-care, stress management, and knowing how to access the resources provided by the UCM Counseling Center. Mental health first aid training should be required of all residence hall staff, academic advisors, and faculty that primarily teach freshman students.

\section{First Year Experiences}

The events, programing, and initiatives that are considered part of the universitywide first-year experience should focus on the successful transition to the academic environment and college life at UCM. Specifically, student mental health, goal setting and utilization of campus resources should be emphasized and addressed regularly. These initiatives should be coordinated across campus and be coordinated with class-level 
initiatives. To reach a diverse student population, the events, programming, and initiatives should be delivered in various formats and diverse avenues.

Similar to the AlcoholEdu course that is required for all first year UCM students who are younger than 24 , a mental health related course or training should be required for all students. Working with the UCM Counseling Center a training or course could be developed. The Counseling Center currently provides several workshops and resources that are available to all students as needed. A current workshop could be used, or a new training developed for this purpose. The training would be provided electronically, so the student can complete self-paced, however, it must be completed during their first semester of enrollment. The trainings would be connected to the resources and services provided by the UCM Counseling Center. In general, the course would cover emotional wellbeing, stress management, personal adjustment, and self-care. By requiring the completion of AlcoholEdu, the University has determined the consumption of alcohol as an important topic to address and emphasize with UCM students. Now is the time to do the same with student wellbeing and mental health.

The concepts of goal setting and perseverance should be incorporated into the first-year experience. Goal setting, both short-term and long-term, is an important skill for students to learn. And research has shown the benefits of goal setting. Typically, goal setting is not specifically addressed in undergraduate curriculum. First-year experience activities should teach students how to set goals and maintain persistence towards the goals. For example, the goals could be related to course grades, semester GPA, a graduation date, campus involvement/experience, or career placement. Through the act of goal setting, specific actions can be identified that will help a student achieve the goals. 
These actions, particularly related to academic goals, can then be connected to class attendance and utilization of campus resources.

Another focus of first-year experience activities and initiatives should be access and utilization of campus resources. Students need to build a comfort level with asking for help and utilizing the academic resources available to them. This goes beyond a student knowing where the Tutoring Center is located. Or merely being aware of the online writing center. A demonstration of how a student uses the Writing Center, either in person or online, would be advantageous. Using current students, who currently utilize the campus resources would provide a perfect example for new students who may not see the benefit. The participants of this study, through serving as peer mentors or on a student panel talking to new students, would be very relatable to other students who are experiencing academic troubles. Other possible initiatives include embedding subject tutors or writing tutors into specific freshman courses. And the organization of freshman only study groups, to help reduce the anxiety of seeking help during a student's first semester. Finally, once mid-term grades are reported, specific outreach to those freshmen that are underperforming or have below average mid-term grades to offer assistance rather than waiting for the student to ask for help.

\section{Students on Academic Probation}

A University-wide plan of action for all students on academic probation must be implemented. More specifically, a plan of action should be developed to support freshman who are on academic probation. If a first-time, full-time freshman is on academic probation after their first semester, a plan to academic recovery, including specific interventions and discussions should be initiated. This plan should be initiated by 
the assigned academic advisor, however, include other staff and faculty as needed. Ideally a coordinated plan of action, or a plan of care, would happen between the student, the academic advising center, academic support (tutoring center and writing center), and the course faculty. If needed, other offices such as the Accessibility Services, Student Financial Services, Career Services, and/or the Counseling Center would be included. Some students may also be comfortable talking to other students in the form of peer mentors or student coaches, which may aid in the discussion of the importance factors of student success.

The plan should include a review of course enrollment and class schedule for the student's second semester. If possible, the student should repeat any failed courses during the second semester. A discussion with the student regarding "fit" or selection of academic major should occur before the start of the second semester. Students should be advised to consider other majors, asked to complete self-assessments regarding career options and personality, and/or enrollment in the Exploring Majors \& Careers course.

The importance of class attendance should be emphasized to the student. UCM should consider implementing the use of technology to track a student's attendance. At a minimum the student should agree to and commit to regularly attending class. And agree to periodic checks of class attendance. Regular meetings with the academic advisor could also be required.

The academic probation plan should also consider a student's mental health and wellbeing. A specific discussion between the academic advisor and the student should address how poor mental health can impact success in college. The importance of selfcare and stress management should be emphasized. This may be an uncomfortable 
conversation; however, the student should be encouraged to seek mental health support if needed. Completion of mental health workshops provided by the Counseling Center could be required. Or the completion of a self-assessment questionnaire regarding a student's emotional wellbeing could be assigned, allowing the student to complete it privately and only share the results if they desired.

Ultimately, these recommendations will improve the educational experience for future UCM students. Specifically, improving the experiences for first-time, full-time freshman who are admitted with the assumption of being successful but may face academic adversity during their first year at UCM. This will then improve the University's retention rate and graduation rate.

\section{Significance of the Study}

First-time, full-time students encounter a plethora of experiences during the initial semester of college (Bass \& Ballard, 2012; Berger \& Lyon, 2005; Tinto, 2007). This study provides significant insight from students' perspectives regarding their academic experience. Specifically, this study allowed students who meet the academic admission standards to describe their experience of recovering from academic probation after their first semester and persisting to graduation. It is important to research retention across campus, for all student populations (Tinto, 2007). The population described in this study is rare; therefore, attention is needed, and the results contribute to the existing literature base.

The transition to college can be a difficult adjustment for many students (Brook, 2010; Friedman \& Mandel, 2009; Swail, 2003). Universities across the country, including UCM, attempt to orientate new students through various methods so they are successful. 
The stories of academic recovery from UCM students can help UCM identify issues which are causing the academic struggles. Institutions across the country, including UCM, are being held accountable for retention and graduation rates of students (Radin, 2006). Knowing what led these students into and out of academic problems provides information to UCM to help other students achieve academic success. This study makes significant contributions to the educational leaders at UCM who are charged with improving retention and graduation rates.

Recruiting and admitting a new student is more costly than retaining students who are currently in attendance (Berger \& Lyon, 2005; Braxton, 2000; Tinto, 1987). There is an economical benefit to UCM to help students recover from academic probation and become successful students. Furthermore, the benefits to the student obtaining a college degree are well researched and include monetary gains (Radin, 2006; U.S. Department of Education, 2017). Retaining students until graduation is a success for the institution, the student, and the greater population as a whole (Braxton et al., 1997). This research supports efforts to increase graduation rates for the financial betterment of the institution, the student, and society (Shin, 2010).

Furthermore, this study provides insight into the current practice of using standard formulas for admissions decisions. Every year students are regularly admitted to institutions with the expectation of being successful based on ACT score, high school class rank, and high school GPA (Westrick, Le, Robbins, Radunzel, \& Schmidt, 2015). To further assess and to view college applicants in a more holistic light, beyond a formula generated score, many institutions require letters of recommendation and/or a personal essay (Nichols \& Chang, 2013; Westrick et al., 2015). To further increase the probability 
of future students being successful, institutions could utilize the theory of grit and a grit measurement tool as part of the admissions decision process.

\section{Summary}

The goal for students and institutions of higher education is the same- graduation. Institutions are accountable for student success and degree completion (Hillman, Tandberg, \& Fryar, 2015; Radin, 2006; Shin, 2010). Data have shown not all students complete a degree, so continued work is needed (National Center for Education Statistics, 2019).

All students will face many struggles, both academic and nonacademic, when transitioning to college (Brook, 2010; Friedman \& Mandel, 2009; Swail, 2003; Tinto, 2007). Institutions such as UCM use programs, initiatives, and policies to support students to be successful and persist to degree completion. Nonetheless, there is always more that can be done to assist these students in this transition and start them on the path of success (Brook, 2010). Specific research is needed for specific populations of students who encountered academic challenges during this transition.

This study is focused on first-time, full-time undergraduate UCM students who meet the set standard for admissions and, therefore, are expected to be academically successful, but struggle academically during their first semester. Those students who overcome the challenge and persist to graduation are the focus of this case study. The researcher hopes to improve retention and graduation rates for this population of students. A qualitative methodology focuses on the students and their experiences (Merriam \& Tisdell, 2016). Interviews allow the students to express their thoughts and feelings 
(Seidman, 2013). The results are a thick, rich description (Merriam \& Tisdell, 2016) aimed to improve the student, UCM, and the greater community.

The results of this study contribute to the current literature on college student retention. Furthermore, the outcomes provide information to university leadership on improving student success, retaining students on probation, and improving graduation rates. Finally, this study also provides information regarding first-year experience programing or activities, academic advising, preparation for college academics, and admission standards. 


\section{SECTION TWO}

PRACTITIONER SETTING FOR THE STUDY 


\section{History of the Organization}

Situated on a 1,561-acre campus, UCM is located in the town of Warrensburg, Missouri with 19,000 local residents (University of Central Missouri, 2018). Founded in 1871 with only a few dozen students, more than 145 years later, UCM has grown to serve more than 11,000 undergraduate and graduate students (University of Central Missouri, 2018). Since its founding as State Normal School Number 2, the institution has undergone several name changes (University of Central Missouri, 2019). In 1919 the institution formally changed the name to Central Missouri State Teachers College, in 1946 it became Central Missouri State College, and in 1972 the institution became Central Missouri State University (University of Central Missouri, 2019). The most recent name changed happened in 2006 to the current name of University of Central Missouri (University of Central Missouri, 2019). Institutional renaming is due in large part to growth in student population, academic program offerings, and academic accreditations (University of Central Missouri, 2018).

According to the UCM Undergraduate Catalog (General Information section, para. 6, 2019):

The University of Central Missouri is a comprehensive, public university dedicated to providing personalized higher education experiences for a diverse body of students. Through its commitment to service and excellence, UCM seeks to meet the educational needs of the region, with extended responsibility to meet state, national, and international needs through selected programs. 


\section{Academic Profile}

Academically, UCM offers 190 programs of study leading to a certificate, bachelor's degree, master's degree, education specialist degree, or cooperative doctorate degree (University of Central Missouri, 2018). The institution is accredited by the Higher Learning Commission, as a member of the North Central Association (University of Central Missouri, 2019). There were 9,300 undergraduate students enrolled at UCM for the fall 2018 semester (University of Central Missouri, 2018). The average America College Testing (ACT) score and high school grade point average (GPA) for the fall 2018 class of first-time freshman is 22 and 3.42, respectively (University of Central Missouri, 2018).

Nearly $70 \%$ of the student population is considered full-time (University of Central Missouri, 2018). UCM has 463 full-time faculty members and the student-tofaculty ratio is 17 to 1 (University of Central Missouri, 2018). Many UCM students live on campus in either residence halls or apartments (University of Central Missouri, 2018) or live in the surrounding community. UCM also offers classes online and at a satellite campus located in a major metropolitan city approximately one hour from the main campus (University of Central Missouri, 2018).

The current student population represents nearly every state in America and 55 countries from around the globe (University of Central Missouri, 2018). The student population consists of $56 \%$ female, $43 \%$ male, and over $82 \%$ percent are residents of the state of Missouri (University of Central Missouri, 2018). Approximately 6\% of the student population has an international residence status (University of Central Missouri, 2018). According to the UCM Fact Book (2018), the average age of a UCM student is 23 
years old. Nearly $90 \%$ of our students receive some form of financial assistance (University of Central Missouri, 2018).

The institutional mission statement is, "The University of Central Missouri experience transforms students into lifelong learners, dedicated to service, with the knowledge, skills and confidence to succeed and lead in the region, state, nation and world" (University of Central Missouri, 2019). With a university motto of "Education for Service," university leadership encourages excellence in teaching, scholarship, and service to the community (University of Central Missouri, 2019). The institution also participates in intercollegiate athletics with student-athletes competing at the NCAA Division II level (University of Central Missouri, 2019).

\section{Organizational Analysis}

The organizational structure of UCM is similar to many universities across the country. Many institutions have a leader who sits atop the organizational hierarchy as the president or perhaps chancellor. Mintzberg (2005) described the framework as a topdown design of organizational structure. The head of the institution is usually charged with setting comprehensive goals, establishing defined personnel roles, and pointing the institution in an overall direction with a top-down coordination (Bolman \& Deal, 2013; Mintzberg, 2005). UCM is affiliated with the State of Missouri's higher education system, therefore the institution operates under a governing body. The UCM Board of Governors consists of eight members, all citizens from Missouri, including a student representative appointed to serve by the governor of Missouri (University of Central Missouri, 2019). The president of UCM reports directly to the Board of Governors. 
Moving down the hierarchy structure, the next line in an organization is a few to several individuals who report directly to the president (Mintzberg, 2005). Depending upon the size and complexity of the organization, the hierarchy continues down with multiple levels, with each individual reporting to the person directly above them (Mintzberg, 2005). At UCM, six individuals with the title of 'vice president' directly report to the president. The units at this level include very broad areas such as finance, marketing, athletics, alumni engagement, student engagement, and academic affairs. Between two and seven departments, units, or offices at the next level down directly report to the vice presidents. The hierarchy structure and division of duties continues down to include every employee in the organization (Bolman \& Deal, 2013; Mintzberg, 2005). Individuals in the bottom levels of the structure provide a more significant impact on the day-to-day operations, working towards the goals set by the individuals at the top of the structure (Manning, 2013; Mintzberg, 2005).

\section{Impact on Student Success}

The effectiveness of an organization and ability to complete organizational goals is dependent upon the organization's structure (Bolman \& Deal, 2013). The top-down organizational structure provides a clear chain of command, leadership, and communication flow (Bolman \& Deal, 2013; Manning, 2013). Many of the policies and initiatives which affect student success, including the rates of student graduation and retention, funnel through the academic affairs area of the structure. At UCM, the vice president of academic affairs, also known as the provost, directs the four college-level academic deans of the university, as well as four vice provosts of auxiliary student support services (University of Central Missouri, 2019). College deans oversee an array 
of matters related to academic programs, including the instructional faculty, course offerings, and the student learning environment. The vice provosts oversee an array of areas as well, including admissions, financial aid, academic advising, accreditation, study abroad, career services, tutoring services, and the university library (University of Central Missouri, 2019). Many of the changes to improve student success at UCM are directed through these offices. Though some individuals are tasked with student success on a dayto-day basis, an ideal institution of education would foster a culture of student success across the organization (Manning, 2013).

\section{Structural Frame Analysis}

Even with a specified hierarchy structure in place, organizations can be complex and diverse, and change over time (Bolman \& Deal, 2013, Manning, 2013). Bolman and Deal (2013) recommended the utilization of frames or lenses to view an organization in order to analyze problems or accomplish goals. According to Bolman and Deal (2013), a frame "is a coherent set of ideas and beliefs forming a prism or lens that enables you to see and understand more clearly what goes on from day to day" (p. 41). Framing or reframing allows the leaders of an organization to view an issue or goal, such as student success, in different ways (Bolman \& Deal, 2013). One frame that can be utilized to view an organization is the structural frame.

The structural frame is one of the oldest and most popular ways of thinking about an organization (Bolman \& Deal, 2013). UCM coordinates individual and group work effort through vertical coordination (Bolman \& Deal, 2013). Using a chain of command, authority, planning, and policies, daily work is completed towards institutional goals (Bolman \& Deal, 2013). Bolman and Deal (2013) asserted the chain of command allows 
supervisors legitimate power to direct and assign tasks of the employees at the next lower level. The hierarchical structure of the organization makes the chain of command, for communication and decision making, clear. The power and authority related to decision making comes from the leader at the top (Manning, 2013). Analysis of UCM reveals a large and complex organization. The "height" of the organizational hierarchy could produce as many as eight levels of reporting between the university president and the lowest level worker. While a top-down structure allows for established roles and defined goals, communication and execution of these goals can be challenging in a large organization (Bolman \& Deal, 2013; Manning, 2013).

\section{Political Frame Analysis}

Bolman and Deal (2013) argued the decision-making process involves politics and, furthermore, scarcity and differing interests affect the allocation of resources in an organization. Institutions of higher education are measured on success by yearly retention of students and graduation rates (Radin, 2006). Just as the responsibility to improve retention and increase graduation rates flows from the top of the administration down, the blame for any declines can be tracked back to the top of the hierarchy. The authorities at UCM who have the ability to shape the future success of the campus are one of the many interest groups caught in a political web of power, coalition and conflict.

Individuals jockey for influence and power at every level of the hierarchy (Bolman \& Deal, 2013). Similarly, when individuals have common interests, alliances form at a certain level or across levels of the organizational hierarchy (Bolman \& Deal, 2013). Adding to these dynamics is scarcity of resources. UCM has been impacted by a decline in tuition-generated revenue and support from state funding. According to 
Bolman and Deal (2013), "scare resources and enduring differences put conflict at the center of day-to-day dynamics and make power the most important asset" (p. 189). When analyzing UCM as an organization, the political frame accounts for competing interests and alliances of power when viewing institutional goals (Bolman \& Deal, 2013).

\section{Leadership Analysis of UCM}

"Leadership is a process whereby an individual influences a group of individuals to achieve a common goal" (Northouse, 2016, p. 6). The leadership process is highly complex and can be viewed in several forms; however, it is necessary for organizations to be effective and meet organizational goals (Kotter, 1990; Northouse, 2016). Similarly, leadership can look different in various situations and from various people; however, all leadership involves the influence of others (Northouse, 2016). In addition, Merriam and Bierema (2014) added effective leaders are lifelong learners, agents of change, and develop a culture, which promotes a learning environment. Gill (2010) added a leader must be linked to the organization's desired outcomes, or goals, in order to create a learning culture. Leadership at all levels of UCM promotes student success. Student success is an integral component of the institution's success and a tenet of the organization's culture.

Leadership is a skill that can be learned and developed (Kotter, 1990; Northouse, 2016). Following the organizational structure of UCM, many individuals at the top of the hierarchy have assigned leadership and positional power (Northouse, 2016). There are also individuals in the organization who exhibit emergent leadership (Northouse, 2016). These individuals may not have a prestigious job title, nevertheless, are still able to influence others and garner support from others (Northouse, 2016). Coordinating 
assigned leadership with emergent leaders will allow UCM to promote the culture of student success and working towards student success goals.

UCM has leaders and managers across the organization. The leadership process and the duties of a manager can overlap, yet are distinct (Kotter, 1990; Northouse, 2016). According to Kotter (1990), managers are involved in planning and budgeting, staffing an organization, organizing individuals, and work to solve problems. In contrast, leaders set the vison of the organization, motivate individuals to work toward common goals, inspire, and align individuals to build a successful organization (Kotter, 1990; Northouse, 2016). Most important to UCM is aligning the right individuals who can communicate the goals of the organization and motivate others to pursue those goals (Kotter, 1990). Though the major activities of leadership and management are different, Kotter (1990) stated, "Both management and leadership are essential if an organization is to prosper" (p.13).

According to Northouse (2016), a primary function of leadership is to produce change and movement. Due to pressures from government, industry, and local needs, institutions of higher education are expected to change and evolve (Manning, 2013; Schein, 2005). Leaders at UCM must embrace this change and produce movement toward improving student success. Furthermore, leaders must create a vision and culture of student success which others in the organization can embrace and accept (Northouse, 2016). Leaders can foster a culture focusing on student success from the top of the organizational hierarchy down to the bottom. Leaders can generate movement and motivate individuals towards organizational goals by removing obstacles and roadblocks 
on the path to the goal (Northouse, 2016). It is clear, when students benefit from improved retention and graduate rates, UCM as an organization benefits as well.

An analysis of an organization's leadership is not complete without ethical considerations. Northouse (2016) stated, "The influence dimension of leadership requires the leader to have an impact on the lives of those being led. To make a change in other people carries with it an enormous ethical burden and responsibility" (p. 336). To be an ethical leader, leadership aspects such as decision making, role modeling and personal character should be based upon a standard of honesty (Mihelic, Lipicnik \& Tekavcic, 2010). Changes at UCM must be made with results in mind in addition to the methods to achieve the results, while always keeping students at the center. A foundation for sound ethical leadership is built by having respect for others, service to others, justice, honesty, and a focus on a common good (Northouse, 2019). The efforts by UCM leadership to graduate more students benefits the institution and society (Braxton et al., 1997; Shin, 2010).

The leadership at the institutional level of UCM falls to the current president. After working for more than 20 years at UCM as a full-time faculty member, department chair, college dean, as well as other administrative roles, the current president was appointed by the UCM Board of Governors in the fall of 2018 (University of Central Missouri, 2019). The next leader of student success beneath the president is the vice president of academic affairs, or provost, who is also known as the chief academic officer of the University (University of Central Missouri, 2019). The provost is responsible for administering the academic programs of the University, as well as many academic support services (University of Central Missouri, 2019). The departments, 
office, and individuals under the provost are able to influence the decisions related to improving student success at UCM.

\section{Implications for Research in the Practitioner Setting}

Since the 1960s, the fields of research devoted to the recruitment, retention, and degree completion of college students have increased (Berger \& Lyon, 2005; Tinto, 2007). According to Shin (2010), the institution's success is predicated on student success, which is measured by the rate students are retained until a degree is successfully

completed. Furthermore, college students, parents of college students, local communities, state legislature, and the United States government are expecting institutions of higher education to take action to improve retention and graduation rates (Hillman, Tandberg, \& Fryar, 2015). This pressure has caused many institutions, including UCM, to evaluate how students are supported until degree completion. This research can be used by university leadership to continue to improve academic success, student retention, and graduation rates at UCM. By studying a set of students who have overcome academic adversity, this research can be used to help other students who face academic struggles while at UCM. Perhaps by using non-cognitive factors, such as grit, UCM can improve student retention and graduation by admitting students who are more likely to overcome academic challenges and be successful. This study highlights a unique sector of students at UCM who deserve attention.

Data resulting from this research supports UCM in meeting the metric standards of student success set by the institution as well as outside stakeholders. Institutions are expected to provide student support services to all students (Shin, 2010). University leaders have the opportunity to use this case study to gain direct feedback from their 
students. Qualitative case studies such as this research focus on meaning and understanding of an experience, in this case the experience of UCM students (Merriam \& Tisdell, 2016). This study reveals the students' experience of being placed on academic probation after their first semester and their experience of overcoming this academic hurdle to persist towards graduation. This is ideal data for UCM leaders to use. Furthermore, this research used an inductive process, whereby the data gathered was used to build concepts, hypotheses or theories (Merriam \& Tisdell, 2016). This study provides insight to why this group of UCM students struggled during their first semester, even though they met the institution's academic standard for admission. It also provides opportunities to improve the first-year experience activities for students and reveal new strategies to support students academically during their first semester of college. Finally, the research results are a thick, rich description of this phenomenon from UCM students (Merriam \& Tisdell, 2016). UCM leaders can use these results to implement new initiatives for students who are on academic probation or use with other programs aimed at serving students. As a unique segment of students has been identified in this study, there is a possibility UCM could invite the participants, or a similar group of students, to serve as peer mentors or student peer models.

The changes and improvement in student success will help UCM retain and graduate more students. College students who feel supported and confident in their academic abilities are more likely to be retained (Pascarella \& Terenzini, 2005; Scott, Bailey, \& Kienzl, 2006; Tinto, 1993). UCM has the opportunity to become a leader for student retention and degree completion. An individual's fit within an organization helps determine if the relationship will be positive or negative (Bolman \& Deal, 2013). A 
student's positive relationship with UCM depends upon the support from and connection to the institution. As more students graduate from UCM, additional prospective students will be interested in attending UCM. UCM can build the reputation as an institution that serves students, all students, regardless of college preparedness or academic ability.

\section{Summary}

From its origins almost 150 years ago, the institution now known as UCM has gone through many changes. The current leader of the organization is the $16^{\text {th }}$ president of the institution (University of Central Missouri, 2019). Over the decades the institution has experienced growth in students, academic programs, campus facilities, and academic excellence. Understanding the setting and background of the organization lays the foundation for this research (Creswell, 2014). An organization seeking to resolve problems or achieve goals can be analyzed through the utilization of different frames or lenses (Bolman \& Deal, 2013). Through leadership at all levels of the institution and a culture focused on student success, UCM can become a leader in degree completion. Identifying and analyzing the setting of this research highlights the importance of the study. 
SECTION THREE

SCHOLARLY REVIEW FOR THE STUDY 
The scholarly review creates a foundation for the research study (Galvan, 2014; Merriam \& Tisdell, 2016). The primary goal of the literature review is to provide a comprehensive overview of the topic of study (Galvan, 2014). This review of the literature includes an overview and synthesis of current research regarding college student success and college student development theories. This literature review is organized according to themes found in the literature (Merriam \& Tisdell, 2016), including graduation rates, retention efforts, academic preparedness, academic probation, and academic recovery. An overview of the theoretical framework to guide the study is also discussed.

\section{Graduation Rates in Higher Education}

The rate of students graduating with a degree is one of the many measures recorded by institutions of higher education across the country (Hillman, Tandberg, \& Fryar, 2015; Radin, 2006; Shin, 2010). According to the U.S. Department of Education, National Center for Education Statistics (2019), the six-year graduation rate for first-time, full-time undergraduate students who started their degree at a four-year public institution in the fall 2011 semester was $60 \%$. In other words, $60 \%$ of the undergraduate students who started in the fall 2011 semester had completed their degree at the same institution within six years (U.S. Department of Education, National Center for Education Statistics, 2019). Completion of a baccalaureate degree in four years is commonly measured, as this is the expected graduation timeframe (Scott, Bailey, \& Kienzl, 2006). In addition, the sixyear graduation rate is also measured as this is typically the maximum amount of time to complete the degree, and what is allowed for federal financial aid funding (National Student Clearinghouse Research Center, 2017b). Research has shown there is not a 
significant increase in the graduation rate after six years (U.S. Department of Education, National Center for Education Statistics, 2017).

Research by the National Student Clearinghouse Research Center (2019) reviewed yearly retention and graduation rates for students starting college in the fall 2012 semester. The four-year graduation rate for first-time, full-time students starting in the fall 2012 semester at a four-year public institution was $41 \%$ (National Student Clearinghouse Research Center, 2019). By the end of the sixth year, the graduation rate increased to $65 \%$ for the same student population (National Student Clearinghouse Research Center, 2019). Some students from this population were still currently enrolled at an institution continuing to work towards a degree, while $20.5 \%$ had left college completely without earning a degree (National Student Clearinghouse Research Center, 2019).

\section{College Completion Agenda}

The College Completion Agenda, started by former President Barack Obama, called for additional transparency with regards to college completion and graduation rates across the country. President Obama's goal for the United States was to hold the highest proportion of college graduates in the world by the year 2020 (The White House, 2016). Since the mid-1990s state legislatures have created policies tying an institution's state funding to graduation rates, retention rates, and other metrics of student success (Hillman, Tandberg, \& Fryar, 2015; Shin, 2010). Not only is transparency and accountability important to legislation, it is also important to students, local communities, and American citizens (Radin, 2006). With increased scrutiny on student success 
measures such as graduation rates, it is important for institutions to research effective models to retain the students who are admitted.

\section{Student Retention}

According to the National Student Clearinghouse Research Center (2019), the overall retention rate for students who started college at four-year public institutions in fall 2017 was $71.2 \%$. At the national level, student retention has been increasing for fouryear public institutions with rates of $69.7 \%$ and $70.1 \%$ for the students starting in the fall 2015 and fall 2016, respectively (National Student Clearinghouse Research Center, 2019). Retention is defined by the National Student Clearinghouse Research Center (2017a) as students who "continued enrollment (or degree completion) within the same higher education institution in the fall semesters of a student's first and second year" (p. 11). Similarly, the U.S. Department of Education defines retention rate as the percentage of students who returned to the institution the following fall semester to continue their studies (U.S. Department of Education, National Center for Education Statistics, 2017). The retention rate for first-time, full-time undergraduate degree-seeking students who enrolled at a four-year public institution in fall 2016 was 81\% (U.S. Department of Education, National Center for Education Statistics, 2019).

The persistence rate for this population was also studied and is defined as “continued enrollment (or degree completion) at any higher education institution including one different from the institution of initial enrollment — in the fall semesters of a student's first and second year" (National Student Clearinghouse Research Center, 2017, p. 11a). The overall persistence rate for students who started college at four-year public institutions in fall 2017 was $82.7 \%$ (National Student Clearinghouse Research 
Center, 2019). Persistence to earning a degree, at any institution, is a success for the student; however, the institutions are concerned with retaining the student and improving the institution's retention rate (Tinto, 2007).

\section{Historical Review}

When discussing retention in higher education many professionals are still influenced by research from the 1970s. Works by Spady (1970) and Tinto (1975) were some of the first to generate a theory to determine why students drop out of college. Both seminal pieces of research are based in part on Emile Durkheim's 1951 sociological theory on suicide (Tinto, 1975, 1993; Spady, 1970). Spady (1970) theorized students leave higher education due to a lack of satisfaction and commitment. Tinto's (1975, 1993) theory of student departure determined students leave college due to a lack of social integration into the academic environment.

Spady. The first widely recognized model for student dropout in higher education was proposed by William Spady (Berger \& Lyon, 2005; Braxton, Sullivan, \& Johnson, 1997; Tinto, 1987). Spady (1970) asserted there are several variables which contribute to the social integration between the student and the educational institution. The variables of academic potential, normative congruence, grade performance, intellectual development, and friendship support, can be linked to whether a student drops out of college or not (Spady, 1970). These variables affect the connection between the student and the environment at the institution (Spady, 1970). Another study by Spady (1971) found the main factor in student retention was academic performance.

Spady (1971) further noted a student's integration into academics and overall adjustment to the college experience is affected by the student's family background. 
Specifically, positive family support allowed students to better adjust to college life, both academically and socially (Spady, 1971). Students who can integrate to the institution, academically and socially, are more likely to have positive grade performance (Spady, 1971). Consequently, academic success leads to higher satisfaction, stronger social relationships, and increased likelihood of persistence to degree completion (Spady, 1971).

Tinto. Building upon Spady's (1970) theory, research by Vincent Tinto looked at academic experiences and social integration of the student (Berger \& Lyon, 2005). Tinto $(1975,1993,2007)$ provided a longitudinal model of student integration covering student transition theory, institutional fit, and the student's level of commitment. An institution could improve student retention by helping students transition from their prior support structure to the new academic and social environment of the institution (Tinto, 1987). These concepts significantly impacted practitioners in higher education and influenced most current research on college retention and graduation (Berger \& Lyon, 2005; Braxton \& Mundy, 2001).

Expanding upon the research by Spady, Tinto $(1975,1987)$ specifically identified how a student's family background, family values, socioeconomic status, and race influenced their integration to the college environment. Furthermore, Tinto (1993) identified how a student's educational experiences prior to college, such as high school grades and personal goals, impact their integration and success at the college level. Tinto $(1987,1993)$ identified academic success and involvement, more so than social integration, as a determinant of students staying enrolled and finishing their degree. 
Using Durkheim's sociological theory on suicide, Tinto $(1975,1987)$ theorized if students view their college experience as positive and beneficial, outweighing any personal cost, students will continue to seek the reward and stay in school. This research on retention examined student experiences, both positive and negative, and how they effected a student's integration to the educational environment (Tinto, 1993). The resulting evidence would suggest the best way to increase student retention is to increase the positive experiences, in both quality and quantity, students receive (Tinto, 1987, 1993). Furthermore, these experiences have a greater impact if they occur informally, inside and outside of a classroom, with other students or peers, in addition to relationships with faculty and staff members (Tinto, 1987, 1993; Valentine, et al., 2011).

Despite the fact student retention and persistence has been studied extensively by numerous researchers, the subject continues to be important and worthy of investigation (Braxton, Brier, \& Steele, 2007; Braxton \& Mundy, 2001; Tinto, 2007). Retaining current students from year to year is more economically beneficial to the institution than recruiting additional incoming students each year (Berger \& Lyon, 2005; Braxton, 2000; Tinto, 1987). Using the past research, institutions can focus on their student population and the factors impacting student retention on their campus. Retaining students until graduation is a success for the institution, the student, and the greater population as a whole (Braxton et al., 1997).

Students who experience low achievement or poor academic performance (i.e. low grades or grade point average) are more likely to drop out of college (Bean, 2005; Getzlaf, Sedlacek, Kearney, \& Blackwell, 1984; Tinto, 2007). However, when looking at students with higher academic abilities and achievement, GPA is not a statistical 
indication of keeping the student through graduation (Bean, 2005). In contrast, Pascarella and Terenzini (2005) concluded a student's success as measured by course grades is a predictor of persistence and degree completion. Typical research on retention is quantitative in nature and focuses on predicting retention based upon student characteristics such as GPA, test scores, class rank, etc. (Braxton et al., 1997; Tinto, 2007).

\section{Academic Preparedness}

Many students who attend college are not academically prepared for the rigor and demand of college-level academics (Brook, 2010; Friedman \& Mandel, 2009; Swail, 2003). This results in students starting college but never graduating with a degree. According to American College Testing (ACT) (2016), 26\% of ACT-tested high school graduates met the college readiness benchmarks for all four subjects (English, reading, mathematics, and science) set by American College Testing. This is a decrease from 2015 when $28 \%$ of ACT-tested high school graduates met the college readiness benchmarks for all four subjects (American College Testing, 2016).

\section{Admission Standards}

Every year students are regularly admitted to institutions with the expectation of being successful based on ACT score, high school class rank, and high school GPA (Braxton, 2000; Westrick, Le, Robbins, Radunzel, \& Schmidt, 2015). Universities use this and other similar information in admission formulas generating percentile index scores for applicants to determine who is admitted (Friedman \& Mandel, 2009; Westrick et al., 2015). The research on student graduation and retention rates questions the validity of these formulas (Pascarella \& Terenzini, 1980; Scott, Bailey, \& Kienzl, 2006; Westrick 
et al., 2015). In an attempt to view college applicants in a more holistic light and more than a number, many institutions require letters of recommendation and/or a personal essay (Nichols \& Chang, 2013; Westrick et al., 2015). However, admissions formulas are still the primary method of admission decisions (Berger \& Lyon, 2005; Braxton, Sullivan, \& Johnson, 1997).

The admissions formulas set by the institution are typically based upon the student's past academic performance (Braxton, Sullivan, \& Johnson, 1997; Tinto, 2007). Research has focused upon which past academic performance measure, such as ACT score, high school class rank, or high school GPA, is the best predictor of future academic success in college (Pascarella \& Terenzini, 2005). Further research is needed considering every semester students who were admitted to college with the expectation of being successful find themselves with poor grades and end up on academic probation (Pascarella, 1985). Many students continue the academic decline and are eventually suspended from the institution or drop out (Tinto, 1993).

\section{Student Success}

“'Student success' can be understood in its simplest form as getting students into and through college to a degree or certificate" (Ewell \& Wellman, 2007, p. 2). Bass and Ballard (2012) researched how retention of freshman students is impacted by student engagement and success. Similarly, research by Scott, Bailey and Kienzl (2006) review the impact of student success on graduation rates. A review of the literature on academic success in higher education shows there are several theories which attempt to determine what makes a student successful. Pascarella (1985) identified several pre-college traits 
which contribute to a student's success in college. These traits include personality, aptitude, achievement and motivational elements (Pascarella, 1985).

Experiences for a student during their first year will significantly impact their overall success in college (Choy, 2002; Siegel, 2003). Academic performance will be a large part of the first-year experience. Pascarella (1985) determined new, first-year students possess varying characteristics that will affect the student's learning experience. This is further evident as the college student population diversifies with non-traditional students. More institutions are implementing programs aimed to help students transition to college (Siegel, 2003; Sriram \& Vetter, 2012) with the hope of improving retention rates. These programs focus on curricular, or academic, as well as co-curricular areas to assist students' integration to the campus environment.

"First year seminars (FYS) are one of the most long-standing and most widespread interventions for the success of first-year students in colleges and universities in the United States" (Keup \& Young, 2018, p. 93). As first year seminars have grown beyond the classroom to include extracurricular activities and events, the term First-Year Experience (FYE) has been widely used (Keup \& Young, 2018; Pascarella \& Terenzini, 2005; Siegel, 2003). Research by Pascarella and Terenzini (2005) found the implementation of a FYE program can have positive outcomes for students, including improved academic performance, an easier transition to the college environment, and increased likelihood of the student returning for their second year. In addition to improved student achievement, research has shown FYE programs can facilitate positive relationships with peers, faculty, and staff; provide a sense of belonging and connection to the institution; increase campus involvement; increase intercultural competence; and 
provide the development of interpersonal and life skills (Keup \& Young, 2018; Pascarella \& Terenzini, 2005; Sriram \& Vetter, 2012).

\section{Student Development Theories}

Most theories related to student development can placed into five broad categories: 1.) psychosocial, 2.) cognitive-structural, 3.) person-environment, 4.) humanistic existential, and 5.) student development process models (Chickering \& Reisser, 1993; Dawson \& Pooley, 2013; Pascarella \& Terenzini, 2005; Schlossberg, 2011; Sriram \& Vetter, 2012). It is important to understand relevant theories and how these theories can be put into practice and applied to student success. The research into student development and student success is exhaustive, however, it is important to identify theories that serve as the foundation to better understand students in higher education. Schlossberg's Transition Theory and Chickering's Seven Vectors of Development Theory are applicable theories for this study.

\section{Schlossberg's Transition Theory}

Schlossberg's theory explained student experiences while transitioning into and through college. Schlossberg (2011) defined a transition as any event, or non-event that results in changed relationships, routines, assumptions, and roles. Furthermore, the type, context, and impact of the transition, as experienced by the student must be fully considered (Schlossberg, 2011). The theory includes 4 primary sets of factors that influence a student's ability to cope during the transition (Schlossberg, 2011). These factors, known as the "4 S's" are situation, self, support, and strategies (Schlossberg, 2011). 'Situation' refers to how the student perceives the overall situation or transition related to timing, control, duration, responsibility, and changing of roles (Schlossberg, 
2011). Personal and demographic characteristics in addition to psychosocial resources are the two primary categories of factors related to 'self' (Schlossberg, 2011). The 'support' variable relates to a student's social support network, groups and individuals, and how each type of support fulfills a need or function (Schlossberg, 2011). The 'strategies' factor refers to how a student copes or responds to the transitional situation, dividing the responses into three options, modification of the situation, controlling the meaning of the problem, and how stress is managed after the transition (Schlossberg, 2011).

\section{Chickering Theory of Identity Development}

The Chickering Theory (1993) established seven vectors, or tasks, that focus on the identity development of students in college. The theory includes a comprehensive model to describe the stages of psychosocial development experienced by college students (Chickering \& Reisser, 1993). The seven vectors proposed by Chickering and Reisser (1993) include: 1.) developing competence (viewed in three dimensionsintellectual, interpersonal, and physical), 2.) managing emotions, 3.) moving through autonomy toward interdependence, 4.) developing mature interpersonal relationships, 5.) establishing identity, 6.) developing purpose, and 7.) developing integrity. Each vector has its own direction and magnitude and students can move through a vector at different rates, in addition, move back and forth between vectors in a non-linear process (Chickering \& Reisser, 1993). Each vector includes various tasks and the development of personal characteristics as students move through the development continuum, however, individuals do develop at different rates (Chickering \& Reisser, 1993). 


\section{Resilience Theory}

Rooted in psychology, resilience theory aims to determine why some individuals can thrive in the face of adversity while others struggle (Cicchetti \& Garmezy, 1993). Garmezy (1991) conceptualized 'resilience' by stating:

The concept is not intended to present a heroic image of such children when compared with others who meet similar situations with retreat, despair, or disorder. Indeed, to speak of resilience does not necessarily reflect an imperviousness to stress. Rather, it is designed to reflect the capacity for recovery and maintained adaptive behavior that may follow initial retreat or incapacity upon initiating a stressful event. (p. 459)

Resiliency is influenced by three factors: (1) individual or personal factors such as temperament and cognitive skills, (2) familial factors such as family cohesion and the presence of a caring parent or adult, and (3) support factors that are external to the family that include individuals, such as teacher or social worker, and external support structures like school system or church (Cicchetti \& Garmezy, 1993, Garmexy, 1991). Research on resilience can positively influence educational, psychological, emotional, and social outcomes of children and young adults who are more likely to pursue education beyond high school (Cicchetti \& Garmezy, 1993, Garmexy, 1991, Werner \& Smith, 1992).

\section{Grit Theory}

Duckworth, Peterson, Matthews, and Kelly (2007) defined grit as "perseverance and passion for long-term goals" (p. 1087). Further explained, "grit entails working strenuously toward challenges, maintaining effort and interest over years despite failure, adversity, and plateaus in progress" (Duckworth, Peterson, Matthews, \& Kelly, 2007, p. 
1088). This description has been used as the foundation of research on grit theory since Duckworth's 2007 study (Perkins-Gough, 2013). As a relatively new theory, applications of grit theory are growing in many areas (Gottfredson, 1997).

Grit theory was developed based on research conducted at the United States Military Academy at West Point (Perkins-Gough, 2013). The United States Military Academy has an extensive admissions process and standards based on several factors, including high school GPA, standardized test scores, writing samples, recommendation letters, and even physical agility assessment (Duckworth et al., 2007). However, approximately one out of 20 new students at the United Stated Military Academy, known as "cadets", will not complete their first year of studies (Perkins-Gough, 2013).

In the summer of 2004, Duckworth et al., (2007) had a group of new cadets (n $=1,218 ; 84 \%$ men, $16 \%$ women) complete a grit predictor questionnaire upon admission to the academy. Investigating the student's grit, self-control, and their overall admissions score, the researchers used logistic regression analysis with retention as the dependent variable (Perkins-Gough, 2013). Analysis showed students who scored higher on the grit survey were more than $60 \%$ likelier to persist to completion $(\beta=.48, p<.001)$, compared to a $50 \%$ likelihood to persist for those students with high levels of self-control $(\beta=.48$, $p<.001$ ); however, the overall admissions score for the students did not predict retention in the program $(\beta=.09, \mathrm{~ns})$ (Duckworth et al., 2007). The researchers claimed the results showed traits like perseverance and self-control are better predictors of retention and success at the academy than intelligence tests or academic scores (Perkins-Gough, 2013).

To strengthen the correlation between grit and success, Duckworth et al., (2007) conducted additional research. In 2009, 273 contestants in the Scripps National Spelling 
Bee agreed to participate in a longitudinal investigation looking at grit, self-control, and a verbal intelligence exam (Duckworth \& Seligman, 2005). Multiple statistical analyses were completed, providing several interesting conclusions. The researchers concluded contestants with higher levels of grit studied more than contestants with lower levels of grit and, therefore, had better performance in the competition (Perkins-Gough, 2013). In a study of 139 undergraduate students (69\% women, 31\% men) attending an ivy league school, Duckworth et al., (2007) analyzed students' score from a grit assessment, grade point average, and Scholastic Achievement Test (SAT) scores. A student's grit score was associated with higher grade point average $(r=.25, p<.01)$, and an even stronger relationship was associated when SAT scores were held constant $(r=.34, p<.001)$ (Duckworth et al., 2007). Research by Duckworth $(2005,2006,2009)$ covered students at all levels of education, and outside of education, determining grit is a better indicator of success than intelligence or personal background.

\section{Grit in Education}

Looking at academic success, including achievement, retention, and the probability of graduation, grit has a significant impact (Duckworth \& Quinn, 2009). The combination of intelligence and non-cognitive traits, such as grit, result in educational achievement (Duckworth et al., 2007). Studies have shown students with high levels of grit are more likely to work harder, including completing additional work or practice to achieve further success (Duckworth \& Quinn, 2009; Hogan \& Wong, 2013). "Compared to their less gritty peers, individuals with higher levels of grit are expected to exhibit greater persistence in the pursuit of their goals despite setbacks, distractions, or other forms of interference" (Wolters \& Hussain, 2014, p. 294). 
Current literature also looks at specific groups of students, such as underrepresented minorities, first-year students, low socioeconomic status, or other specific demographics, to determine why some disadvantaged students, or high-risk students, persevere to academic success (González-Torres, \& Garde, 2014; Morales, 2014). Studies are mixed when attempting to understand the effect of grit on academic performance when considering gender, age, and ethnicity (Duckworth, 2007; Duckworth \& Quinn, 2009; González-Torres, \& Garde, 2014). Research has revealed concepts such as the grit theory, student development theory, and resilience theory explain why some students are more academically successful than their peers (Bashant, 2014; Dawson \& Pooley, 2013). Furthermore, psychological models such as self- efficacy, persistence, and having a growth mindset aim to predict which student will be academically successful (Garza, Bain, \& Kupczynski, 2014; Hochanadel, 2015). The student success theories and models are applied to students who are high achievers, to determine why one student or group of students are academically superior when compared to other students.

\section{Measuring Grit}

With the supportive research on grit influencing success came the need to reliably measure grit in people. Duckworth et al., (2007) developed a self-reporting questionnaire as an instrument to measure grit. The original survey has been updated and adjusted over time based upon additional data. Research has documented the survey to consistently measure perseverance as a stable characteristic of an individual (Wolters \& Hussain, 2015). A similar assessment instrument called the Inventory of College Students' Resilience (ICSR) was developed by Huang and Lin (2013) to assess the resilience of 
college students. With these instruments available, institutions of higher education could potentially use a grit measurement tool as part of the admissions process.

\section{Limitations}

Through multiple studies, Duckworth et al. (2007) revealed "individual differences in grit accounted for significant incremental variance in success outcomes over and beyond that explained by IQ, to which it was not positively related" (p. 1098). Even with this evidence, the theory has limitations. The measurement scale for grit is a self-reporting questionnaire relying on individuals to provide accurate information. Duckworth et al. (2007) pointed out the grit questionnaire is open to social desirability biases and relies on respondents to accurately remember and reflect on past experiences.

Further research on the personal development of grit is needed. Recent research has shown the importance of grit in college students (Bashant, 2014; Duckworth, 2006; Garza, Bain, \& Kupczynski, 2014); however, there are questions remaining. Can grit be taught? Or is it naturally occurring in a person? Can grit be developed over time? Or can grit be triggered when met with adversity? How and when is grit manifested? Is grit needed to recover from an academic failure or challenge?

\section{Academic Standing}

One of the biggest factors impacting student retention is academic performance during the first year of college (Choy, 2002; Pascarella \& Terenzini, 1980; Tinto, 1987). A student's academic performance is based upon the final grades earned in the course work completed. These grades are then computed into a single numerical number called grade point average, commonly abbreviated as GPA (Glossary of Education Reform, 2013). The cognitive measure of GPA has traditionally been viewed as one of the most 
important indicators of student success (Pascarella \& Terenzini, 2005). This GPA determines a student's academic standing at the institution.

An academic standing policy, to determine if a student is on academic probation or not, is usually set by the institution. According to the UCM Undergraduate Catalog (2019), academic standing is determined by a student's cumulative GPA as well as the institutional GPA. At the end of each academic semester, a student's GPA is calculated, and academic standing determined (UCM Undergraduate Catalog, 2019). To identify and help those students who are underachieving, institutions implement academic probation policies (Kelly, 1996; Pascarella \& Terenzini, 2005).

Students at UCM are considered to be in good academic standing if their cumulative and UCM GPA is 2.00 or above (UCM Undergraduate Catalog, 2019). Once the student's cumulative or UCM GPA drops below 2.00, the student will be placed on, or have their academic standing changed to, academic probation (UCM Undergraduate Catalog, 2019). A student placed on academic probation will continue on probation until the student increases their cumulative and UCM GPA to 2.00 or higher (UCM Undergraduate Catalog, 2019). Once the student increases their cumulative and UCM GPA to 2.00 or above, the student is removed from academic probation and returned to good academic standing (UCM Undergraduate Catalog, 2019). However, if a student on academic probation does not earn a GPA of 2.00 or above during the next semester of enrollment, the student will be suspended from the institution (UCM Undergraduate Catalog, 2019). According to the UCM Undergraduate Catalog (2019) academic suspension is for a period of one full semester, not including the summer semester, after which students can petition for reinstatement to the institution. Pascarella and Terenzini 
(2005) claimed academic policies set by the institution impact a student's learning environment.

When comparing the academic policies of nine large, public universities over 17 years, Brawner, Frillman, and Ohland (2010) found the term "probation" varies vastly from one institution to the next. Research by Preuss and Switalski (2008) found students were more motivated to improve their academic performance once they were placed on academic probation. A study by Bell and Short (2003) asked college students how they define achievement and underachievement. In the end, qualitative data were synthesized to produce thirteen different definitions, with some definitions of achievement going beyond a typical grading scale (Bell \& Short, 2003).

Another academic policy impacting a student's GPA and academic standing relates to students retaking or repeating coursework, with the ability to increase their GPA. If a student fails a course, the ability to repeat the course and earn a higher grade is essential (Valentine et al, 2011). According to the UCM Undergraduate Catalog (2019), a student may repeat a course regardless of the original grade earned in the course. All previous class grades earned will not factor into the student's GPA or earned hours, only the most current grade and hours will count, although all prior grades will remain on the transcript as a matter of record (UCM Undergraduate Catalog, 2019). The policy further states the most current grade earned will be the only one calculated in the student's GPA, even if it is not the highest grade (UCM Undergraduate Catalog, 2019).

Students' academic ability or intellect is not the only factor contributing to their academic performance. Several other factors such as study habits, extracurricular activities, effort and motivation, gender, and student-faculty interaction, to name a few, 
have a significant impact on a student's GPA (Balduf, 2009; Brophy, 1998; Pascarella \& Terenzini, 1991; Preuss \& Switalski, 2008; Tinto, 1987). Tinto (1993) stated students experience "a mismatch between the abilities, skills, and interests of the student and the demands placed upon that person by the academic system of the institution" (p. 51). For a student to persist the student and the institution must hold the same goal and the same commitment towards the goal (Tinto, 1993), including academic goals.

\section{Overcoming Academic Challenges}

Students on academic probation are not a lost cause. Responsibility lies on the institution to help students succeed and complete a degree (Radin, 2006). This includes students who experience academic struggles. Research has shown retention of a student is impacted by academic performance (Spady, 1971; Swail, 2004; Tinto, 1993, 2007); however, not all students on academic probation desire to quit school. Focusing on students who overcome academic adversity is important.

Balduf (2009) completed a qualitative study by interviewing 83 freshmen who were placed on academic probation during their first year at college. These students, who were considered high achievers in high school, faced academic challenges early in their collegiate career (Balduf, 2009). The interviews were conducted during the semester the student was placed on academic probation and examined the causes for underachievement (Balduf, 2009). Balduf (2009) discovered three recurring themes contributed to the student's underachievement: lack of academic preparation for college, issues with time management, and problems with self-discipline and motivation. This research provided a good basis to determine what led this particular group of students to 
be placed on academic probation; however, the research did not follow the students past the particular semester to study if they were able to overcome the academic setback.

Sriram and Vetter (2012) completed a qualitative study on students who were conditionally admitted to college as freshmen and were able to persist to be academically successful seniors. In a series of interviews the students described what strategies they used throughout college to become successful and on the path towards graduation (Sriram \& Vetter, 2012). Conditionally admitted students are a different population of students, on many levels, than regularly admitted students.

For a new student, the first semester of college can be challenging in many ways (Pascarella \& Terenzini, 2005). The student persisting to degree completion will depend upon the student's integration into the academic and social environment of the institution (Tinto, 1993). For those students who face academic challenges, there is hope for success. There is a shared interest between the student and the institution for the student to overcome the adversity and persevere towards the common goal of graduation.

\section{Conclusion}

As college student enrollment started to increase during the 1960s in the United States, the literature on student success and completion grew as well (Berger \& Lyon, 2005). Research since then has shaped the current practices in higher education (Braxton, Sullivan, \& Johnson, 1997). The College Completion Agenda (The White House, 2016) and other initiatives provide a goal for institutions (Hillman, Tandberg, \& Fryar, 2015). The goal is student success.

Student success is measured by graduation and retention rates (Shin, 2010). This literature review outlines current statistics on graduation and retention rates in higher 
education. A historical review of retention theory is provided to set the stage for current practices. Further review of how academic success and academic preparedness are tied to retention is provided. In addition to the study of successful students, there is a need to research students who were able to overcome academic hardship to complete a degree.

Research has shown how success in college is not completely based upon intelligence (Duckworth \& Seligman, 2005). This scholarly review includes an overview of grit theory, including the impact on a student's performance (Duckworth et al., 2007). The results of this research may help institutions improve retention, academic persistence, and graduation rates of college students. 
SECTION FOUR

CONTRIBUTION TO PRACTICE 
Merriam and Tisdell (2016) emphasized the importance of reporting and disseminating the results of research. "The research is of little consequence if no one knows about it; other practitioners have no way to benefit from what the researcher learned in doing the study" (Merriam \& Tisdell, 2016, p. 267). "The primary purpose of a report is to enlighten someone- to expand knowledge, help understand feelings, or convey information" (Krueger \& Casey, 2015, p. 164).

\section{Dissemination of Practitioner Contribution}

It is important to share the experiences of the UCM students who participated in this research with others at UCM. The results of this research include an oral presentation and executive summary to leaders of UCM who have direct impact on student success. Newcomer, Hatry, and Wholey (2015) labeled these types of individuals as "thought leaders" (p. 744). These are the audience members who must be persuaded by the research and motivated to take action on the results (Newcomer, Hatry, \& Wholey, 2015). These individuals include the UCM Provost, Vice Provost of Enrollment Management, Vice Provost of Academic Programs and Services, Assistant Vice Provost of Admissions and Financial Aid, Director of Academic Advising, and Director of First Year Programs.

The oral presentation is scheduled for approximately 30 - 40 minutes with an additional 15 minutes for discussion. Electronic visual aids will be utilized for the presentation. A presentation provides the opportunity for the research to make a powerful impression and provide insight into the study (Newcomer, Hatry, \& Wholey, 2015). In addition to the presentation an executive summary is provided to the audience members. 


\title{
A Qualitative Case Study of Student Success: High Risk Students on Track to Graduation
}

\author{
Presented by Drew Burkeybile \\ University of Central Missouri
}

UNIVERSITYOF

CENTRAL

MISSOURI

- The presentation will include welcoming the audience members/invited guests and sharing my appreciation for their attendance.

- After introducing myself, I will explain the reason behind the presentation, connected to completion of the EdD program.

- Since I was allowed to complete this research at UCM, I wanted to share the findings. 


\section{Introduction}

Not all students who start college will finish...

... institutions are unable to keep the students enrolled through degree completion...

... poor academic performance results in students not completing a degree...

(Choy, 2009; Pascarella \& Terenzini, 1980; York, Gibson, \& Rankin, 2015).

Historically, students who earn low first semester GPA's are retained at a lower rate (Tinto, 1993).

Academic performance has a strong correlation to student retention and degree completion (Bean, 2005; Pascarella \& Terenzini, 2005; Tinto, 2007).

- For context, I will share my current position at UCM and also discuss my past position in undergraduate academic advising.

- I will specifically discuss my experiences creating class schedules for new incoming freshman. And noticing how many of these students did not return to UCM for their second semester or second year.

- I will specifically discuss my experiences working with students as they completed their degree; the challenges many students faced; the relationships that were developed.

- My firsthand experiences contributed towards this research topic. 


\section{UCM Graduation}

FTFT Freshman Graduate Rates

\begin{tabular}{|c|c|c|c|c|c|c|}
\hline \multirow{2}{*}{$\begin{array}{c}\text { Cohort } \\
\text { year }\end{array}$} & Number & $\begin{array}{c}\text { Four } \\
\text { Years }\end{array}$ & $\begin{array}{c}\text { Five } \\
\text { Years }\end{array}$ & $\begin{array}{c}\text { Six } \\
\text { Years }\end{array}$ & $\begin{array}{c}\text { Seven } \\
\text { Years }\end{array}$ & $\begin{array}{c}\text { Eight } \\
\text { Years }\end{array}$ \\
\hline 2010 & 1,547 & $32.1 \%$ & $48.7 \%$ & $52.8 \%$ & $53.9 \%$ & $54.6 \%$ \\
2011 & 1,649 & $28.6 \%$ & $45.5 \%$ & $49.1 \%$ & $50.5 \%$ & $50.9 \%$ \\
2012 & 1,762 & $28.9 \%$ & $45.1 \%$ & $49.4 \%$ & $50.5 \%$ & \\
2013 & $-\frac{1,746}{30.0 \%}$ & $47.5 \%$ & $50.9 \%$ & & \\
2014 & 1,687 & $32.4 \%$ & $47.4 \%$ & & & \\
Average & $\mathbf{1 , 4 9 2}$ & $\mathbf{2 6 . 5 \%}$ & $\mathbf{4 5 . 0 \%}$ & $\mathbf{4 9 . 7} \%$ & $\mathbf{5 1 . 3} \%$ & $\mathbf{5 2 . 1} \%$ \\
\hline
\end{tabular}

UCM Fact Book, 2019

- I will quickly review UCM graduation rates.

- This is not new information, but important to keep in mind. Ultimately, this research is aiming to move the needle on graduation rates.

- $\quad$ The average rate indicated is since 1993.

- The highest 4-year graduation rate was 2015-35.8\%.

- Overall, there is a positive trajectory for graduation rates at UCM. 


\section{UCM Retention}

\begin{tabular}{|c|r|r|r|r|}
\hline \multirow{2}{*}{$\begin{array}{c}\text { Cohort } \\
\text { year }\end{array}$} & & \multicolumn{3}{|c|}{ Retention } \\
\cline { 3 - 5 } & Number & $\begin{array}{c}\text { One } \\
\text { Year }\end{array}$ & $\begin{array}{c}\text { Two } \\
\text { Years }\end{array}$ & $\begin{array}{c}\text { Three } \\
\text { Years }\end{array}$ \\
\hline 2014 & 1,687 & $70.8 \%$ & $61.7 \%$ & $56.3 \%$ \\
2015 & 1,641 & $70.8 \%$ & $63.7 \%$ & $58.6 \%$ \\
2016 & 1,578 & $71.9 \%$ & $62.3 \%$ & $57.7 \%$ \\
2017 & 1,665 & $69.9 \%$ & $60.2 \%$ & \\
2018 & 1,459 & $73.8 \%$ & & \\
& & $70.8 \%$ & $\mathbf{6 1 . 3} \%$ & $\mathbf{5 7 . 3} \%$ \\
\hline
\end{tabular}

\section{FTFT Freshman}

Retention Rates

UCM Fact Book, 2019

- Similarly, to graduation rates, I will quickly review retention rates at UCM.

- This is not new information, but important to keep in mind. Ultimately, this research is aiming to move the needle on retention rates as well. 


\section{Statement of the Problem}

- FTFT Freshman, meeting UCM admission standards

- placed on academic probation after their first semester

- Over $80 \%$ end up leaving, with a poor GPA and no degree

- Challenge to retain students who earn low first semester GPA's (Tinto, 1993).

- Every year students are regularly admitted to institutions based upon ACT score and high school GPA with the expectation of being successful (Westrick, Le, Robbins, Radunzel, \& Schmidt, 2015).

- Following the admission standards set by the university, these student should be successful (Balduf, 2009).

- The problem my research looks to address is he high number of students admitted to UCM, meeting academic requirements - should be successful - but are not.

- Discuss combing Probation, Suspension, Dismissal reports for fun.

- My research focused on the Fall 2014, 2015, and 2016 cohort of freshman at UCM. 


\section{Purpose of the Study}

The purpose of this qualitative study was to explore the experiences of UCM students who:

- were regularly admitted to UCM as first-time, full-time freshmen

- were subsequently placed on academic probation after their first semester

- were able to recover to persist and be on track to complete a degree

- The purpose of my study was to explore the experience of UCM students who have overcome academic adversity.

- These students are examples of student success; went from failure to success.

- The research also has implications on freshman orientation - fresh enroll/registration - FYE - advising - tutoring services - other student support services.

- Lastly, the research provided information on how to work with students on academic probation, especially freshman. 


\section{Research Questions}

RQ 1: What contributed to the students being placed on academic probation?

RQ 2: How did the students recover academically, return to good standing, and be on track to degree completion?

RQ 3: What concepts of Grit Theory (self-motivation, persistence, overcoming adversity) were demonstrated by the student participants of this study?

- The three research questions will be reviewed. 


\section{Theoretical Framework}

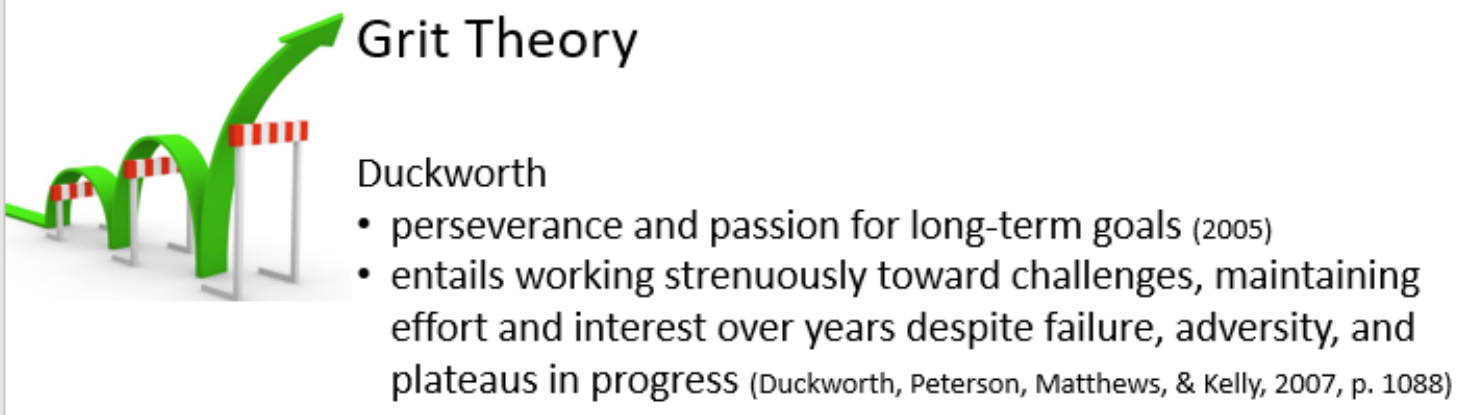

- To support the research, I have identified a theoretical framework or conceptual framework.

- Review process of the lit review to identify possibilities.

- Review why Grit theory was selected - most fitting- Duckworth.

- Review definitions - both include time- over time- long term goals - college 4year experience - event a class or semester longer time - continual effort towards goal - overcoming failure.

- Research has shown how success in college is not completely based upon intelligence. 


\section{Theoretical Framework}

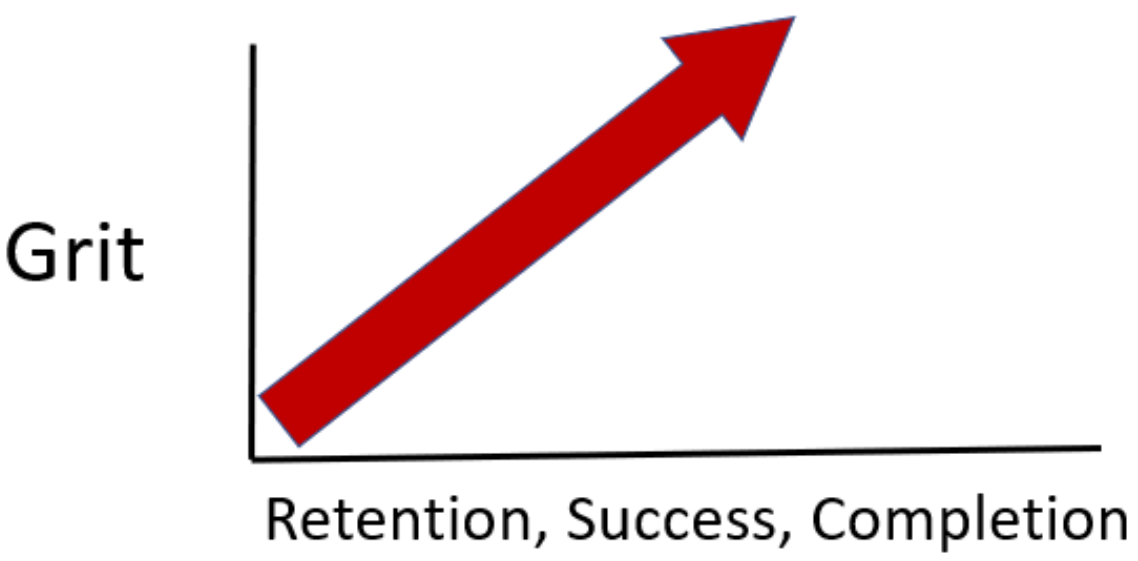

- Quickly mention the multiple studies - K-12 and higher education.

- College students with more grit are more likely to be retained, to be academically successful, and to graduate.

- Discuss Duckworth developed a grit measuring tool

- to quantify the personality trait

- to identify students who hold a greater probability of academic success

- and it is more than high school GPA and ACT test scores 


\section{Design of Study}

- Qualitative Case Study

- Focus on a specific phenomenon, bound by setting and time

- Seeks to understand the meaning of an experience

- The academic success of high-risk students

- Allows these individuals to convey their experiences relating to academic struggles and success

- For this qualitative study, the goal is to understand the meaning of what these students have experienced.

- The design allowed the student to tell their story and describe their experiences of achieving success. 


\section{Participants}

- Purposeful Sampling

- UCM Undergraduate students

- FTFT Freshman

- Met regular admission requirements

- Academic Probation after $1^{\text {st }}$ semester

- Persisted, continually enrolled

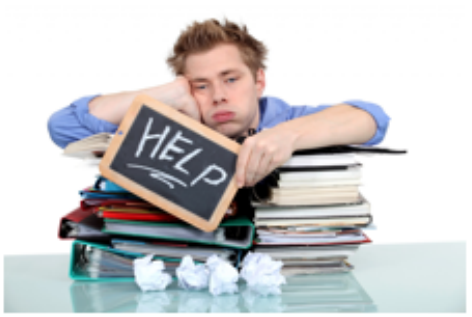

- Has returned to good academic standing - 2.40 GPA +

- Will graduate, within 6 years of first enrollment

- For this study - sample will be purposeful - selected specific for this study

(Merriam \& Tisdell, 2016).

- UCM undergrad students

- Population does not include students who were conditionally admitted outside of the institution's regular admission standards.

- Also exclude students who participated in the TRIO Student Support Services Program, - student-athletes - transfer students - students with prior military experience - post-baccalaureate students - international students.

- Discuss how a "GPA limit" was set.

- Based upon the student's transcripts there was a delineation in performance.

- Discuss other students- roller coaster, hover around 2.00 GPA, earn every grade possible in a semester, or on and off probation. 


\section{Participants - 24 UCM Students}

- Fall $15+$ Fall $16+$ Fall 17= 36 met requirements

- 9 identified as male

- 15 identified as female

- Current age range: 20 - 24

- 12 participants were $\underline{1}^{\text {st }}$ generation student

- Ethnicity

- 3-African American

- 2-Asian

- 2-Hispanic

- 17 - White/Caucasian

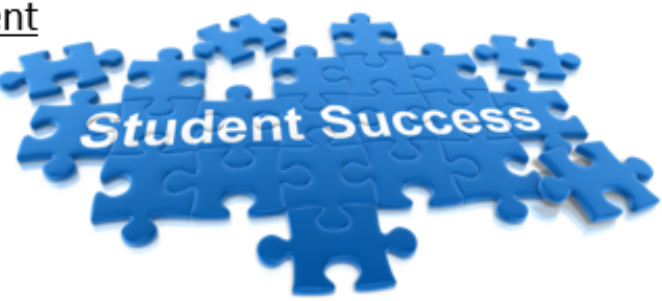

- 19 participants (80\%) changed their major at least once after their first semester

- 2.86 Average UCM GPA

- Outline the 24 students who agreed to be interviewed. Their willingness to talk was surprising.

- Review the High School Descriptive Statistics:

- Various high schools

- Size: Brookfield vs Lee’s Summit

- Location: Kansas side, Missouri- KC to St. Louis, Warrensburg, rural vs urban cities

- Private vs public: Rockhurst vs Clinton

- $\quad$ Average HS GPA 3.05 (range 3.74 - 2.16)

- $\quad$ Average ACT score 21.83 (range 16 - 30)

- Overall, 15 of the 36 were first generation

- Every UCM college was represented in the majors 


\section{Data Collection}

- Individual Interviews

- Semi-structured

- Conversational style, exploring the participants lived experiences

- Follow-up with questions

- Document Review

- Mining data from documents

- Admission application

- Transcript

- Degree audit

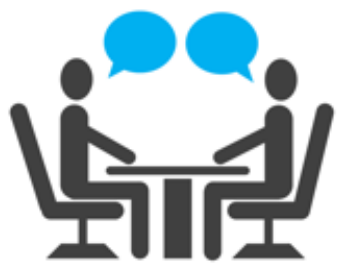

- Review the data collection methods, included:

- one on one interviews.

- review and analysis of documents.

- Discuss the interview process, most via phone and video conference.

- Discuss the document review process. 


\section{Qualitative Findings - Themes}

- "Fit" makes huge difference

- Mental Health

- Utilization of Student Resources

- Discuss how analysis revealed themes throughout the data.

- I used open and collapsed coding, identified 3 major themes:

- "Fit" is very important. Fit can be applied in a few different ways.

University level was good; students enjoyed UCM as a whole; loyal to UCM.

- Fit in a major was key. Also, fit with peer support group.

- Mental Health. Not surprising to hear students talk about mental health, however, it continually came up during the interviews.

- Utilization of Student Resources. This is broad theme that can be applied to several areas at UCM. 
Research Question 1:

\section{What contributed to the students being placed on academic probation?}

- The answers to the research questions follow the themes identified.

- So what did the participants say contributed to their poor academic performance during their first semester? 
RQ1 Answered

\section{Attendance, Attendance, Attendance}

"Being in college, you don't have anyone else relying on you to go to class... it's all on you", advised Aaron.

My early morning class was hard to attend. I would also miss due to being sick, then I would end up missing a

whole week of certain classes" remarked Charlie.

When reflecting upon his first semester, Jack stated, "...I stopped going to class."

Silas stated, "Missing class makes a different. I got behind and could not catch up."

- The most common response was class attendance.

- Supported by research and quantitative data, the importance of attending class is connected to student success.

- An overwhelming reason as to why these students performed poorly during their first semester was class attendance. 


\section{RQ1 Answered}

\section{Not the right "Fit"}

- Academic Major

- $80 \%$ of the participants changed their major after the first semester

- Friends/Peer Support/Student Organizations

Most people who come to college don't know what they want to do; I thought I did, but when I got here it was nothing like I had thought" stated Charlie.

Grace advised, "I was not engaged by teachers and could not relate to what I was learning."

Ben stated, "I would sleep on the couch of my friends house most of the time... I spent very little time in my dorm room that semester."

Emma remarked, "After my first semester, I requested my own room, with no room mate and continue to have my own room."

- The second factor that contributed to the students earning poor grades and being placed on academic probation after their first semester was a poor fit academically.

- $80 \%$ of participants changed their major after their first semester.

- Also discuss participant's challenges of fit with new peers, roommates, living arrangements, friends, student organizations connected to academic programs.

- A lot of first-generation students, would explain the difficulty adjusting to college. 


\section{RQ1 Answered}

\section{Poor Mental Health and Well Being}

- Depression

- Home Sick/Personal issues

- Adjusting to college life and integrating into academia

"I felt overwhelmed for most of the semester", Zack commented.

"It all kind of snow balled on me...", stated Evelyn.

Matthew stated, "It was really weird, I have never struggled before [academically], but I got into a funk. And kind of sent me into a depression for a little bit, had a couple of days where I did not get out of bed."

- The third factor that contributed to the students earning poor grades and being placed on academic probation after their first semester was a poor mental health and wellbeing.

- During the interviews, the participants described their mental and physical wellbeing and how it impacted their academic performance.

- The impact of mental health on academic success was not completely surprising, however, the magnitude or prevalence was surprising.

- The "snowball" effect is a common feeling for a first-time college student.

- A lot of first-generation students, would explain the difficulty adjusting to college. 


\section{RQ1 Answered}

\section{Utilization of Student Resources}

- Freshman orientation/activities did not provide beneficial results

- Faculty-student relationship

- Comfort level with support individuals/office

Ben stated, "Even though I knew I was doing bad in my classes, I did not know what to do about it."

Bill stated, "I did not really need to study in high school, or put much time into it, to get good grades. So when I got to UCM did not know how to study."

"I knew I had failed them before December; I had come to terms with this before the end of the semester. When I handed in the final for math, I knew I had failed the class" Emma stated.

"I have never felt comfortable getting tutoring from someone I do not know; I need a personal relationship to ask the for help" commented Jack.

- The fourth factor that contributed to the students earning poor grades and being placed on academic probation was not utilizing

- or not knowing how to utilize the resources available to students on campus.

- Based upon the participant responses, they rarely or never utilized

- their faculty teaching the courses,

- their assigned academic advisor, nor the tutoring services provided on campus. 
Research Question 2:

How did the students recover academically, return to good standing, and be on track to degree completion?

- The answers to the research questions follow the themes identified.

- So what did the participants say allowed them to recover academically, return to good academic standing, and be on to graduation. 


\section{RQ2 Answered}

\section{Finding the right "Fit"}

- Enjoyment in coursework/major led to increased attendance

Silas stated, "...staying motivated has not been too much of a challenge since I changed my major."

"I found something I loved to do" exclaimed Liam.

Taylor commented, "I was allowed to pick my own classes for second semester, so I picked the best times and the best professors. Now I talk to other students and research which teachers to take..."

Chris stated, "Living in the residence hall was not bad but, when I moved into my apartment, I could focus more. I did not have a roommate, and my apartment felt more like home, which helped me focus."

- Obviously, attending class was the answer heard from many participants.

- But specifically, it came down to why they were attending now compared to their first semester.

- They are enjoying what they are learning. They can see how the class material relates to a future career.

- Realize a new or different career aspiration. 


\section{RQ2 Answered}

\section{Improved Mental Health}

- UCM Counseling Center

- Self Care

- Change in situation

Milo stated,

"The Counseling Center helped me learn about taking care of yourself. Or taking care of myself during times of stress."

Chris added, "There needs to be more counselors at UCM. There are a lot of new students in a new area and they don't know anyone, and they get all depressed."

Axel stated,

"I figured out my way of doing things, so time management, and how to handle the workload of college classes. After this my stress went down."

- When asked what changed the most since your first semester, many of the participants stated their mental health, specifically an improvement in their mental health.

- Access to the Counseling Center.

- Coping with stress and self-care. 


\section{RQ2 Answered}

\section{Utilizing Student Resources}

Amy state, "Get help earlier, when you see the signs of failing."

Mia stated, "It is now easier to ask for help when I am having issues. I feel comfortable talking to my teachers. I email all my teachers now."

Bill stated, "My advisor made me take a learning strategies class, ... and that was useful."

Marcus stated, "My sophomore year, I believe, for one of my first social work classes, the instructor required our final paper be reviewed at the writing center. This was the first time I went there. I have went there for other classes since then. I do not use it all the time, but it is helpful."

Taylor stated, ...I am also now registered with the Office of Accessibility. I now use the services that are available to me...

- When asked what advice you would give yourself as a freshman, many students talked about getting help or asking for help.

- Review the specific resources: instructors outside of class, academic advisors, and tutoring center. 
Research Question 3:

\section{What concepts of Grit Theory (self-motivation,} persistence, overcoming adversity) were demonstrated by the student participants of this study?

- What concepts of Grit were identified in the students participating in this study? 


\section{RQ3 Answered}

Never considered leaving UCM

- Persistence

- Resiliency

Mia stated, "I wanted to finish what I started. Leaving never crossed my mind."

Sophia stated, "Leaving was not an option for me, staying in college was the only option."

"It was only one semester. I knew I could try again the next semester. And do better. " stated Sam

"I never considered leaving, but in my head, I was worried about suspension and trying to think what would I do if I get suspended" Aaron commented.

- None of the students considered leaving UCM after being placed on academic probation after their first semester.

- This shows the concept of persistence and the personal characteristic of resiliency demonstrated by the participants.

- This is especially evident considering statistics surrounding the student's academic situation.

- Since 2014, a high percentage (consistently over $80 \%$ ) of the regularly admitted first-time, full-time freshman at UCM who struggle academically during their first semester and are subsequently placed on academic probation, end up leaving the university no degree.

- The participants of this study are in the minority compared to their peers in a similar situation. 


\title{
RQ3 Answered
}

\author{
Goal Setting and Motivation \\ - Short term vs long term goals \\ - Grades and GPA \\ "Setting goals helps me get through the semester, something to look forward to. I have a goal in mind \\ and work towards it" commented Sam. \\ Heather described, "My motivation is to not go back to where I was my freshman year. I have come so far \\ now, compared to where I was. I want to get good grades now." \\ Axel stated, "My motivation now is to get a good job." \\ Amy commented, "My advisor has been a big part of my motivation to finish. She is very supportive."
}

- Goal setting was a common response.

- Supports student success.

- Review the other motivations as the student near graduation. 


\section{Implications}

- Importance of $1^{\text {st }}$ semester class schedule/professors

- Student mental health and well being

- Freshman Orientation, Week of Welcome, FYE

- Advising freshman probation students

- Working with incoming freshman to schedule fall semester courses.

- Programing specifically to help all freshman transition to college

- Expend the Counseling Center services, counselors, outreach to residence halls

- Add to freshman orientation and FYE

- Mental Health first aid training for residence hall staff

- The first semester freshman on probation should consider a major change. Major $\&$ Career Exploration. At least a discussion if the student fits into major. 


\section{Recommendations}

Freshman Integration

- Starts with Freshman Orientation

- Allow more input from freshman on schedules

- Courses geared towards freshman

- Specific assignments/activities

- Connect to campus resources; faculty office hours

- Based upon the research findings, several recommendations for practice were developed.

- First area related to integrating freshman to college life and UCM.

- Discuss importance of first semester schedule.

- Discuss “freshman only" sections of general education classes; Sections of Gen Ed that are first time freshman students only, with faculty that "specialize" in teaching freshman.

- Add emphasize on class attendance 


\section{Recommendations}

First Year Experience

- Require Student Mental Health course/training

- i.e. Alcohol Edu

- Incorporate goals setting and goal achievement

- Access/Utilization of campus resources

- Writing Center

- Tutoring Center

- FYE focus on student mental health, goal setting and utilization of campus resources

- Discuss need for coordinated plan, various formats to reach diverse student population.

- Review the need for a required student wellbeing and mental health training, connected to the UCM Counseling Center.

- Teach goal setting, and the actions related to goal achievement; connect to class attendance and using campus resources.

- Describe possibly initiatives or ideas to improve comfort level. Discuss need to go beyond showing new students where the Learning Commons is located. 


\section{Recommendations}

Academic Probation Plan

- Academic Recovery Plan for freshmen on probation

- Coordinated plan of care

- Major change?

- Class attendance

- Mental Health

- If student put on probation after first semester, should be considered high risk.

- Discuss plan to engage student, by discussion and assessments, major exploration/personal or personality (UNIV 1410)

- Review plan, starts with academic advisor, but needs to include all support offices and faculty.

- Discuss need to address second semester schedule ASAP.

- Discuss the importance of self-care and stress management. 


\section{Future research}

- Use grit scale

- Alternative admissions standards/criteria

- More on student mental health \& well being

- Expand to other student populations

- $1^{\text {st }}$ Generation Students

- Discuss future research, with Test Optional Admissions.

- Other options or alternative admissions criteria.

- Other measures for admission.

- Hearing about student's issues with mental health was really eye opening.

- Discus other populations of students to consider and research? 
"Failure is an opportunity to move yourself in a different direction."

- Oprah Winfrey

- To wrap it up, I will leave you with this quote... 


\section{References}

- Balduf, M. (2009). Underachievement among college students. Joumal of Advanced Academics, 20(2), 274-294.

- Bean, J. P. (2005). Nine themes of college student retention. In A. Seidman (Ed.), College student retention: Formula for student success (pp. 215-243). Westport, CT: American Council on Education and Praeger Publishers.

- Braxton, J. M., Sullivan, A. S., \& Johnson, R. M. (1997). Appraising Tinto's theory of college student departure. In J. C. Smart (Ed.), Higher education: $A$ hondbook of theory and research, 12,107-164. New York: Agathon Press.

- Choy, S. P. (2002). Access \& persistence: Findings from 10 years of longitudinal research on students. Washington, DC: American Council on Education.

- Creswell, J. W. (2014). Reseorch design: Quantitotive, qualitative, and mixed methods opproaches. (4th ed.). Thousand Oaks, CA: Sage.

- Duckworth, A. L., \& Seligman, M. E. P. (2005). Self-discipline outdoes IQ in predicting academic performance of adolescents. Journal of Educational Psychology, 16(12), 939-944.

- Duckworth, A., Peterson, C., Matthews, M., \& Kelly, D. (2007). Grit: Perseverance and passion for long-term goals. Journal of Personality and Social Psychology, 92(6), 1087-1101.

- Glossary of Education Reform (2013). Grade point overoge. Retrieved from https://www.edglossary.org/grade-pointaverage

- Hillman, N. W., Tandberg, D. A., \& Fryar, A. H. (2015). Evaluating the impacts of "new" performance funding in higher education. Educational Evaluation and Policy Analysis, 37(4), 501-519.

- Merriam, A. B., \& Tisdell, E. J. (2016). Quolitotive research: A guide to design and implementotion. (4th ed.). San Francisco, CA Jossev-Bass.

- National Student Clearinghouse Research Center. (2018). Snopshot report: First-yeor persistence and retention.

- National Student Clearinghouse Research Center. (2018). Snapshot report: Yearly success and progress rates. 


\section{References}

- Pascarella, E. T., \& Terenzini, P. T. (1980). Predicting freshman persistence and voluntary dropout decisions from a theoretical model. Journal of Higher Educotion, 51(1), 60- 75.

- Pascarella, E. T., \& Terenzini, P. T. (2005). How college affects students: Volume 2: A third decade of research. San Francisco, CA: Jossey-Bass,

- Shin, J. C. (2010). Impacts of performance-based accountability on institutional performance in the U.S. Higher Education, 60(1), 4768.

- Sriram, R., \& Vetter, D. (2012). Thriving in high-risk students. In L. A. Schreiner, M. C. Louis, \& D. D. Nelson (Eds.), Thriving in transitions: A research-based approach to college student success (pp. 87-110). Columbia, SC: University of South Carolina, National Resource Center for The First-Year Experience and Students in Transition.

- Tinto, V. (1993). Leaving college: Rethinking the causes and cures of student attrition (2nd. ed.). Chicago, IL: The University of Chicago Press.

- Tinto, V. (2007). Research and practice of student retention: What next? Journal of College Student Retention: Research, Theory \& Practice, 8(1), 1-19.

- University of Central Missouri (2018). Foct Book.

- University of Central Missouri (2019). Undergraduate cataiog (2019 ed.).

- Westrick, P. A., Le, H., Robbins, S. B., Radunzel, J. M. R., \& Schmidt, F. L. (2015). College performance and retention: A meta-analysis of the predictive validities of ACT scores, high school grades, and SES. Educotional Assessment, 20, 23-45.

- York, T. T., Gibson, C., \& Rankin, S. (2015). Defining and measuring academic success. Proctical Assessment, Reseorch \& Evaluotion, 20(5), 1-20. 


\section{Questions?}

Thank you for your time and attention. 


\section{Executive Summary}

A Qualitative Case Study of Student Success- High Risk Students on Track to Graduation Drew M. Burkeybile

\section{Statement of the Problem}

Every year students are admitted to college by meeting the admission standards set by the institution (Westrick, Le, Robbins, Radunzel, \& Schmidt, 2015). The expectation is that students will be academically successful throughout their studies, earning a college degree (York, Gibson, \& Rankin, 2015). However, research has shown not all students who start college will finish college, and institutions are unable to keep the students enrolled through degree completion (Choy, 2009; Pascarella \& Terenzini, 1980).

The problem is the large number of first-time, full time freshman, regularly admitted to the university, being placed on academic probation after their first semester at UCM. Furthermore, the problem is the high percentage (consistently over $80 \%$ ) of regularly admitted first-time, full-time freshman at UCM who struggle academically during their first semester, are placed on academic probation, and end up leaving the university with a poor GPA and no degree.

\section{Purpose of the Study}

The purpose of this qualitative case study was to understand the shared experiences of UCM students who faced significant academic adversity during their first semester, resulting with them being placed on academic probation, even though the students met the regular admissions criteria and were admitted with the expectation of being successful. Despite this hardship, these students were able to recover academically, improving their GPA, are currently in good academic standing, and are on the path towards degree completion.

\section{Design of the Study}

To understand the shared experiences of these UCM students a qualitative case study will be utilized. This will allow for the individuals to convey their experiences relating to academic struggles and success. Date were collected through one-on-one interviews and document analysis.

\section{Participants}

The participants of the study were 24 undergraduate students who were regularly admitted to UCM as first-time, full-time freshmen, were subsequently placed on academic probation following their first semester, but were able to return to good academic standing and were currently on track to complete their college degree from UCM. Furthermore, these students have improved their GPA to 2.40 or above, showing their improved academic abilities. Excludes conditionally admitted students, TRIO students, student-athletes, transfer students, etc.

\section{Research Questions}

RQ1: What contributed to the students being placed on academic probation? 
RQ2: How did the students recover academically, return to good standing, and be on track to degree completion?

RQ3: What concepts of Grit Theory (self-motivation, persistence, overcoming adversity) were demonstrated by the student participants of this study?

\section{Theoretical Framework}

Grit: Perseverance and passion for long-term goals (Duckworth, Peterson, Matthews, \& Kelly, 2007); the ability to sustain interest and effort over an extended period of time to achieve a long-term goal (Crede, Tynan, \& Harms, 2017).

"Fit" is Important-

\section{Findings}

All students were happy to be at UCM! However, poor "fit" within their freshman major contributed to the students being placed on academic probation after their first semester. Almost $80 \%$ of the students changed their major at least once after first semester. A "proper fitting" academic program resulted in improved class attendance and student success (furthermore for some students, finding a better social support network of peers) which contributed to the students returning to good academic standing and being on track to graduation.

\section{Student Mental Health -}

Poor mental health and wellbeing contributed to the students being placed on academic probation after their first semester. Students described increased stress and anxiety adjusting to college life, feeling overwhelmed, and suffering from depression. The students reported the improvement in their mental health was the most significant change since their first semester and was a significant contribution to the students returning to good academic standing and being on track to graduation.

\section{Utilization of Campus Resources -}

Students admitted to not taking advantage of, or not knowing about, the resources available to them during their academic struggles through their first semester. Now, the students credit their academic recovery and return to good standing on communication/relationships with their faculty and academic advisors. The students developed a level of comfort and are now aware of the resources available to them as they are close to graduation.

\section{Demonstration of Grit -}

Students showed persistence and resiliency and did not quit like some many of their peers when they were faced with academic adversity. The students now rely on goal setting and motivation to get them through graduation day.

\section{Recommendations}

- Like Alcohol Edu, it is recommended that required student mental health training be incorporated into the freshman FYE programing, starting before classwork begins. 
- First semester freshman who end up on probation should be considered high risk and have a set academic recovery plan that includes major exploration and emphasis on class attendance.

- Incorporate goal setting into FYE and freshman coursework.

- Expand the Counseling Center services, counselors, and outreach to reach more freshman- incorporate into freshmen orientation, FYE programming, and residence life. 
SECTION FIVE

CONTRIBUTION TO SCHOLARSHIP 


\section{Target Journal}

The target journal for this study is the NACADA Journal. NACADA, the National Academic Advising Association, is an international association of individuals engaged in the work of academic advising, specifically for professional advisors, counselors, faculty, and administrators working to enhance the educational development of students (NACADA, 2020). The journal is a biannual refereed journal founded in 1981 with the intent to advance scholarly discourse about the research, theory and practice of academic advising in higher education (NACADA, 2020). A print version of the journal is available for all NACADA members (NACADA, 2020). The journal can be accessed electronically via the NACADA website hosted by Allen Press (NACADA, 2020). The mission of the NACADA Journal is to advance the field of academic advising through the publication of peer-reviewed research and scholarship that contributes to our understanding and improvement of the learning experiences of all students within an academic advising context (NACADA, 2020).

\section{Rationale for this Target}

This journal was chosen because the research topic aligns with the overall purpose of the journal. In general, the $N A C A D A$ Journal focuses on topics related to student achievement and advising student success. Current articles published by this journal focus on students on academic probation, advising philosophy and practice, student retention, at-risk students, student perceptions of advising, and working with certain groups of students based upon demographic factors, to name a few. Readers of the journal include professional advisors, faculty advisors, and administrators serving areas of enrollment management, academic support, academic programing, and student 
services. The NACADA Journal has served as the preeminent authority on academic advising in higher education for over 35 years (NACADA, 2020). NACADA members, which include over 12,000 individuals representing all 50 United States, Puerto Rico, Canada, and several other international countries from higher education institutions across the spectrum of Carnegie classifications, as well as nonmembers have easy access to the journal online free of charge (NACADA, 2020). Therefore, numerous professionals working in higher education will have access to the findings of this study, promoting the contribution to scholarship and practice.

\section{Plan for Submission}

Once the dissertation process is completed, the researcher will submit the manuscript. The NACADA Journal editors select submissions for peer review from manuscripts that address a wide variety of interest areas (NACADA, 2020). Manuscripts are uploaded electronically in the Peer Track manuscript management system website (NACADA, 2020). The editors of the journal will accept manuscripts submitted under APA 6th Edition, however, any manuscript that will be printed and/or published after January 1, 2021 will be required to follow the APA 7th Edition guidelines (NACADA, 2020). The manuscript review process is an extensive blind peer review (NACADA, 2020). 


\section{Journal Article}

High Risk Students on Track to Graduation:

A Qualitative Case Study of Student Success

Drew M. Burkeybile

University of Central Missouri 


\begin{abstract}
This qualitative case study was designed to investigate how first-time, full-time undergraduate students who met standard admissions requirements ended up on academic probation after their first semester. Furthermore, this study explores how these students were able to overcome the academic adversity, return to good academic standing, and be on track to graduation. This study focusses on a small group of students who stay enrolled, persisted, and are on track to graduation. Data collection included individual interviews with students and document analysis. Findings indicate three major themes that impact student success: "fit" in an academic program, student mental health, and utilization of student resources. The findings can provide academic advisors with valuable insight on the best ways support students on probation.
\end{abstract}


Key Words

Academic probation, graduation, student success, student experiences, high risk advising, retention, grit 
Every year students are admitted to college by meeting the admission standards set by the institution (Westrick, Le, Robbins, Radunzel, \& Schmidt, 2015). The expectation is that students will be academically successful throughout their studies, earning a college degree (York, Gibson, \& Rankin, 2015). However, research has shown not all students who start college will finish college, and institutions are unable to keep the students enrolled through degree completion (Choy, 2009; Pascarella \& Terenzini, 1980).

According to the National Student Clearinghouse Research Center (2019), the four-year graduation rate for first-time, full-time students starting in the fall 2012 semester at a four-year public institution was $41 \%$. In comparison, the University of ABC $(\mathrm{ABC})$ is behind the national averages for four-year and six-year graduation rates. According to the ABC (2018) Fact Book, the four-year graduation rate for first-time, fulltime freshmen starting in the fall 2014 semester is $32.4 \%$. This rate is the highest since graduation rates were formally tracked by the institution in 1993. The average four-year graduation rate for first-time, full-time $\mathrm{ABC}$ freshmen from 1993 to 2014 is $26 \%$. The average six-year graduation rate for first-time, full-time $\mathrm{ABC}$ freshmen from 1993 to 2012 is $49.6 \%$. For full-time, first-time freshmen starting the fall 2012 the six-year graduation rate is $49.4 \%$.

The overall retention rate for students who started college at four-year public institutions in fall 2017 was $71.2 \%$ (National Student Clearinghouse Research Center, 2019). According to the ABC (2018) Fact Book, the average one-year retention rate for first-time, full-time ABC freshmen from 1993 to 2017 is $70.7 \%$. The average retention rate for the same student population at two-years and three-years is $61.3 \%$ and $57.2 \%$, 
respectively. For full-time, first-time freshmen starting the fall 2017 the one-year retention rate is $69.9 \%$. As the research shows, there is room for improvement in retaining students to degree completion both nationally and at $\mathrm{ABC}$. Even more interesting is retention and graduation data specific to student populations.

Students are regularly admitted to universities across the country by fulfilling the admission standards, but do not progress to graduate with a degree. Every year students are regularly admitted to institutions based upon ACT score and high school GPA with the expectation of being successful (Westrick, Le, Robbins, Radunzel, \& Schmidt, 2015). However, every semester, students who were admitted to college with the expectation of being successful find themselves with poor grades and end up with academic problems. Many students continue the academic decline and are eventually suspended from the institution or drop out (Tinto, 1993). Some students, however, recover from academic distress, go on to improve academically, and complete a college degree. Rather than focusing institutional resources on student attrition, Tinto (1987) recommended a focus on student persistence in order to promote student success.

The problem is the large number of first-time, full time freshman, regularly admitted to the university, being placed on academic probation after their first semester at $\mathrm{ABC}$. Furthermore, the problem is the high percentage (consistently over $80 \%$ ) of regularly admitted first-time, full-time freshman at $\mathrm{ABC}$ who struggle academically during their first semester, are placed on academic probation, and end up leaving the university with a poor GPA and no degree. Following the admission standards set by the university, these students should be successful (Balduf, 2009). The small percentage of students who were placed on academic probation after their first semester, however, were 
able to recover academically, stay enrolled at $\mathrm{ABC}$, and continue their academic progress towards graduation are an important population to study.

\section{Purpose of the Study}

The purpose of this study was to research students who were regularly admitted to $\mathrm{ABC}$ as first-time, full-time freshmen, who were subsequently placed on academic probation after their first semester, but were able to recover from the academic setback, persist and be on track to complete a baccalaureate degree. According to the $\mathrm{ABC}$ admission standards, students who are regularly admitted based upon high school GPA and ACT test scores should possess the academic capacity to successfully complete a degree. Specific emphasis of this study included researching what caused these students to be placed on academic probation and how these students were able to recover academically after experiencing a large academic setback.

\section{Research Questions}

The research questions guiding this study are:

RQ1: What contributed to the students being placed on academic probation?

RQ2: How did the students recover academically, return to good standing, and be on track to degree completion?

RQ3: What concepts of Grit Theory (self-motivation, persistence, overcoming adversity) were demonstrated by the student participants of this study?

\section{Conceptual/Theoretical Framework}

A review of the literature on academic success in higher education shows there are several theories which attempt to determine what makes a college student successful. Research by Duckworth (2006) recommended identifying the personality traits or 
influences which make a student successful. Research has revealed concepts such as grit theory, the student development theory, and resilience theory explain why some students are more academically successful than their peers (Bashant, 2014; Dawson, \& Pooley, 2013, Duckworth, 2006).

Furthermore, psychological models such as self-efficacy, persistence, and having a growth mindset aim to predict which student will be academically successful (Garza, Bain, \& Kupczynski, 2014; Hochanadel, 2015). The student success theories and models are applied to students who are high achievers, to determine why one student or group of students is academically superior when compared to other students. Current resources also examine specific groups of students, such as underrepresented minorities, first-year students, low socioeconomic status, or other specific demographics, to determine why some disadvantaged students, or high-risk students, persevere to academic success (González-Torres, \& Garde, 2014; Morales, 2014).

\section{Grit Theory}

The ability to sustain interest and effort over an extended period of time to achieve a long-term goal is referred to as 'grit' (Crede, Tynan, \& Harms, 2017). Components of grit include self-motivation, persistence, and overcoming adversity (Duckworth, Peterson, Matthews, \& Kelly, 2007; Perkins-Gough, 2013; Wolters \& Hussain, 2015). Duckworth, Peterson, Matthews, and Kelly (2007) defined grit as "perseverance and passion for long-term goals" (p. 1087). Further explained, "grit entails working strenuously toward challenges, maintaining effort and interest over years despite failure, adversity, and plateaus in progress" (Duckworth, Peterson, Matthews, \& Kelly, 2007, p. 1088). 
According to Crede, Tynan, and Harms (2017), grit has been found to be a crucial characteristic in predicting the success and academic performance of students. To determine if the personality trait of grit is a better indicator of future success than intelligence alone, Duckworth $(2006,2009)$ researched students at all levels of education. Research is focused on ways to identify students with grit in addition to focusing on ways to foster grit within students in order to increase the opportunities for students to be successful (Duckworth et al., 2007; Crede, Tynan \& Harms, 2017). This framework is consistent with research on college students who overcome academic challenges such as academic probation early in their academic career.

Duckworth et al. (2007) developed a grit measuring tool in order to quantify the personality trait. Huang and Lin (2013) used a similar instrument to measure the resilience of college students. Studies by Wolters and Hussain (2015) and Hogan and Wong (2013) were able to successfully test and measure the characteristic of grit in individuals.

In the academic setting, college students with more grit are more likely to be retained, to be academically successful, and to graduate (Duckworth \& Quinn, 2009). Students with high levels of grit work harder and can overcome setbacks or challenges (Hogan \& Wong, 2013; Wolters \& Hussain, 2014). The tools are available to identify students who hold a great probability of academic success (Duckworth \& Quinn, 2009), and it is more than high school GPA and ACT test scores. Completing a college degree is a long-term goal which takes perseverance. In addition, students who are placed on academic probation are faced with a significant academic challenge that must be 
overcome to achieve this goal. Considering the components of grit, the theoretical framework of Grit Theory was used for this study.

\section{Design of the Study}

The methodology for this research was qualitative in nature. The qualitative approach seeks to understand the meaning of an experience, in this case, the academic success of high-risk students. A qualitative investigation of the student participants allowed these individuals to convey their experiences relating to academic struggles and success.

\section{Setting}

The setting of this study was public 4-year institution. The University is located approximately 50 miles from a major metropolitan city, located in a Midwest town of 19,000 residents. Academically, ABC offers nearly 200 undergraduate degree program to approximately 9,000 undergraduate students. Nearly $70 \%$ of the student population is considered full-time with a majority of the students residing on campus or in the local. With a student-to-faculty ratio of $17: 1, \mathrm{ABC}$ has 463 full-time faculty members.

$\mathrm{ABC}$ is considered a moderately selective institution for admission standards. According to the University's Incoming Freshman Admission Requirements website (2019), to be admitted to ABC, a student must complete the 24-unit state collegepreparatory curriculum. In addition, a student needs either a score of 21 or higher on the ACT and $2.0 \mathrm{GPA}$; or a score of 20 on the ACT and $2.85 \mathrm{GPA}$; or a score of 19 on the ACT and $2.95 \mathrm{GPA}$; or a score of 18 on the ACT and $3.25 \mathrm{GPA}$; or a score of 17 on the $\mathrm{ACT}$ and $3.45 \mathrm{GPA}$; or a percentile index score, combining class rank, class size, and 
ACT score, to equal or exceed 100). In the fall 2018 semester, 1,493 first-time, degreeseeking, freshmen were enrolled at $\mathrm{ABC}$.

\section{Participants}

The participants of the study were undergraduate students who were regularly admitted to $\mathrm{ABC}$ as first-time, full-time freshmen, were subsequently placed on academic probation following their first semester, but were able to return to good academic standing and were currently on track to complete their college degree from ABC. These students had persisted after their early struggles, staying at $\mathrm{ABC}$ and being continually enrolled since their first semester to be on track to graduate from $A B C$ within six years of their first enrollment. Furthermore, these students have improved their GPA to 2.40 or above, showing their improved academic abilities. These parameters provide a population of students who faced academic adversity early in their academic careers but have persevered to complete their degree or who were currently in good academic standing and on track to degree completion.

This population does not include students who were conditionally admitted outside of the institution's regular admission standards. Every semester students are admitted conditionally, but are considered high-risk; therefore, the students receive special academic intervention and advising. This study also excluded students who participated in the TRIO Student Support Services Program, student-athletes, transfer students, students with prior military experience, post-baccalaureate students, international students, and students who have earned more than 21 credit hours of college credit before starting at ABC. This study focused on students who, based on admissions scores, were regularly admitted and were not required to complete special academic 
programming or requirements, and did not receive any special academic intervention or attention during their first semester and subsequent semesters.

For the fall 2015, 6 students meet the definition provided to be included in this study. For the fall 2016 semester cohort, 16 students meet the definition provided to be included in this study. And for the fall 2017 cohort, 14 students meet the definition provided to be included in this study.

\section{Data Collection Tools}

The research methods were semi-structured interviews with individual student participants following an interview question protocol. The nature of the interview questions focused on the how and the why of the student experiences. In an attempt to produce data to answer the research questions, the interviews were conversational, exploring the participants lived experiences. If needed, additional questions were asked to follow up on the answers provided and to ask the participant to expand upon their answer.

\section{Data Analysis}

Data analysis commenced once data were collected. Data collected from the participant interviews and document reviews were analyzed. In addition to listening to the recorded interviews, data analysis included reading and rereading the transcribed interviews to look for common themes in the data. The coding process involved assigning categories or labels to the various points of data, looking for themes. From the open coding and collapsed coding, the categories were condensed, and themes were further defined, data analysis memos were created (Creswell, 2016). 


\section{Results}

A total of 24 students consented to participate and were interviewed to collect data to answer the research questions. The participants were currently enrolled, either in their junior or senior year, based upon credit hour generation, with the intent to graduate within six years of their first semester of enrollment at ABC. The participants included nine students who identified as male and 15 students who identified as female. The participants ranged in age from 20 to 24 years old. Ethnicity of the of the participants included 3 African America students, 2 Asian students, 2 Hispanic students, and 17 White/Caucasian students. At the time the research was being conducted the average ABC GPA for all student participants was 2.86. Almost $80 \%$ (19 out of the 24 participants) changed their academic major at least once after their first semester. Another interesting finding identified 12 of the 24 student participants, $50 \%$, were first generation students. Several interesting findings resulted from the analysis of the data. The findings can be group into three broad themes: the importance of "fit" for the student, student mental health, and utilization of student resources.

\section{"Fit" is Important}

A common response from the participants when discussing their experiences revolved around the idea of "fit". Overall, the students were happy to be at ABC and were comfortable with being a student at $\mathrm{ABC}$. Besides fitting in at the University, the students shared their experiences about fitting in with regards to academic major, residence hall roommate(s) and living arrangements, meeting new peers, and joining student organizations. Students fitting in their major and fitting in with close peers really made an impact on academic performance. Most students lived in university housing 
their first year at $\mathrm{ABC}$. Almost $80 \%$ of the students interviewed changed their major at least once after their freshman year. Charlie stated "After I changed my major I did better in all my classes. I was much more interested in Music and enjoyed all my music classes." Similarly, when asked why she changed her major, Grace advised, "I was not engaged by my teachers and could not relate to what I was learning." Evelyn really elaborated on how changing her major impacted her experience at ABC. Evelyn stated Changing my major changed so many other things. The Theater teachers are just different, they teach different. And the learning is different. Changing majors also changed who was in my class and who I hung out with. The other theater students are really supportive and fun to meet. I really enjoy my classes.

Bill commented on his experience before changing his major, I did not get to fly my first semester, which is really important. I was learning stuff in class but not flying. Other students were able to fly, and this helped them learn. I was really struggling and could tell I was falling behind in my aviation classes.

Charlie stated, "Most people who come to college don't know what they want to do; I thought I did, but when I got here it was nothing like I had though.” When asked about the coursework in his current major, Jack stated, "I am definitely more interested. It helps to see how your classes will connect to future careers." Taylor commented, I was allowed to pick my own classes for the second semester, so I picked the best times and the best professors. Now I talk to other students and research which teachers to take before I sign up for my classes each semester. This has helped a lot. 
The participants also discussed how their relationships with peers impacted their academic success. Sam admitted, "My roommate and I did not get along. We never talked, and she just kept to herself.” Similarly, Evelyn stated, “... my roommate went home every weekend, so I was by myself a lot. I did not get to know her that much.” Also, Ben stated, "I would sleep on the couch of my friend's house most of the time my first semester or two. I spent very little time in my dorm room that semester. I was not comfortable living there."

Thinking back to her freshman year, Grace stated, "I was hanging out with the wrong people. They were not good for me. I was in a bad place and the people in my life did not help." When asked about her friends now, Grace stated, "I have a couple really close friends, that are like my best friends, and I can really rely on. We do a lot together and they support me"

\section{Students Mental Health and Well Being}

A common theme from the participants when discussing their experiences at $\mathrm{ABC}$ revolved around their mental health and wellbeing. A poor mental health or concerns about their mental health were large contributors to the student's overall academic performance. Many students expressed how their mental health during their first semester negatively impacted their academics, in various ways. The participants expressed concerns with their mental health that ranged from increased stress and challenges adjusting to college life, to negative personal feelings and severe depression. Zack recalled,

I felt overwhelmed for most of the semester that year. I remember just feeling a sense of dread and pressure and not knowing exactly what to do. I was on my own 
which was good in some ways and bad in other ways. I did not know what to do when my grades started going bad.

Similarly, when asked about failing her classes during her first semester, Evelyn stated, "It kind of snow balled on me and I did not know what to do." This "snowball" effect of pressure and stress seemed to be a similar experience for many students. When asked about her academic struggles her first semester, Heather stated, "It was too much for me and I got overwhelmed."

Several participants discussed how college classes and college life in general was an adjustment. Half of the participants are first generation students which may have contributed to this challenging adjustment period. When asked to reflect upon his freshman year experiences, Jack stated, It was really the first time on my own. I don't love too far away, but I didn't want to go home. I was on my own so I could make all my own choices. Like what I ate, I had a meal plan, but I could eat whenever. I remember going to Walmart a lot.

Similarly, Amy stated, "I really enjoyed myself that first year, maybe a little too much, looking back on it." Liam stated, “...the freedom was an adjustment. I always had good time management, but college classes are different than high school classes. In college you do not see your teacher every day, like high school." When asked how it felt to fail a class, Matthew stated,

It was really weird, I have never struggled before, but got into a funk. And kind of sent me into a depression for a little bit, had a couple of days where I did not get out of bed. I remember feeling very stressed. 
Other students also expressed feeling stressed trying to balance their personal lives and their education. Charlie stated, "I had responsibilities at home and stuff I needed to do for school. It was hard to find the time for both. And many times, I would put off my schoolwork and be at home."

Students also discussed feeling sad due to being away from family and friends. Ava stated, "I remember being very home sick. I was very sad when my parents dropped me off." Similarly, Jennifer explained, "I am an only child and the first in my family to go to college. I was surprised how isolated I felt being here and my family back home. Being away from my family was a bid adjustment.”

When describing the challenges of their first semester at $\mathrm{ABC}$, a few students specifically stated they felt depressed. Silas stated, In the past I have suffered from depression. My junior year of high school, my family moved from Florida and this was a big change for me. I had to receive counseling at my high school to really get over it. I felt pretty good coming to $\mathrm{ABC}$, but I guess all the changes were too much. It was about halfway through my first semester, I remember getting really depressed again. I kind of shut down. When asked what she remembers most about her first semester, Amy stated, Depression. I could tell I was sad for some reason. If I was in my room, I would be laying down. So, I would purposefully try to stay out of my room, and stay out till 4 in the morning, so I would not be in my room. I did not have the energy to do anything, and I didn't feel like doing anything. 
When asked his initial thoughts on coursework during his first semester, Axel stated, “...it kind of sent me into a depression for a little bit. My first two semesters were not great in a mental capacity."

\section{Utilization of Student Resources}

A common theme from the participants when discussing their experiences revolved around the utilization, or lack of utilizing, student resources on campus. This is broad theme that can be applied to several areas at ABC. Specific areas include academic advising, freshman orientation, course tutoring services, and student/faculty relationship. The utilization of these resources appeared to correlate with the student's academic performance. Many students admitted to not taking advantage of, or not knowing about, the resources available to them during their academic struggles through their first semester. Again, with half of the participants being first generation students, this may have contributed to the lack of utilization. Ben stated, "Even though I knew I was doing bad in my classes, I did not know what to do about it." When asked about what contributed to her underperformance in her first semester, Heather stated,

I was not sure what resources I was able to utilize here, and I think that was because I never asked about it or asked anyone. I did not know who to ask. It was not the lack of resources, but the lack of knowledge of resources.

When asked to think about their first semester on campus, and the challenges they faced, many students did not know how to ask for help or who to ask. The students advised they did not know how to approach their faculty and ask for help. Grace stated,

I was not used to having to interact with my professors. I never had to study. I never got a good schedule of how assignments should be done. I felt hopeless and 
not used to it. I had not been integrated to this kind of system ever before.

Working with college teachers was different, just operated completely different.

Zack stated,

I know the professor offered office hours, but I never went. I never felt

comfortable. The history class had several students, so it was easy to blend in and not ask any questions, and not get called on to answer questions.

Taylor stated, "At the time, I was embarrassed to ask questions. I thought I could figure it out myself by reading the book." Similarly, Mia stated, "I was doing bad in the class, so I didn't see any point in asking for help." And Bill stated, "I had given up. I didn't think there was anything that could be done."

As a result of the interviews, it was clear most of the participants did ask or seek help from the other academic resources and offices at ABC. Even when the students knew they were failing classes they did not reach out to the tutoring center, their academic advisor, residence hall staff, or use peer support. When asked directly, most of the participants denied participating study groups or studying with peers in their classes or attending supplemental instruction sessions. Grace replied, "No, I never went to the tutoring center. I was not sure how it worked at that time."

Another underutilized resource were the academic advisors assigned to each student. Each student is assigned an academic advisor based upon their declared major. However, most of the participants could not recall meeting their advisor during freshman orientation or during any events related to the Week of Welcome or the first-year experience activities. And most of the participants did not meet with their assigned academic advisor during their first semester. 
When asked when he knew he was in academic trouble during his first semester, Aaron stated,

Probably around Thanksgiving... I got an email from my advisor. It may have been from one of the teachers, but the email said I needed to schedule a meeting with my advisor. I never did. At that point, I felt like it was too late.

Similarly, when asked what she remembers regarding her academic struggled during her first semester, Heather replied,

I remember just not know what to do. I did not know how to reach out to anybody, I did not know how to utilize my resources, because I never had to do something like that before. I think I only say my academic advisor once all semester. I remember feeling hopeless and skipping my finals.

When comparing their current academic success with their past academic challenges, many participants attributed the improvement to utilizing their academic resources and connecting with $\mathrm{ABC}$ staff and faculty. Jennifer stated, I am in constant communication with my faculty members and my advisor. And the OAS [Office of Accessibility Services] office; using them for testing. If I have a bad day for mental health, I can ask for a day off. All my faculty members, they have been a big help. I could talk praise about them all day.

Similarly, Liam said,

I know how to utilize my resources now. She [academic advisor] is happy to help out and is a really huge support system for me. I am super close with all my professors now. They are here to help you. I stopped being so anxious. I got over it. They will help you out the best they can. 
Likewise, Marcus stated, "I now see my advisor at least once per semester. And visit the counseling center if I need to." When asked what advice you would give yourself as a freshman, Ben stated, 'Utilize the teacher's office hours. And don't be afraid to ask for help from the teachers. They are there to help you. It is part of their job. And use your resources." Sam shared very similar advice, stating, "Talk to your advisor, talk to your professor. Their job is to help you and to teach you."

\section{Recommendations}

Based upon the results and findings from the research, recommendations were developed. In the context of academic advising, the recommendations revolve around the importance of a student's first semester class schedule and the implementation of a freshman academic probation plan. The ultimate goal of these recommendations is to improve the experiences for first-time, full-time freshman who are admitted with the assumption of being successful but may face academic adversity during their first year.

It is recommended to incorporate information and input from the student regarding their first semester class schedule. In addition to the academic program requirements that are considered when developing the class schedule, the student's personal preferences should also be considered. Knowing the student's preference regarding class scheduling (time of day, days of week, etc.) is key. Other personal factors or student activities may impact a student's schedule as well. Furthermore, communication between the student and the academic advisor is key. Once the schedule is set, feedback from the student should be gathered. Discussing the specific classes and 
schedule of classes with the student may result in changes to the schedule that ultimately benefit the student.

First semester freshman who end up on probation should be considered high risk and have a set academic recovery plan that includes major exploration and emphasis on class attendance. If a first-time, full-time freshman is on academic probation after their first semester, a plan to academic recovery, including specific interventions and discussions should be initiated. This plan should be initiated by the assigned academic advisor, however, include other staff and faculty as needed. Ideally a coordinated plan of action, or a plan of care, would happen between the student, the academic advising center, other academic support units, and the course faculty. Some students may also be comfortable talking to other students in the form of peer mentors or student coaches, which may aid in the discussion of the importance factors of student success.

A discussion with the student regarding "fit" or selection of academic major should occur before the start of the second semester. Students should be advised to consider other majors, asked to complete self-assessments regarding career options and personality, and/or enrollment in a course that explores other majors and career. The importance of class attendance should be emphasized to the student. The student should agree to and commit to regularly attending class. And agree to periodic checks of class attendance. Regular meetings with the academic advisor could also be required.

The academic probation plan should also consider a student's mental health and wellbeing. A specific discussion between the academic advisor and the student should address how poor mental health can impact success in college. The importance of selfcare and stress management should be emphasized. This may be an uncomfortable 
conversation; however, the student should be encouraged to seek mental health support if needed. Completion of mental health workshops provided by the campus counseling center could be required. Or the completion of a self-assessment questionnaire regarding a student's emotional wellbeing could be assigned, allowing the student to complete it privately and only share the results if they desired.

\section{Limitations and Assumptions}

Due to the limited scope and qualitative nature of this study, there are limitations. The study was limited to a purposeful and specific sample of ABC students, in a given time period; therefore, the results may not be transferable or generalizable. However, the information gathered can be used in part to improve student success at $A B C$ and provide some contribution to the field of study. The study also relied on data reported by the students, which requires accurate recollection and memory.

In addition, assumptions were made regarding the research participants used for this study. The study assumed all students who agreed to serve as participants have all experienced the same or similar phenomenon during their time at ABC. Specific parameters regarding a student's admission indicators and academic status were used to select participants to control for this assumption. However, the participants' experiences prior to their time at $\mathrm{ABC}$ are uncontrollable and can influence this study. Similarly, the study assumed all participants understood the questions they were asked and were honest during the interview process, providing truthful responses. Confidentiality was preserved to support students providing candid and honest answers. 


\section{Summary}

All students were happy to be at ABC. However, poor "fit" within their freshman major contributed to the students being placed on academic probation after their first semester. Almost $80 \%$ of the students changed their major at least once after first semester. A "proper fitting” academic program resulted in improved class attendance and student success (furthermore for some students, finding a better social support network of peers) which contributed to the students returning to good academic standing and being on track to graduation.

Poor mental health and wellbeing contributed to the students being placed on academic probation after their first semester. Students described increased stress and anxiety adjusting to college life, feeling overwhelmed, and suffering from depression. The students reported the improvement in their mental health was the most significant change since their first semester and was a significant contribution to the students returning to good academic standing and being on track to graduation.

Students admitted to not taking advantage of, or not knowing about, the resources available to them during their academic struggles through their first semester. Now, the students credit their academic recovery and return to good standing on communication/relationships with their faculty and academic advisors. The students developed a level of comfort and are now aware of the resources available to them as they are close to graduation.

Students showed persistence and resiliency and did not quit like some many of their peers when they were faced with academic adversity. The students now rely on goal setting and motivation to get them through graduation day. 


\section{SECTION SIX}

SCHOLARLY PRACTITIONER REFLECTION 
In this section, I will take the opportunity to reflect upon myself and the dissertation process. Specifically, I will attempt to reflect upon the impact and influence the dissertation process has had on me as a leader and scholar. Reflecting upon my journey through the Doctor of Education (EdD) program and completing the dissertation process, I first think about how fortunate I am to be able to participate in the program. I am truly grateful for my spot in the program as this opportunity has been life changing.

Starting the dissertation process, I did not have any specific expectations. I did not have any preconceived notions. I was not sure what to think. At the start of the EdD program, I said to myself, 'I will worry about the dissertation after I finish coursework.' Thankfully parts of the coursework forced me to consider and plan for the dissertation process.

Step one was to select a dissertation topic. For some of my fellow students in the EdD program selecting the topic was a challenge as they were unable to find a topic of interest. In my case, the challenge was not a lack of topics or areas of interest, it was too many topics that interested me. Soon after starting the EdD program, I started making a list of possible dissertation topics. This list grew as I progressed through the program. Furthermore, my research interests are wide and varied. One piece of advice I received before selecting a topic was, 'find a topic you are passionate about and a topic that keeps you interested'. As I am finishing the dissertation process, I can attest that is the truth. The dissertation process is long- longer for some than others. I am happy and satisfied with the topic I selected. It has kept my interest from start to end.

The use of the dissertation-in-practice in the EdD program is intentional. The EdD program is designed for students like me who are practicing professionals and leaders in 
the field of education. The program teaches individuals to be reflective practitioners (hence the many reflection writing assignment like this one) and provides them the skills to solve complex problems of practice that exist in the field of education. The dissertation-in-practice is an appropriate capstone to the EdD program. The dissertation process supports identifying a problem of practice that is specific to the practitioner setting. The significance my dissertation contributes to my practice as an educational leader and contributes to overall scholarship in the field of education.

\section{Influence on Practice as Educational Leader}

As part of the dissertation process, the examination and review of scholarly work had a significant influence on my leadership development. The dissertation process included scholarly work form multiple scholars and experts. These texts impacted me personally and impacted my professional practice. The EdD program and the dissertation process has given me the knowledge and tools to become a leader. Furthermore, I strive use what I have learned, to put knowledge into practice and to be an ethical leader. As I continue in my career, I hope to further develop my leadership skills and use my knowledge learned from the program. I can use the research process to inform policy decisions and make decisions based upon data. Using a systematic process, versus a singular line of thinking, will support my decision-making abilities. It is important that my professional decisions are informed and guided by valid research. The data must support my leadership judgements and influence in my line of work.

Another area of influence on my practice as an education leader was the review and analysis of the practitioner setting section of the dissertation process. I have a feeling this will not be the last time I will need to complete an organization analysis. Hopefully, 
in the future, as a leader of an organization, whether big or small, I can complete a thorough analysis of the organization. Completing an organizational analysis as part of my dissertation has given me valuable experience. Similarly, completing a leadership analysis as part of my dissertation has also provided me with valuable experience and given me the opportunity to reflect upon my leadership.

The dissertation process is supported by ethical considerations and research integrity. As an educational leader it is my responsibility to conduct myself ethically and act for the greater good. An ethical leader attempts to balance the diverse needs of stakeholders, is consistent with espoused values, and fully discloses all information and consequences of decisions (Mihelic, Lipicnik, \& Tekavcic, 2010). It is important to consider equality, equity, fairness, and justice. In the setting of educational research, I must respect the rights, dignity and worth of all people. I will consider and be sensitive to individual, cultural and role differences among people. I will strive to maintain high levels of competence in my work, be honest, and take responsibility for my actions.

\section{Influence on Scholarship}

Lifelong learning can be tied to academic inquiry in education. Lifelong learning is important to face the challenges and changes in our social, economic, and political systems (Gill, 2010). Although I may not have been able to articulate this sentiment a few years ago, one of the reasons I applied for the EdD program was due to my interest in lifelong learning. One of my favorite lines from Merriam and Bierema (2014), "Being an educator is an honor and responsibility, and striving to continually improve as educators is a lifelong learning endeavor" (p. 251). 
The knowledge and experience I have gained through the dissertation process will support my future as a scholar. As cited and quoted by many, the phrase, "standing on the shoulders of giants" seems fitting as this process nears the end. Through this process I have gained knowledge and intellect from the scholars before me.

It is important for me to complete scholarly work, both professionally and personally. Although my dissertation is qualitative in nature, I plan to also complete quantitative research. Once I finish the dissertation process, I am super excited to revisit that list of possible dissertation topics on my phone. Rather than writing a dissertation, I will use these topics as future research projects and expand my scholarship. I hope to present my future research at professional conferences and submit my research for publication in scholarly journals. The concepts of equality and social justice will guide my professional research.

Another area of influence on me as a scholar was the process of finding the gap in the literature and finding the problem of practice. The dissertation is focused on a problem of practice and the study should contribute to scholarship and practice. My future scholarship will advance my work in education and develop new information with the potential to guide educational practice.

Overall, the dissertation process has made me a more confident person. A more confident practitioner. A more confident scholar. More confident as a lifelong learner. More confident in my ability to identify a problem of practice. More confident in developing appropriate research questions and research methodologies to address the problem. More confident to lead an organization. More confident in my ability to review 
and analysis extant literature. And more confident in my ability to contribute to my practice as an educational leader and as a scholar.

I am very grateful for the opportunity to complete the EdD program and the dissertation process. It has been a wonderful, yet challenging, scholarly experience. The impact this process has made on me will be lasting. As I close this chapter of my life (and this chapter of the dissertation) I move forward well prepared and equipped as an educational leader and scholar. 


\section{References}

American College Testing. (2016). The condition of college \& career readiness report. Retrieved from http://www.act.org/content/dam/act/unsecured/documents/CCCR_National_2016. pdf

Balduf, M. (2009). Underachievement among college students. Journal of Advanced Academics, 20(2), 274-294. doi: 10.1177/1932202X0902000204

Bardach, E. \& Patashnik, E. M. (2016). Practical guide for policy analysis: The eightfold path to more effective problem solving (5th ed.). Thousand Oaks, CA: CQ Press.

Bashant, J. (2014). Developing grit in our students: Why grit is such a desirable trait, and practical strategies for teachers and schools. Journal for Leadership and Instruction, 13(2), 14-17.

Bass, L. H., \& Ballard, A. S. (2012). Student engagement and course registration methods as possible predictors of freshman retention. Research in Higher Education Journal, 18(2012), 1-13. Retrieved from http://0search.proquest.com.innopac.up.ac.za/docview/1288616012/291C282343B5459B $\mathrm{PQ} / 2$ ?accountid=14717

Bean, J. P. (2005). Nine themes of college student retention. In A. Seidman (Ed.), College student retention: Formula for student success (pp. 215-243). Westport, CT: American Council on Education and Praeger Publishers.

Bell, J. H., \& Short, S. (2003). Buckling down: Achieving and underachieving in the first year of university. Journal of College Reading and Learning, 34(1). 
Berger, J. B., \& Lyon, S. C. (2005). Past to present: A historical look at retention. In A. Seidman (Ed.), College student retention: Formula for student success (pp. 1-29). Westport, CT: American Council on Education and Praeger Publishers.

Bolman, L. G., \& Deal, T. E. (2013). Reframing organizations: Artistry, choice, \& leadership (5th ed.). San Francisco, CA: Jossey-Bass.

Brawner, C. E., Frillman, S., \& Ohland, M. W. (2010). A comparison of nine universities' academic policies from 1988 to 2005. Retrieved from http://files.eric.ed.gov/fulltext/ED508293.pdf

Braxton, J. M. (Ed.). (2000). Reworking the student departure puzzle. Nashville, TN: Vanderbilt University Press.

Braxton, J. M., Brier, E. M., \& Steele, S. L. (2007). Shaping retention from research to practice. Journal of College Student Retention, 9(3), 377-399.

Braxton, J. M., \& Mundy, M. E. (2001). Powerful institutional levers to reduce college student departure. Journal of College Student Retention, 3(1), 91-118.

Braxton, J. M., Sullivan, A. S., \& Johnson, R. M. (1997). Appraising Tinto's theory of college student departure. In J. C. Smart (Ed.), Higher education: A handbook of theory and research, 12,107-164. New York: Agathon Press.

Brophy, J. (1998). Motivating students to learn. New York, NY: McGraw-Hill.

Chickering, A. W., \& Reisser, L. (1993). Education and identity (2nd ed.). San Francisco, CA: Jossey-Bass.

Choy, S. P. (2002). Access \& persistence: Findings from 10 years of longitudinal research on students. Washington, DC: American Council on Education. 
Cicchetti, D., \& Garmezy, N. (1993). Prospects and promises in the study of resilience. Development and Psychopathology, 5(4), 497-502.

Crede, M., Tynan, M. C., \& Harms, P. D. (2017). Much ado about grit: A meta-analytic synthesis of the grit literature. Journal of Personality and Social Psychology, 113(3), 492-511. https://doi.org/10.1037/pspp0000102

Creswell, J. W. (2014). Research design: Quantitative, qualitative, and mixed methods approaches. (4th ed.). Thousand Oaks, CA: Sage.

Dawson, M., \& Pooley, J. A. (2013). Resilience: The role of optimism, perceived parental autonomy support and perceived social support in first year university students. Journal of Education and Training Studies, 1(2), 38-49. https://doi.org/10.11114/jets.v1i2.137

Dirkx, J. (2006). Studying the complicated matter of what works: Evidence-based research and the problem of practice. Adult Education Quarterly, 56, 273-290. doi: $10.1177 / 0741713606289358$

Duckworth, A. (2006). Intelligence is not enough: Non -IQ predictors of achievement. Dissertations available from ProQuest. Paper AAI3211063. http://repository.upenn.edu/dissertations/AAI3211063

Duckworth, A. L., \& Seligman, M. E. P. (2005). Self-discipline outdoes IQ in predicting academic performance of adolescents. Journal of Educational Psychology, 16(12), 939-944.

Duckworth, A., Peterson, C., Matthews, M., \& Kelly, D. (2007). Grit: Perseverance and passion for long-term goals. Journal of Personality and Social Psychology, 92(6), 1087-1101. http://dx.doi.org/10.1037/0022-3514.92.6.1087 
Duckworth, A., \& Quinn, P. (2009). Development and validation of the short grit scale (Grit-S). Journal of Personality Assessment, 91(2), 166-174.

http://dx.doi.org/10.1080/00223890802634290

Ewell, P., \& Wellman, J. (2007, May). Enhancing student success in education: Summary report of the NPEC initiative and national symposium on postsecondary student success. In The National Postsecondary Education Cooperative Symposium on Student Success conducted by the U.S. Department of Education in Washington, DC: November 1-3, 2006. Retrieved from http://nces.ed.gov/npec/pdf/Ewell_Report.pdf

Friedman, B. A., \& Mandel, R. G. (2009). The prediction of college student academic performance and retention: Application of expectancy and goal setting theories. Journal of College Student Retention, 11(2), 227-246. doi: 10.2190/CS.11.2.d

Galvan, J. L. (2014). Writing literature reviews: A guide for students of the social and behavioral sciences ( $6^{\text {th }}$ Ed). Glendale, CA: Pyrczak Publishing.

Garmezy, N. (1991). Resilience in children's adaptation to negative life events and stressed environments. Pediatric Annals, 20(9), 459-460, 463-466. Retrieved from https://login.cyrano.ucmo.edu/login?url=https://www-proquestcom.cyrano.ucmo.edu/docview/1023314829?accountid $=6143$

Garza, K. K., Bain, S. F., \& Kupczynski, L. (2014). Resiliency, self-efficacy, and persistence of college seniors in higher education. Research in Higher Education Journal, 26(26), 1-19.

Getzlaf, S., B., Sedlacek, G., M., Kearney, K. A., \& Blackwell, J. M. (1984). Two types of voluntary undergraduate attrition. Research in Higher Education, 20, 257-268. 
González-Torres, M. C., \& Garde, R. A. (2014). Resilience and coping strategy profiles at university: Contextual and demographic variables. Electronic Journal of Research in Educational Psychology, 12(3), 621-648.

https://doi.org/10.14204/ejrep.34.14032

Glossary of Education Reform (2013). Grade point average. Retrieved from https://www.edglossary.org/grade-point-average/ on 7/20/2019.

González-Torres, M. C., \& Garde, R. A. (2014). Resilience and coping strategy profiles at university: Contextual and demographic variables. Electronic Journal of Research in Educational Psychology, 12(3), 621-648. https://doi.org/10.14204/ejrep.34.14032

Gottfredson, L. S. (1997). Why grit matters: The complexity of everyday life. Intelligence, 24, 79-132.

Hillman, N. W., Tandberg, D. A., \& Fryar, A. H. (2015). Evaluating the impacts of "new" performance funding in higher education. Educational Evaluation and Policy Analysis, 37(4), 501-519. doi:10.3102/0162373714560224

Hochanadel, A. (2015). Fixed and growth mindset in education and how grit helps students persist in the face of adversity. Journal of International Education Research - First Quarter, 11(1), 47-50.

Hogan, M., \& Wong, K. (2013). Grit and mindset: Do you have the grit to go the distance? Women Lawyers Journal, 98(3).

Huang, Y., \& Lin, S. (2013). Development of the inventory of college students' resilience and evaluating the measurement invariance. British Journal of Guidance \& Counselling, 41(5), 471-486. http://dx.doi.org/10.1080/03069885.2012.749973 
Jansson, N. (2013). Organizational change as practice: A critical analysis. Journal of Organizational Change Management, 26(6), 1003-1019. doi: 10.1108/JOCM-09-2012-0152

Keup, J. R., \& Young, D. G. (2018). Investigating the first-year seminar as a high-impact practice. In R. Feldman (Eds), The first year of college: Research, theory, and practice on improving the student experience and increasing retention (pp. 93245). New York, NY: Cambridge University Press. doi: $10.1017 / 9781316811764$

Krueger, R. A., \& Casey, M. A. (2015). Focus groups: A practical guide for applied research. $\left(5^{\text {th }}\right.$ ed.). Thousand Oaks, CA: Sage.

Kuckartz, U. (2014). Qualitative text analysis: A guide to methods, practice \& using software. Los Angeles, CA: Sage.

Levi, D. (2014). Group dynamics for teams (4th ed.). Los Angeles, CA: Sage.

Locke, L. F., Waneen, W., Spirduso, W., \& Silverman, S. J. (2000). Proposals that work: A guide for planning dissertations and grant proposals ( $4^{\text {th }}$ ed.). Beverly Hills, CA: Sage.

Manning, K. (2013). Organizational theory in higher education. New York, NY: Routledge.

Merriam, S. B. (2009). Qualitative research: A guide to design and implementation. San Francisco, CA: Jossey-Bass.

Merriam, A. B., \& Tisdell, E. J. (2016). Qualitative research: A guide to design and implementation. (4th ed.). San Francisco, CA: Jossey-Bass. 
Merriam, S. B., \& Bierema, L. L. (2014). Adult learning: Linking theory and practice. San Francisco, CA: Jossey-Bass.

Mihelic, K. K., Lipicnik, B., \& Tekavcic, M. (2010). Ethical leadership. International Journal of Management \& Information Systems, 14(5), 31-41.

Mintzberg, H. (2005). The five basic parts of the organization. In Y. S. Jang, J. S. Ott, \& J. M. Shafritz, Classics of organizational theory (pp. 219-230). Belmont, CA: Wadsworth. (Reprinted from The structure of organizations: A synthesis of research, pp. 18-34, by H. Mintzberg, 1979, Upper Saddle, NJ: Prentice Hall).

Morales, E. E. (2014). Learning from success: How original research on academic resilience informs what college faculty can do to increase the retention of low socioeconomic status students. International Journal of Higher Education, 3(3), 92-102. https://doi.org/10.5430/ijhe.v3n3p92

NACADA [website]. (2020). Retrieved January 11, 2020, from https://nacada.ksu.edu/ National Student Clearinghouse Research Center. (2019). Snapshot report: First-year persistence and retention for fall 2017 cohort. Retrieved from https://nscresearchcenter.org/snapshotreport35-first-year-persistence-andretention/

National Student Clearinghouse Research Center. (2017a). Snapshot report: First-year persistence and retention. Retrieved from https://nscresearchcenter.org/snapshotreport28-first-year-persistence-andretention/ 
National Student Clearinghouse Research Center. (2017b). Snapshot report: Yearly success and progress rates. Retrieved from https://nscresearchcenter.org/snapshotreport-yearlysuccessandprogressrates25/

Nellis, L. M. (2011). Maximizing the effectiveness of building teams in response to intervention implementation. Psychology in the Schools, 49(3), 245-256.

Newcomer, K. E., Hatry, H. P., \& Wholey, J. S. (2015). Handbook of practical program evaluation. (4th ed.). Hoboken, NJ: Jossey-Bass.

Nichols, T. J., \& Chang, K. L. (2013). Factors influencing honors college recruitment, persistence, and satisfaction at an upper-midwest land grant university. Journal of the National Collegiate Honors Council, 14(2), 105-127. Retrieved from http://www.eric.ed.gov/contentdelivery/servlet/ERICServlet?accno=EJ1081919

Pascarella, E. T. (1985). Students' affective development within the college environment. Journal of Higher Education, 56(6), 640-663.

Pascarella, E. T., \& Terenzini, P. T. (1980). Predicting freshman persistence and voluntary dropout decisions from a theoretical model. Journal of Higher Education, 51(1), 60- 75.

Pascarella, E. T., \& Terenzini, P. T. (1991). How college affects students. San Francisco, CA: Jossey-Bass.

Pascarella, E. T., \& Terenzini, P. T. (2005). How college affects students: Volume 2: A third decade of research. San Francisco, CA: Jossey-Bass.

Perkins-Gough, D. (2013). The significance of grit: A conversation with Angela Lee Duckworth. Educational Leadership, 71(1), 14-20. 
Preuss, M., \& Switalski, R. (2008, February). Academic probation intervention through academic assistance advising. Retrieved from http://www.eric.ed.gov/PDFS/ED502891.pdf

Radin, B. A. (2006). Challenging the performance movement: Accountability, complexity, and democratic values. Washington, DC: Georgetown University Press.

Schlossberg, N. K. (2011). The challenge of change: The transition model and its applications. Journal of Employment Counseling, 48, 159-162.

Scott, M., Bailey, T., \& Kienzl, G. (2006). Relative success? Determinants of college graduation rates in public and private colleges in the U.S. Research in Higher Education, 47(3), 249-279. doi:10.1007/s11162-005-9388-y

Seidman, I. (2013). Interviewing as qualitative research: A guide for researchers in education and the social sciences. (4th ed.). New York, NY: Teachers College Press.

Shin, J. C. (2010). Impacts of performance-based accountability on institutional performance in the U.S. Higher Education, 60(1), 47-68.

Siegel, M. J. (2003). Primer on assessment of the first college year. Brevard, NC: Policy Center on the First Year of College.

Spady, W. G. (1970). Dropouts from higher education: An interdisciplinary review and synthesis. Interchange, 1(1), 64-85.

Spady, W. G. (1971). Dropouts from higher education: Toward an empirical model. Interchange, 2(3), 38-62. 
Sriram, R., \& Vetter, D. (2012). Thriving in high-risk students. In L. A. Schreiner, M. C. Louis, \& D. D. Nelson (Eds.), Thriving in transitions: A research-based approach to college student success (pp. 87-110). Columbia, SC: University of South Carolina, National Resource Center for The First-Year Experience and Students in Transition.

Swail, W. S. (2003). Retaining minority students in higher education: A framework for success. ASHE-ERIC Higher Education Report, 30(2). San Francisco, CA: Wiley.

Swail, W. S. (2004). The art of student retention: A handbook for practitioners and administrators. Austin, TX: Educational Policy Institute.

The White House (2016). Higher Education. Retrieved on July 7, 2016 from: https://www.whitehouse.gov/issues/education/higher-education

Tinto, V. (1975). Dropout from higher education: A theoretical synthesis of recent research. Review of Educational Research, 45, 89-125.

Tinto, V. (1987). Leaving college: Rethinking the causes and cures of student attrition. Chicago, IL: University of Chicago Press.

Tinto, V. (1993). Leaving college: Rethinking the causes and cures of student attrition (2nd. ed.). Chicago, IL: The University of Chicago Press.

Tinto, V. (2007). Research and practice of student retention: What next? Journal of College Student Retention: Research, Theory \& Practice, 8(1), 1-19.

University of Central Missouri (2018). Fact Book. Retrieved from https://www.ucmo.edu/offices/university-analytics-and-institutionalresearch/factbook.pdf 
University of Central Missouri (2016). Fact Book. Retrieved from

https://www.ucmo.edu/ir/documents/factbook.pdf

University of Central Missouri (2019). Undergraduate catalog (2019 ed.). Retrieved from https://catalog.ucmo.edu/

University of Central Missouri Incoming Freshman Admission Requirements [website]. (2019). Retrieved June 5, 2019, from https://www.ucmo.edu/futurestudents/admissions/incoming-freshman/admission-requirements/index.php

U.S. Department of Education, National Center for Education Statistics. (2019). The Condition of Education 2017 (NCES 2019-144), Undergraduate Retention and Graduation Rates. Retrieved online from https://nces.ed.gov/programs/coe/indicator_ctr.asp

U.S. Department of Education, National Center for Education Statistics. (2017). The Condition of Education 2017 (NCES 2017-144), Undergraduate Retention and Graduation Rates. Retrieved online from https://nces.ed.gov/fastfacts/display.asp?id=40

Valentine, J. C., Hirschy, A. S., Bremer, C. D., Novillo, W., Castellano, M., \& Banister, A. (2011). Keeping at-risk students in school: A systematic review of college retention programs. Educational Evaluation and Policy Analysis, 33(2), 214-234.

Werner, E. E., \& Smith, R. S. (1992). Overcoming the odds: High risk children from birth to adulthood. Ithaca, NY: Cornell University Press.

Westrick, P. A., Le, H., Robbins, S. B., Radunzel, J. M. R., \& Schmidt, F. L. (2015). College performance and retention: A meta-analysis of the predictive validities of 
ACT scores, high school grades, and SES. Educational Assessment, 20, 23-45. https://doi.org/10.1080/10627197.2015.997614

Wolters, C., \& Hussain, M. (2015). Investigating grit and its relations with college students' self-regulated learning and academic achievement. Metacognition Learning, 10, 293-311. doi:10.1007/s11409-014-9128-9

Yin, R. K. (2014). Case study research: Design and methods (5th ed.). Los Angeles, CA: Sage.

York, T. T., Gibson, C., \& Rankin, S. (2015). Defining and measuring academic success. Practical Assessment, Research \& Evaluation, 20(5), 1-20. http://pareonline.net/getvn.asp?v=20\&n=5 


\section{Appendix A}

Participant Interview Questions and Format

\section{RQ1：What contributed to the students being placed on academic probation?}

1. Describe yourself in high school?

2. What type of student were you in high school? Did you take any honors, AP, dual credit type classes? How many times did you take the ACT?

3. What were you plans after high school? Did you always plan to attend college?

4. Leaving high school did you believe you were prepared to be successful in college?

5. What was the biggest misconception about college?

6. Why did you select UCM for college?

7. Did you attend freshman orientation during the summer before you started at UCM? If no, why not? If yes, what do you remember most about freshman orientation?

8. What do you remember most about your first semester at UCM?

9. Did you live on campus/residence hall? If so, which one? Describe your living arrangements during your first semester/year?

10. What were your initial thoughts about your classes during the first semester?

11. How many times did you meet with your academic advisor during the first semester?

12. How did it feel to fail a class?

13. How did it feel to underperform your first semester?

14. When did you realize you were in academic trouble?

15. At what point in the semester did you know it was bad? Who did you reach out to or contact when you were in trouble? What do you believe contributed the most to your poor performance? 
16. What help did you seek after your first semester? Who did you talk to?

RQ2: How did the students recover academically, return to good standing, and be on track to degree completion?

17. How often did you attend class during your first semester? Compare class attendance between then and now?

18. Did you repeat any classes your first year? Why or why not? If repeated, what was that experience like for you?

19. Did you ever consider leaving UCM? Why or why not?

20. Most students in this situation, leave UCM. Why did you stay?

21. What resources did you use during your first semester? Compared to now, what resources do you use? Do you know who your academic advisor is currently?

22. Did you change your major during your time at UCM? If yes, what majors? And why?

23. Describe your extracurricular activities or campus activities during your freshman year?

24. How do you primarily pay for college? Do you receive the Pell Grant?

25. Are you the first person in your family to attend college? If no, who else?

26. How did it feel to succeed?

27. What changed between your first and second semester? Academic? Personal Life? Focus?

28. What are you plans after graduation? What are you career aspirations?

RQ3: What concepts of Grit Theory (self-motivation, persistence, overcoming adversity) were demonstrated by the student participants of this study? 
29. How do you usually react when facing a challenge?

30. Describe how you overcome a setback in your life?

31. How did it feel to fail a class?

32. How did it feel to underperform your first semester?

33. What was or is the hardest aspect of going to college?

34. Describe your time management techniques?

35. How do you stay motivated to complete a college degree?

36. Do you set goals for yourself? If yes, would you share some? If no, why not?

37. How would close friends and family describe your personality?

38. What advice would you give yourself your freshman year? 


\section{Appendix B}

\section{Email to UCM Students Requesting Participation in Study}

Subject: Your participation is requested!

Hello STUDENT NAME, You have accomplished something very few other UCM students have done.

My name is Drew and I am doctoral candidate under the supervision of Dr. Sandy Hutchinson at the University of Central Missouri and University of Missouri. I am seeking participants for my study titled: A qualitative case study of student's experiences on the path to graduation at the University of Central Missouri. Through this case study, I am attempting to increase understanding about the experiences of students who have overcome academic adversity and are on track to graduation at UCM. This study involves research and I am inviting a unique set of current UCM students to participate.

Your experience at UCM meets the requirements to participate in this research.

Participants will be invited to contribute in individual interviews, lasting no more than 60 minutes, via phone or video conference. Confidentiality will be kept by removing any identifiable information from the data collection process and data analysis. There are no anticipated risks in participating in this study. The benefits of participating in this study are you may enjoy the opportunity to express your experiences and thoughts as a student at UCM to the benefit of other UCM students.

If you are interested in speaking about your experiences as a UCM student, I hope you will please consider participating in this study. Please reply to this email to participate and/or with any additional questions.

Thank you for your time and consideration. I look forward to hearing from you.

Drew Burkeybile 


\title{
Appendix C
}

\section{Consent with Waiver of Documentation for Participation in a Research Study}

\author{
NAme(s) Of Researcher(s): Drew Burkeybile \\ PROJECT IRB \#:
}

STUdy TitLE: High Risk Students on Track to Graduation: A Qualitative Case Study of Student Success

\section{INTRODUCTION}

You are being asked to participate in a research study. This research is being conducted to investigate the experiences of UCM students who successfully overcame academic adversity to complete a degree. This consent form tells you why we are doing the study, and what will happen if you join the study. Please take as much time as you need to read this consent form. When you are invited to participate in research, you have the right to be informed about the study procedures so that you can decide whether you want to consent to participation. This form may contain words that you do not know. Please ask the researcher to explain any words or information that you do not understand.

You have the right to know what you will be asked to do so that you can decide whether or not to be in the study. Your participation is voluntary. You do not have to be in the study if you do not want to. You may refuse to be in the study and nothing will happen. If you do not want to continue to be in the study, you may stop at any time without penalty or loss of benefits to which you are otherwise entitled.

\section{Why Is This Study Being Done?}

The purpose of this research is to investigate the experiences of UCM students who successfully recovered from academic probation during their first semester of enrollment and are on track to complete or have completed a degree from UCM.

\section{How Many People Will Be In This Study?}

Approximately 36 individuals will take part in this study.

\section{What Will Happen If I Take Part In This Study?}

If you agree, you will be interviewed by the researcher at a convenient day and time via phone or video conference. The interview will be digitally recorded.

\section{How Long Will I Be In The Study?}

This study will take 45 minutes to an hour for each individual interview that you take part. You can stop participating at any time without penalty.

\section{Can I Stop Being In The Study?}

Yes, you can stop being in the study at any time without giving a reason. Just tell the researcher right away if you wish to stop taking part. Also, the researcher may decide to take you off this study at any time, even if you want to stay in the study. The researcher will tell you the reason why you need to stop being in the study 


\section{Are There Any Benefits To Taking Part In This Study?}

Your participation might benefit future students and UCM by understanding your lived experiences as a student. Furthermore, the researcher and UCM will gain knowledge regarding student success. There may be no direct benefits to you from taking part in this study, however, you may enjoy sharing your experiences and contributing to research.

\section{Are There Any Risks From Being In This Study?}

There are no foreseeable risks from participating in this study. The risks to this study are similar to the risks of everyday life discussions. You may skip any question(s) you prefer not to answer.

\section{What Other Choices do I Have If I Don' T TAKe Part?}

You can stop participating at any time without penalty.

\section{Will Information About Me Be Kept Private?}

The interviews will take place in a private setting to maintain confidentiality. You will be assigned a pseudonym as an additional safeguard in your confidentiality. The information collected about you will be stored in the researcher's electronic/computer or paper files. Computer files are protected with a password and the computer is in a locked office that only the researcher can open. Paper files are kept in a locked drawer in a locked office that only the researcher can open.

The information we collect from you for this study will not be used or shared with other investigators for future research studies. This applies even if we remove all information that could identify you from your information.

You must provide permission to use the audio recordings taken during this research. The audio recordings will be destroyed after the project is completed. There will be no visual recordings or photographs.

Information produced by this study will be identified by a pseudonym only. Information contained in your records may not be given to anyone unaffiliated with the study in a form that could identify you without your written consent, except as required by law.

\section{Will I Be Paid For Taking Part In This Study?}

You will receive no payment for taking part in this study.

\section{What Are My Rights as a Study Participant?}

Taking part in this study is voluntary. If you do decide to take part, you have the right to change your mind and drop out of the study at any time. Whatever your decision, there will be no penalty to you in any way. You will also be told about any new information discovered during this study that might affect your health, welfare, or change your mind about taking part.

\section{Who Can I Call If I Have Questions, Concerns, Or Complaints?}


Please contact Sandy Hutchinson, Dissertation Chair, hutchinson@ucmo.edu if you have questions about the research. Additionally, you may ask any questions or voice concerns to the researcher.

You may contact the University of Missouri Institutional Review Board (IRB if you:

- Have any questions about your rights as a study participant;

- Want to report any problems or complaints; or

- Feel under any pressure to take part or stay in this study.

The IRB is a group of people who review research studies to make sure the rights of participants are protected. Their phone number is 573-882-3181.

If you want to talk privately about your rights or any issues related to your participation in this study, you can contact University of Missouri Research Participant Advocacy by calling 888-280-5002 (a free call), or emailing MUResearchRPA@missouri.edu.

It is recommended you keep a copy of this consent form. Please keep it where you can find it easily. It will help you to remember what we discussed today. 


\section{Appendix D}

Statement of the Problem Charts

\section{Fall 2014 - 266 Students FTFT Freshman on Probation}

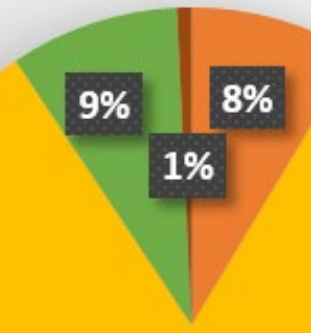

$$
\begin{aligned}
& \text { Graduated } \\
& \text { Left UCM, On Acad Probation } \\
& \text { Left UCM, Good Standing } \\
& \text { Still working }
\end{aligned}
$$

\section{$82 \%$}

\section{Fall 2015 - 230 Students FTFT Freshman on Probation}

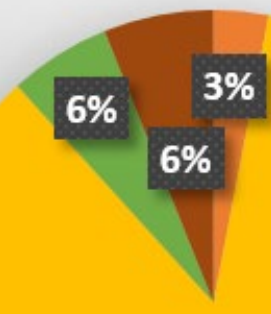

$85 \%$

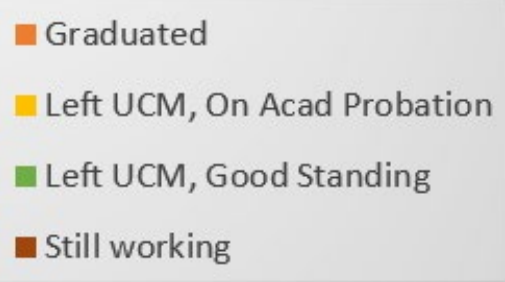




\section{Fall 2016 - 228 Students FTFT Freshman on Probation}

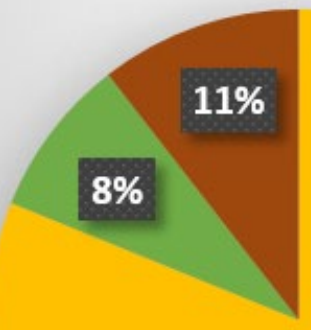

Graduated

Left UCM, On Acad Probation

- Left UCM, Good Standing

$\mathbf{8 1 \%}$

— Still working

\section{Fall 2017 - 230 Students} FTFT Freshman on Probation

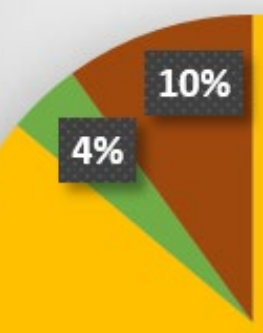

n Graduated

Left UCM, On Acad Probation

- Left UCM, Good Standing

$86 \%$

- Still working 


\section{Appendix E}

\section{Findings}

The purpose of this qualitative case study was to understand the shared experiences of UCM students who faced significant academic adversity during their first semester, resulting with them being placed on academic probation, even though the students met the regular admissions criteria and were admitted with the expectation of being successful. Despite this hardship, these students were able to recover academically, improving their GPA, are currently in good academic standing, and are on the path towards degree completion. The personality and motivation behind this academic recovery was also investigated. The following sections will present the research findings organized by themes identified in the data.

A total of 24 students consented to participate and were interviewed to collect data to answer the research questions. Analysis of documents was also completed to support this research. These documents included various ready-made and available student records, including the student's academic degree audit, transcript, and admissions record. Pseudonyms are used for all participants in this research project.

Participant Profiles

\begin{tabular}{|l|l|l|l|}
\hline Pseudonym & $\begin{array}{l}\text { First } \\
\text { Generation } \\
\text { Student }\end{array}$ & $\begin{array}{l}\text { Interview } \\
\text { Format }\end{array}$ & $\begin{array}{l}\text { First } \\
\text { Enrolled } \\
\text { Semester }\end{array}$ \\
\hline Grace & $\mathrm{X}$ & Phone & Fall 2017 \\
\hline Amy & $\mathrm{X}$ & Phone & Fall 2016 \\
\hline Ben & $\mathrm{X}$ & Phone & Fall 2015 \\
\hline Zack & $\mathrm{X}$ & Phone & Fall 2016 \\
\hline Evelyn & $\mathrm{X}$ & Phone & Fall 2016 \\
\hline Taylor & & Phone & Fall 2017 \\
\hline Chris & $\mathrm{X}$ & Phone & Fall 2017 \\
\hline Aaron & & Video Conf & Fall 2015 \\
\hline
\end{tabular}




\begin{tabular}{|l|l|l|l|} 
Bill & & Phone & Fall 2016 \\
\hline Matthew & & Phone & Fall 2016 \\
\hline Heather & $\mathrm{X}$ & Phone & Fall 2015 \\
\hline Marcus & $\mathrm{X}$ & Phone & Fall 2016 \\
\hline Sam & $\mathrm{X}$ & Phone & Fall 2014 \\
\hline Jennifer & & Video Conf & Fall 2016 \\
\hline Liam & & Phone & Fall 2016 \\
\hline Milo & & Phone & Fall 2017 \\
\hline Emma & & Phone & Fall 2017 \\
\hline Ava & X & Phone & Fall 2017 \\
\hline Mia & & Phone & Fall 2017 \\
\hline Silas & & Video Conf & Fall 2017 \\
\hline Jack & & Phone & Fall 2017 \\
\hline Sophia & X & Phone & Fall 2017 \\
\hline Charlie & X & phone & Fall 2015 \\
\hline Axel & & Video Conf & Fall 2016 \\
\hline
\end{tabular}

The participants included nine students who identified as male and 15 students who identified as female. The participants ranged in age from 20 to 24 years old. Ethnicity of the of the participants included 3 African America students, 2 Asian students, 2 Hispanic students, and 17 White/Caucasian students. At the time the research was being conducted the average UCM GPA for all student participants was 2.86. Almost $80 \%$ (19 out of the 24 participants) changed their academic major at least once after their first semester. Another interesting finding identified 12 of the 24 student participants, $50 \%$, were first generation students. These two findings were identified in the document analysis and confirmed during the interviews.

The participants were currently enrolled, either in their junior or senior year, based upon credit hour generation, with the intent to graduate within six years of their first semester of enrollment at UCM. Various academic majors were represented in the sample of students, including multiple academic programs from all four academic 
colleges at UCM. During the interviews each student answered questions and spoke about their experiences during their time at UCM as well as their experiences and thoughts while in high school.

Document analysis also revealed these students came to UCM from diverse and varying secondary education settings. The size of high school, based upon student population, varied. Similarly, the location of high school varied from small rural towns to large urban cities, including locations in Missouri and Kansas, from Kansas City to St. Louis, and from UCM's hometown of Warrensburg. Also, both public high schools and private high schools were represented. The participants average high school GPA was 3.05, with a range of 3.74 to 2.16. The participants average ACT score was 21.83, with a range of 30 to 16 .

Data collection via one-on-one interviews were concluded once saturation was reached. The data coding analysis was able to turn individual pieces of data into meaningful information. Several interesting findings resulted from the analysis of the data. The findings can be group into three broad themes: the importance of "fit" for the student, student mental health, and utilization of student resources.

\section{"Fit" is Important}

A common response from the participants when discussing their experiences revolved around the idea of "fit". Overall, the students were happy to be at UCM and were comfortable with being a student at UCM. When reflecting about her time at UCM, Sam exclaimed, "I love UCM, I am so glad is picked UCM. I am looking forward to finishing my degree from UCM.” Similarly, Zack stated, 
Overall, UCM has been great. I have made new friends, that will be lifelong friends, I have learned so much, I have grew as a person, and have really enjoyed my time on campus and the opportunities UCM has provided. I will miss UCM after I graduate.

Zack elaborated, “...my first year was definitely a challenge, and I wish I could have a do over, because the last few semesters have been great." When asked about his experiences at UCM, Silas stated

I went to a small high school in a pretty small town, there was not much going on. Now, I stay in Warrensburg every summer, I work in town, and would love to stay in Warrensburg after I graduate from UCM.

Regarding the extracurricular activities and student organizations at UCM, Taylor said, "I am really involved in my sorority, it was great way to meet new people and to learn about other organizations." Matthew also talked about his experiences outside the classroom,

Once I joined the rugby team, it was a much better time. I have been able to get involved in several other groups and do intramurals. All the additional activities and leadership opportunities have been great. The smaller size of UCM allows you to meet other people and be active in student groups.

Several students discussed how the faculty have positively impacted their experience at UCM. Ava stated, "They [faculty] have always been supportive and have given me opportunities to succeed. Besides my first semester, I have been very happy with my teachers and the classes." Emma also stated, "I am comfortable talking to my professors. Especially this year, as I am looking for a job, the professors have been very 
helpful and supportive." When asked about giving advice to a new UCM student, Grace stated,

I would recommend students to talk to their professors. You will have the same professors in several classes, so you can really get to know them. My professors are now my references when I apply for jobs. My program is small, small enough I have the same professors for multiple classes and for advising. These relationships have really helped enjoy my program.

Fit with academics and peers. Besides fitting in at the University, the students shared their experiences about fitting in with regards to academic major, residence hall roommate(s) and living arrangements, meeting new peers, and joining student organizations. Students fitting in their major and fitting in with close peers really made an impact on academic performance. Most students lived in university housing their first year at UCM. Almost $80 \%$ of the students interviewed changed their major at least once after their freshman year. Charlie stated "After I changed my major I did better in all my classes. I was much more interested in Music and enjoyed all my music classes.” Similarly, when asked why she changed her major, Grace advised, "I was not engaged by my teachers and could not relate to what I was learning.” Evelyn really elaborated on how changing her major impacted her experience at UCM. Evelyn stated Changing my major changed so many other things. The Theater teachers are just different, they teach different. And the learning is different. Changing majors also changed who was in my class and who I hung out with. The other theater students are really supportive and fun to meet. I really enjoy my classes.

Bill commented on his experience before changing his major, 
I did not get to fly my first semester, which is really important. I was learning stuff in class but not flying. Other students were able to fly, and this helped them learn. I was really struggling and could tell I was falling behind in my aviation classes.

Charlie stated, “Most people who come to college don't know what they want to do; I thought I did, but when I got here it was nothing like I had though.” When asked about changing his major, Liam stated, I changed my major twice. I did not really know what I wanted to do when I left high school. I wanted to own my own business in the future but was not sure which major would allow me to do that. After taking some classes, I learned what I liked and did not like. Now, I found something I loved to do.”

Aaron gave a similar response regarding an out of class experience that prompted her to change her to look at another major. Aaron explained, I did an internship related to construction management the summer before my junior year, in Orlando, Florida. My friend and I live together and thought it was be fun. We ended up working different shifts and worked a lot, long hours. It was hot, dirty, tiring work. One day on the job a safety inspector pulled up in a nice, clean truck, wearing nice, clean cloths and caught my attention. I spoke to him for a few minutes that day and talked to him later on. He was a very nice guy that answered all my questions. I got a better understanding of his work in safety and other careers in the safety field. As soon as I got back to campus that fall, I changed my major to occupational safety.

When asked about changing her major, Mia stated, 
Both my parents are doctors. That was kind of the expectation for me, as least that is what I assumed. I would go to college and probably be a doctor as well. I failed chem 1 my first semester, so took it again second semester, and about halfway through I knew I was not cut out to be a doctor. It was not right for me. I did really well in my first general psychology class, and that really interested me, so I changed my major before my second year.

When asked about how her parents reacted to changing her major, Mia commented, "I was nervous to tell but they were supportive. And it helps that I am passing all my classes now." Jack also talked about his experience with challenging academic coursework during his first semester,

I was always good at math and enjoyed it. I took all the advanced math classes in high school, so thought I could handle it in college. College was different. I struggled with the tests. I did alright on the homework, but the stuff did not really interest me, so I stopped going to class.

When asked about the coursework in his current major, Jack stated, "I am definitely more interested. It helps to see how your classes will connect to future careers." Taylor commented,

I was allowed to pick my own classes for the second semester, so I picked the best times and the best professors. Now I talk to other students and research which teachers to take before I sign up for my classes each semester. This has helped a lot.

Axel discussed how changing his major impacted his extracurricular activities. Axel stated, 
I love playing the saxophone and wanted to continue playing in college, so I joined the marching band and the jazz band. However, it did not take long for me to get burnt out. That first year was hard. I still wanted to play but it seemed like all I did was practice and go to class.

After talking to his parents, Axel changed his major but stayed in the marching band. Axel explained, I switched to music education, to be a music teacher. I now have other classes besides music. And I have made friends outside of my ensembles. I am involved in student organizations for music and education. This is a better fit and has allowed me to do more.

The participants also discussed how their relationships with peers impacted their academic success. Sam admitted, "My roommate and I did not get along. We never talked, and she just kept to herself.” Similarly, Evelyn stated, “... my roommate went home every weekend, so I was by myself a lot. I did not get to know her that much.” Also, Ben stated, "I would sleep on the couch of my friend's house most of the time my first semester or two. I spent very little time in my dorm room that semester. I was not comfortable living there."

When discussing how a new group of peers impacted his experience, Matthew stated, My close friends are also on the rugby team. After my freshman year I moved into an apartment with four other guys from the rugby team. That is who I live with now. We have more in common that I did with my first roommate. We got along okay but were not close friends.

When asked to reflect upon her freshman year living arrangements, Emma stated, 
I hated my roommate. After the first semester, I went down to the housing office and asked to have a room by myself. It is hard for me to live with someone else. Ever since then, I have lived by myself, it so much better for me.

Similarly, Chris stated,

Living in the residence hall was not, bad but when I moved into my apartment, I could focus more. I did not have a roommate, and my apartment felt more like home, which helped me focus. I am also not a person who can study at the library. That is not for me.

Zack's living arrangements his freshman year included living in the residence hall with a special interest house program (SHIP). Zack stated

I lived in a SHIP my first semester and my roommate was also an aviation major, so we had a couple classes together, that were aviation, but not all the same classes. We had different gen ed classes. He did not take public speaking. We would study together sometime for the aviation classes but not always. I also ended up dropping the ground school class.

Thinking back to her freshman year, Grace stated, "I was hanging out with the wrong people. They were not good for me. I was in a bad place and the people in my life did not help." When asked about her friends now, Grace stated, "I have a couple really close friends, that are like my best friends, and I can really rely on. We do a lot together and they support me"

\section{Students Mental Health and Well Being}

A common theme from the participants when discussing their experiences at UCM revolved around their mental health and wellbeing. A poor mental health or 
concerns about their mental health were large contributors to the student's overall academic performance. Many students expressed how their mental health during their first semester negatively impacted their academics, in various ways. The participants expressed concerns with their mental health that ranged from increased stress and challenges adjusting to college life, to negative personal feelings and severe depression. Zack recalled,

I felt overwhelmed for most of the semester that year. I remember just feeling a sense of dread and pressure and not knowing exactly what to do. I was on my own which was good in some ways and bad in other ways. I did not know what to do when my grades started going bad.

Similarly, when asked about failing her classes during her first semester, Evelyn stated, "It kind of snow balled on me and I did not know what to do." This "snowball" effect of pressure and stress seemed to be a similar experience for many students. When asked about her academic struggles her first semester, Heather stated, "It was too much for me and I got overwhelmed."

Adjustment to college life. Several participants discussed how college classes and college life in general was an adjustment. Half of the participants are first generation students which may have contributed to this challenging adjustment period. When asked to reflect upon his freshman year experiences, Jack stated,

It was really the first time on my own. I don't love too far away, but I didn't want to go home. I was on my own so I could make all my own choices. Like what I ate, I had a meal plan, but I could eat whenever. I remember going to Walmart a lot. 
Similarly, Amy stated, "I really enjoyed myself that first year, maybe a little too much, looking back on it.” Liam stated, “...the freedom was an adjustment. I always had good time management, but college classes are different than high school classes. In college you do not see your teacher every day, like high school." Liam went on to explain, In college the teachers are not going to constantly remind you about homework. If you don't get it done, they don't care... well the college teachers care... but they are not going to constantly remind you. If you do not complete an assignment, you lose the points in the class. The responsibility is on the student.

Mia also spoke about the freedom in college, she stated, "I would go to work rather than class. I don't think I understood how to be a college student or what it took to be a good student in college. The independence I had was a big responsibility."

When asked how it felt to fail a class, Matthew stated,

It was really weird, I have never struggled before, but got into a funk. And kind of sent me into a depression for a little bit, had a couple of days where I did not get out of bed. I remember feeling very stressed.

Other students also expressed feeling stressed trying to balance their personal lives and their education. Charlie stated, "I had responsibilities at home and stuff I needed to do for school. It was hard to find the time for both. And many times, I would put off my schoolwork and be at home." Ben recalled,

I remember putting things off, like assignments and papers. I would make time to hang out with friends or go hunting, and say to myself, I will do my homework later. But I would end up not doing it. I got into a bad habit of putting pretty much all other things before my schoolwork. 
Axel stated, "besides all the personal stuff going on in my life, I was just not used to college." Heather was involved one extracurricular activity that challenged her and contributed to her stress and academic struggles. Heather remembered,

I had practice every day. I would go to class all day and then straight to practice. I would not eat dinner until late in the evening and then by that time I was tired and would just go to bed. I didn't feel like I had time to homework. As the semester went on I just fell behind in all my classes.

Students also discussed feeling sad due to being away from family and friends. Ava stated, "I remember being very home sick. I was very sad when my parents dropped me off." Similarly, Jennifer explained, "I am an only child and the first in my family to go to college. I was surprised how isolated I felt being here and my family back home. Being away from my family was a bid adjustment." When asked about his experience at freshman orientation, Aaron stated, I remember that day being very busy. We had to get up early and drive to Warrensburg. And then the day was filled with things to do. We got moved around to different places and presentations on campus. There was a time to meet other students, but I remember none of the other students in my group was in my major. I did not take the time to get to know them because I did not think I would have any classes with these students.

Sophia, who was unable to attend freshman orientation, stated I am from Kansas and I was the only one from my high school to come to UCM, so I did not know anyone. When I moved in, I did not know my roommate. It took 
a while before I really met some people and developed friendships. Most of my freshman year, I would just stay in my room and not go anywhere.

Feelings of Depression. When describing the challenges of their first semester at

UCM, a few students specifically stated they felt depressed. Silas stated, In the past I have suffered from depression. My junior year of high school, my family moved from Florida and this was a big change for me. I had to receive counseling at my high school to really get over it. I felt pretty good coming to UCM but I guess all the changes were too much. It was about halfway through my first semester, I remember getting really depressed again. I kind of shut down.

When asked how he coped with or recovered from his feelings of depression, Silas stated, "I did talk to a counselor here in town [Warrensburg]. And that helped. Going home for Christmas break also helped." Later during our discussion, Silas talked about how changing his major also impacted his mental wellbeing. Silas stated, Part of my program is talking about your feelings, that is just what you do. During class we would be open and have open discussions. It helped me talk to my faculty and be more comfortable talking to them. We tend to talk about our feelings a lot and that really helped.

When asked what she remembers most about her first semester, Amy stated, Depression. I could tell I was sad for some reason. If I was in my room, I would be laying down. So, I would purposefully try to stay out of my room, and stay out till 4 in the morning, so I would not be in my room. I did not have the energy to do anything, and I didn't feel like doing anything. 
When asked his initial thoughts on coursework during his first semester, Axel stated, “...it kind of sent me into a depression for a little bit. My first two semesters were not great in a mental capacity.”

Students were also open about their use of the UCM Counseling Center. Amy, Ben, Chris, Sam, and Milo confirmed they did use the services of the UCM Counseling Center. When asked about why he went to the Counseling Center, Chris stated, ...after talking to my advisor about my grades, she walked with me to the office. I knew there was a counseling place on campus but did not know exactly where it was. I was really stressed out at the time and was worried I would get kicked out, so my advisor recommended I talk to a counselor.

Milo stated,

The Counseling Center helped me learn about taking care of yourself. Or taking care of myself during times of stress. We talked about time management and how to cope with stress. Little things like eating regularly and getting enough sleep. And trying to exercise, which is hard for me. Talking through some of my worries helped reduce my anxiety.

Taylor discussed how the adjustment to college and being in a new routine resulted in her stopping her medication for depression. Taylor admitted, "I stopped taking my medication and that was a big problem. My mental health went down pretty quick after that." When asked what changed since then, Taylor stated,

I did go to the counseling center on campus and was able to get back on my medication. I went to see my doctor back home as well. Now, I am feeling much better and I am in a better place. And, oh ya, I am also now registered with the 
Office of Accessibility. I now use the services that are available to me, like more time on assignments and tests, and taking my test in their office.

Those students who experienced depression and poor mental health during their first semester at UCM admitted to this being a primary reason in their poor academic performance. Those students were also quick to point out when their mental health improved, so did their academic performance and lives in general. Ben stated, I now know the signs of being over stressed or stressed out. And can tell when an anxiety levels are going up. This does not happen very often but being able to recognize it and deal with my anxiety helps a lot.

Similarly, Chris stated, "I remember just staying in my room all the time and not really doing anything. A lot has changed. I feel better now, and I am looking forward to my classes next semester." When asked what advice you would give yourself as a freshman, Amy stated,

Get the emotional support that you need while you are there. Go see a therapist early on and see a counselor to help guide you. Know your options, to change classes and if needed, changed your classes. Depression is normal, know what it is and try to fix it.

\section{Utilization of Student Resources}

A common theme from the participants when discussing their experiences revolved around the utilization, or lack of utilizing, student resources on campus. This is broad theme that can be applied to several areas at UCM. Specific areas include academic advising, freshman orientation, course tutoring services, and student/faculty relationship. The utilization of these resources appeared to correlate with the student's academic 
performance. Many students admitted to not taking advantage of, or not knowing about, the resources available to them during their academic struggles through their first semester. Again, with half of the participants being first generation students, this may have contributed to the lack of utilization. Ben stated, "Even though I knew I was doing bad in my classes, I did not know what to do about it." When asked about what contributed to her underperformance in her first semester, Heather stated, I was not sure what resources I was able to utilize here, and I think that was because I never asked about it or asked anyone. I did not know who to ask. It was not the lack of resources, but the lack of knowledge of resources.

Orientation activities. Many of the students reported little recollection of freshman orientation (albeit orientation was three or more years ago for the participants). Many of the participants were unable to recall if they attended freshman orientation or not, let alone being able to cite specific information learned or benefits received from attending. When asked what he remembered most about freshman orientation, Bill stated, I remember being brought to a lot of different places on campus, walking around on campus. But it was places that did not interest me like the swimming pool. I was more interested in finding my classrooms. And I remember being in the Union listening to presentations all day.

When asked if he could remember any specific presentations from the day, Bill stated, "No, not really. There was one about my classes and one about textbooks." Similarly, Jennifer stated, "I do remember meeting a lot of people and being in a big group in the Union." Sophia and Jack both commented on the weather, and how hot of a day it was, but could not recall any specifics from the actual orientation. When asked about his 
experience at freshman orientation, Chris stated, "I went with my parents and they did everything." Along those lines, both Charlie and Axel commented that their mom signed them up for orientation. Marcus stated, "It was my first time on campus, so I was excited to get a tour. That was helpful." When questioned for other specifics from his attendance, Marcus could not recall any.

Considering the planning and effort that goes into freshman orientation, by many UCM offices/department, faculty, and staff, it is surprising to hear this response from the participants. Furthermore, many of the participants confused the single day freshman orientation with the multiday Week of Welcome. However, many participants were still unable to recall specific information learned or benefits received from the Week of Welcome activities. When asked what she remembered from the Week of Welcome activities, Ava stated, "I remember all the ice breakers, just lots of groups of people doing ice breakers." When discussing her thoughts during the Week of Welcome days, Heather stated,

It was not for me. I stayed in my room for most of the time. I remember there were a few of us that pretended to be sick, so we did not have to go. I was just not in the mood and was not up for all the activities.

Student/faculty relationship. When asked to think about their first semester on campus, and the challenges they faced, many students did not know how to ask for help or who to ask. The students advised they did not know how to approach their faculty and ask for help. Grace stated,

I was not used to having to interact with my professors. I never had to study. I never got a good schedule of how assignments should be done. I felt hopeless and 
not used to it. I had not been integrated to this kind of system ever before.

Working with college teachers was different, just operated completely different.

Zack stated,

I know the professor offered office hours, but I never went. I never felt

comfortable. The history class had several students, so it was easy to blend in and not ask any questions, and not get called on to answer questions.

Taylor stated, "At the time, I was embarrassed to ask questions. I thought I could figure it out myself by reading the book." Similarly, Mia stated, "I was doing bad in the class, so I didn't see any point in asking for help." And Bill stated, "I had given up. I didn't think there was anything that could be done."

Jennifer's experience during her first semester was a little different but still resulted in her not reaching out for assistance when she needed it. She said,

Besides all the personal stuff happening in my life at that time, I did not know how to use the technology; the email, Blackboard, and my math class was all new to me and was overwhelming. I was not used to contacting my teachers like this, it was different than high school.

Comparing his experience now as a senior versus his first semester, Milo said, I have a much better relationship with my professors now. There is a big difference between now and my freshman. I never use to talk to my professors. It helps that I go to class now, and they actually know who I am.

Comparing her experience now as a senior versus her first semester, Evelyn stated, "Now I am very comfortable asking my professors for help. I can email them and I can meet them during office hours." Similarly, Mia stated, "It is no easier to ask for help when I 
am having issues. I feel comfortable talking to my professors. I email all my teachers now."

Other academic resources. As a result of the interviews, it was clear most of the participants did ask or seek help from the other academic resources and offices at UCM. Even when the students knew they were failing classes they did not reach out to the tutoring center, their academic advisor, residence hall staff, or use peer support. When asked directly, most of the participants denied participating study groups or studying with peers in their classes or attending supplemental instruction sessions. Grace replied, "No, I never went to the tutoring center. I was not sure how it worked at the time." Similarly, Amy stated, "I would ask my roommate, who had already took the class, but no, I never went to the tutoring center." When asked about going to the tutoring center during his freshman year, Matthew said, "I remember going with a group from my class, but it did not seem to help, so I never went back."

When asked if he ever went to the tutoring center for help during his first semester, Jack commented, "I have never felt comfortable getting tutoring from someone I do not know; I need a personal relationship to ask the for help." Though not directly stated by all participants, a low level of comfort seems to be the reason behind why many of the students did not utilize the resources provided by the tutoring center.

When comparing utilization of academic resources now as a senior versus his first semester, Marcus stated,

I use the writing center all the time now. I never did my first semester. I had heard about it and knew it was available but never went there. My sophomore year, I believe, for one of my first social work classes, the instructor required our final 
paper be reviewed at the writing center. This was the first time I went there. I have went there for other classes since then. I do not use it all the time, but it is helpful.

Similarly, Bill stated,

I did not really need to study in high school, or put much time into it, to get good grades. So, when I got to UCM did not know how to study. I did not know I could get help with study skills until after I was on probation. My advisor made me take a learning strategies class, I think, and that was useful.”

Other students talked about feeling like any help was useless during their first semester. When asked about failing classes her first semester, Emma stated, "I knew I had failed them before December; I had come to terms with this before the end of the semester. When I handed in the final for math, I knew I had failed the class." Sophia stated, "I had pretty much stopped going to class, so going to the tutoring center never really crossed my mind.” Similarly, Amy stated,

Because I had missed so many classes, I was really behind. I could not keep up. Even with help, I assumed I could not get past it. Once I stated failing tests and homework, I knew I was in trouble and didn't think anything would help. Another underutilized resource were the academic advisors assigned to each student. Each student is assigned an academic advisor based upon their declared major. However, most of the participants could not recall meeting their advisor during freshman orientation or during any events related to the Week of Welcome or the first-year experience activities. And most of the participants did not meet with their assigned academic advisor during their first semester. 
When asked when he knew he was in academic trouble during his first semester, Aaron stated,

Probably around Thanksgiving... I got an email from my advisor. It may have been from one of the teachers, but the email said I needed to schedule a meeting with my advisor. I never did. At that point, I felt like it was too late.

Similarly, when asked what she remembers regarding her academic struggled during her first semester, Heather replied,

I remember just not know what to do. I did not know how to reach out to anybody, I did not know how to utilize my resources, because I never had to do something like that before. I think I only say my academic advisor once all semester. I remember feeling hopeless and skipping my finals.

When comparing their current academic success with their past academic challenges, many participants attributed the improvement to utilizing their academic resources and connecting with UCM staff and faculty. Jennifer stated, I am in constant communication with my faculty members and my advisor. And the OAS [Office of Accessibility Services] office; using them for testing. If I have a bad day for mental health, I can ask for a day off. All my faculty members, they have been a big help. I could talk praise about them all day.

Similarly, Liam said,

I know how to utilize my resources now. She [academic advisor] is happy to help out and is a really huge support system for me. I am super close with all my professors now. They are here to help you. I stopped being so anxious. I got over it. They will help you out the best they can. 
Likewise, Marcus stated, "I now see my advisor at least once per semester. And visit the counseling center if I need to." When asked what advice you would give yourself as a freshman, Ben stated, 'Utilize the teacher's office hours. And don't be afraid to ask for help from the teachers. They are there to help you. It is part of their job. And use your resources." Sam shared very similar advice, stating, "Talk to your advisor, talk to your professor. Their job is to help you and to teach you."

\section{Summary of Findings and Themes}

The qualitative data analysis of the findings revealed three themes associated with the experiences of the students selected for this research. The three themes include the impact of "fit", student mental health, and utilization of student resources. At the institutional level, these students fit at UCM. However, not fitting into an academic program, and the connected peer groups, negatively impacted academic performance. Similarly, poor mental health and personal wellbeing negatively impacted academic performance. Finally, the lack of knowing or knowing how to adequately utilize important campus resources also has a negative impact on the student's academic performance. To overcome the academic adversity, the participants had to find their right fit on campus, improve their mental health, and learn how to utilize the student resources that are available to them. The students in the study have shown it is possible to beat the odds, to achieve success, and be on track to graduation. 


\section{Appendix F}

\section{Research Questions Answered}

The purpose of this qualitative case study was to research students who were regularly admitted to UCM as first-time, full-time freshmen, who were subsequently placed on academic probation after their first semester, but were able to recover from the academic setback, persist and be on track to complete a baccalaureate degree and understand their experiences. The research questions guiding this inquiry include: RQ1: What contributed to the students being placed on academic probation?

RQ2: How did the students recover academically, return to good standing, and be on track to degree completion?

RQ3: What concepts of Grit Theory (self-motivation, persistence, overcoming adversity) were demonstrated by the student participants of this study?

\section{Research Question One}

Research question one of this study is what contributed to the students being placed on academic probation? This question was answered through analyzing data collected from participant interviews and through document analysis. In the end, there were several factors that contributed to the participants of this study being place on academic probation after their first semester at UCM. The four primary factors found in this study include poor class attendance, students not fitting in the right academic program, poor mental health, and not knowing how to utilize the campus resources.

Class attendance. The first factor that contributed to the students earning poor grades and being placed on academic probation was not attending class regularly. At some point during all the interviews, all of the participants mentioned the importance of 
going to class. Based upon the answers to the interview questions, the participants had poor attendance during their first semester which resulted in poor grades. Subsequently, their class attendance improved, which resulted in improve class grades and GPA.

When asked what advice you would give yourself your freshman year, most of the participants responded with, go to class. Milo’s specific advice was, "If you are not going to attend an 8am class, then do not sign up for 8am classes." Jennifer also stated, "Wake up and go to class." Bill thoughtful response included, "Go to class. Everyone says, 'you have to go to class to do well', but it is so true." When comparing their current academic success with their past academic failures, most of the participants contributed the success, at least in part, to attending class. When reflecting upon his first semester, Jack stated, “...I stopped going to class.” Silas stated, "Missing class makes a different. I got behind and could not catch up."

Finding the right "fit". The second factor that contributed to the students earning poor grades and being placed on academic probation after their first semester was a poor fit academically. Based upon the answers to the interview questions, the participants were happy with their choice to attend, and stay at UCM, however, most of the participants changed their major after their first semester. Nineteen out of the 24 participants (79\%) changed their academic major at least once after their first semester. This does include one student participant who was an undeclared major, also known as open option degree seeking student, who planned to select a major after their first semester.

When asked why he changed his major, Silas stated, Nursing not going the way I wanted it to. It made me depressed. After the first semester I tried harder, but I still struggled. I was watching peers who were doing 
better, and I was not. The information was not sticking in my head even if studied. The more thought about it, less I wanted to do it.

Some students divulged struggling in a particular major or subject and needed to change. Ava stated, "The math requirement was hard, too hard for me." Similarly, Charlie admitted, “... I realized I don’t like science and could not do it.” When asked why he changed his major, Liam simply stated, "It was not for me." Some students had a change in career aspirations. Marcus stated,

I knew I wanted to do therapy with children, but I also like to create, and be an artist. So, I learned I can do art therapy, which is popular with kids. And kind of combine the two. This resulted in my changing my major but also adding a minor. Whatever the reason was, the students did not fit in their academic major and the result was poor grades.

Poor mental health. The third factor that contributed to the students earning poor grades and being placed on academic probation after their first semester was a poor mental health and wellbeing. During the interviews the participants described their mental and physical wellbeing and how it impacted their academic performance. Many of the students described a challenging adjustment period during their first semester. Grace stated,

I did not need to study that much in high school to do alright. I found out that my study habits from high school would not work in college. It was very different and challenging the first semester, trying to figure out how to handle all the homework and assignments. 
Several students described their first semester as feeling "overwhelmed" with lots of "stress." When asked about his first semester classes, Zack stated, "My class schedule first semester was kind of weird. I remember all my classes spread out throughout the day. I was not use to all the free time between classes during the day." When asked about her class during the first semester, Evelyn stated, "It kind of snow balled on me. I could not keep up with the work. I remember feeling stressed out." When asked about what she remembers the most about her first semester, Emma stated, "I remember feeling very homesick after moving in. College was a new experience for me and initially it was a lot to handle."

While other students directly reported feeling depressed or suffering from depression. Matthew stated, It was really weird, I have never struggled before [academically], but I got into a funk. And kind of sent me into a depression for a little bit, had a couple of days where I did not get out of bed."

When asked what she remembers most about her first semester, Mia bluntly stated,

"Depression." For the same question, Bill recalled,

It was 2016, and a lot was happening in the world that year. After the election, some friends committed suicide. It was messy. That was when everything culminated up to the election and that was a big part of everything for me. I just stopped going to class. I was not on my anti-depressants; I was very depressed. I did not know what to do.

Utilization of campus resources. The fourth factor that contributed to the students earning poor grades and being placed on academic probation was not utilizing or 
not knowing how to utilize the resources available to students on campus. Based upon the participant responses, they rarely or never utilized their faculty teaching the courses, their assigned academic advisor, nor the tutoring services provided on campus. When directly asked about using these resources during the interviews, most participants replied, "No." When asked about how he reacted to failing a test, Chris stated, "I was not sure what to do. In high school it always worked itself out." Similarly, Ben stated, "Even though I knew I was doing bad in my classes, I did not know what to do about it."

The opportunities provided by UCM to inform these students of the resources available to them did work. The single day orientation during the summer months before the semester started as well as the multiple first year experience activities did not provide beneficial results for these students. Based upon the participants answers, these students either did not know about the resources available to them or were not comfortable using the resources. As first semester freshman, these students did not feel comfortable asking for help from their course faculty or advisors. When asked who she contacted regarding her academic troubles during her first semester, Emma stated, "No one really. I did not reach out to my faculty. I never went to tutoring. I knew I had to get it together, so I tried harder." When asked what contributed most to him underperformance, Axel stated, “...lack of understanding how to interact with my professors. I was not sure how they could help me. I was not sure the best way to ask for help given my situation. I had some much going on my first semester, I was kind of over loaded, and I was not sure where to go.

Rather than reaching out to his professors, Aaron stated, "I worked with friends who were in my major, but not in the same class. I did not have a good connection with my teachers 
at that time. And no tutoring." When asked who he contacted regarding his academic troubles during his first semester, Charlie stated,

I did reach out to math teacher. He was one of my favorite teachers that semester. He was always open to work with students and helped me as much as he could. I don't think I was ready to listen. I had my own mental block that stopped me. And I worked with other students in major on other classes.

\section{Research Question Two}

Research question two of this study is how did the students recover academically, return to good standing, and be on track to degree completion? This question was answered through analyzing data collected from participant interviews and through document analysis. Simply stated, the students were able to recover academically by addressing the factors that contributed to their poor academic performance during their first semester. The same four factors from research question one were also involved in the academy recovery, but conversely. The four primary reasons the participants were able to recover academically, return to good standing, and be on track to degree completion include improved class attendance, students finding the right fit academically, improved mental health, and utilizing the campus resources available to them.

Improved class attendance. When asked what advice you would give yourself as

a freshman, the most common response from all participants was, "go to class." Axel stated, "It's not that hard, you have to go to class." Sophia added to the advice and said, "Go to class and sit up front." Sophia added, “...try to schedule your classes that work for your personal schedule. I like all my classes back-to-back, which makes it easier for me 
to go to all my classes." Grace stated, "With the exception of being sick, I go to all my classes now."

Finding the right "fit". Considering that 19 out of the 24 participants (79\%) changed their academic major at least once after their first semester, there appears to be a relationship between a student's fit in their academic program of study and their academic success. Silas stated, “...staying motivated has not been too much of a challenge since I changed my major.” When discussing changing his major, Ben stated, “... so I thought back to what I really enjoyed, which was acting and performing. I did band in high school, and I enjoyed performing. I had fun then, and still had a desire to perform, so I chose theater. I am happy I changed. No regrets.

Ava, who changed her major four times stated, I am glad I did not quit, early on. Even though I will be a fifth year, I am glad to be here. I really enjoy my classes and the teachers now. They [faculty] have been supportive and really, I can’t say enough good things about my program.

During the interviews, three students also mentioned their plans to seek a graduate degree after finishing their bachelor's degree. Taylor stated, "I will finish my psychology degree in December, and then I am planning to stay [at UCM] and start my master's degree the next semester. I hope to do some work in the biomedical lab." Similarly, Liam talked about the connection between his classes and his future. Liam said,

The classes were much more interesting. There was a direct connection to my future job. At least what I hope to be doing as a job. My teachers do a good job of using real world examples and real problems that we have to solve in class. 
Sophia stated, "I have really enjoyed my student teaching experiences, so I am looking forward to having my own class after graduation."

A change in academic major also meant a change in peers, friends, or social network. Milo stated, "Another big change after my freshman year was joining LAE, which is the student group for all CJ [criminal justice] students. I am involved with them and participate in some of the competitions. Similarly, Matthew stated, "After my freshman year I moved into an apartment with four other guys from the rugby team. That is who I live with now. We have more in common that I did with my first roommate." When asked what advice you would give yourself as a freshman, Jack recommended, Don't go home every weekend. Stay on campus but get out of your dorm room. Get involved in the campus community and the organizations on campus. Get into the clubs and organizations earlier. Make new friends. College is more than just going to class. You can learn new things outside of class too.

Taylor said, "I am really involved in my sorority, it was great way to meet new people and to learn about other organizations." Evelyn said, "My sorority sisters have been very supportive." When asked about what changes occurred after his freshman year, Marcus stated,

I joined a fraternity my junior year. It was a new one and I was asked to join. When you join a fraternity there are certain rules you have to follow. One of those is your GPA, you have to keep your GPA up to stay in the chapter.

Several students discussed how their living arrangements impacted their success. Emma stated, “... I have lived by myself, it so much better for me.” Grace stated, "Since I left 
the Ellis I have lived in the same apartment. I am more comfortable in my apartment. It feels more like home for me."

Improved mental health. To conclude the interview, Chris was asked if there was anything else, he would like to add or be included in this interview about your experience at UCM since your first semester, and he stated,

There needs to be more counselors at UCM. There are a lot of new students in a new area and they don't know anyone, and they get all depressed. Add more people to help with mental health needs and offer more free counseling to students. A lot of people are not able to pull themselves up.

When asked what changed the most since your first semester, many of the participants stated their mental health, specifically an improvement in their mental health. Several participants stated they had visited the UCM Counseling Center to talk with a counselor since their freshman year. Milo stated,

The Counseling Center helped me learn about taking care of yourself. Or taking care of myself during times of stress. Talking through some of my worries helped reduce my anxiety.

When asked what has changed the most since her first semester, Taylor stated, I did go to the counseling center on campus and was able to get back on my medication. I went to see my doctor back home as well. Now, I am feeling much better and I am in a better place.

Axel stated,

I figured out my way of doing things, so time management, and how to handle the workload of college classes. After this my stress went down. Some semesters 
have been more stressful than others, but my first semester was the toughest, mentally.

When asked to provide the biggest misconception about attending college, Charlie stated, "No one in my family went to college, so I did not know what to expect. I was not prepared for the pressure. It is easy to get overwhelmed." Charlie added, "You have to stay organized and keep up to reduce the anxiety; that helped me." Bill recommended, Talk to your friends or who you live with. Knowing you are not alone helps. There are other students who might feel worried or stressed out, like you do. This will help during your first couple semesters as you adjust to college.

Utilizing campus resources. When asked what advice you would give yourself as a freshman, Amy state, "Get help earlier, when you see the signs of failing." A common theme from the participants as they approach graduation was an increase level of comfort utilizing the resources that are available to them. Many of the participants discussed working with their class teachers, outside of the regular class time, and communicating with their faculty via email or through attending office hours. Mia stated, "It is now easier to ask for help when I am having issues. I feel comfortable talking to my teachers. I email all my teachers now."

Many of the participants were able to name their assigned advisor showing they knew who to contact for questions relating to their academic progress. When asked what resources you use now compared to your first semester, Jennifer explained,

I started seeing my academic advisor more. To sign up for classes, and I needed help with technology. I then thought, I might as well keep doing this, it is easier. And it feels better to have someone who knows what they are doing help me, 
rather than me trying to do it by myself. After I changed my major I got transferred to Christine. She is the best. She is actually now a reference for me on my resume.

Aaron stated, "I have met with my teachers several times, when I need to, and meet with my advisor at least once per semester. Usually to make sure I get enrolled." Jennifer stated, "I am in constant communication with my faculty members and my advisor. And the OAS [Office of Accessibility Services] office." Regarding who to contact if he is having academic difficulties, Ben stated, "Now, it is easier for me, if I am having issues, I feel very comfortable talking to teachers. And have gotten help from them. I will email teachers now. Marcus stated,

My sophomore year, I believe, for one of my first social work classes, the instructor required our final paper be reviewed at the writing center. This was the first time I went there. I have went there for other classes since then. I do not use it all the time, but it is helpful.

Furthermore, Marcus explained, "I now see my advisor at least once per semester. And visit the counseling center if I need to.”

\section{Research Question Three}

Research question three of this study is what concepts of Grit Theory (selfmotivation, persistence, overcoming adversity) were demonstrated by the student participants of this study? This question was answered through analyzing data collected from participant interviews. A consensus from the participants was none of them considered leaving UCM after being placed on academic probation after their first semester. This shows the concept of persistence and the personal characteristic of 
resiliency demonstrated by the participants. This is especially evident considering statistics surrounding the student's academic situation. Since 2014, a high percentage (consistently over $80 \%$ ) of the regularly admitted first-time, full-time freshman at UCM who struggle academically during their first semester and are subsequently placed on academic probation, end up leaving the university no degree. The participants of this study are in the minority compared to their peers in a similar situation.

Sophia stated, "Leaving was not an option for me, staying in college was the only option.” Similarly, Mia stated,

I wanted to finish what I started. Leaving never crossed my mind. I knew I had to make changes and was eager to make changes after my first semester. I didn't think it could get any worse after that semester, so I was kind of looking forward. When asked if he ever considered leaving UCM, Chris stated,

No, it was never a consideration, at all. I had a come to terms at the moment, and I need to just do this. I had to do it, I had no other options, besides going to college. There was nothing else for me to do. Leaving was not an option. Similarly, Aaron said, "I never considered leaving, but in my head, I was worried about suspension and trying to think what would I do if I get suspended."

When asked why she stayed at UCM, Jennifer stated, "It was only one semester. I just couldn't give up after one semester and because of a few teachers." Sam gave a very similar response by stating, "It was only one semester. I knew I could try again the next semester. And do better. I also found out I could repeat courses, and I did." Another commonality among the participants related to self-motivation was goal setting. Milo stated, 
Setting goals helps me get through the semester. It gives me something to look forward to each semester. I have to have goals in mind and have something to work towards. This semester, it is to get all A's.

Similarly, when asked about setting goals, Charlie stated, "Yes, I always set goals for grades." Ava answered, "Yes, I always like to know what the end goal is. I am big on planning. I have GPA goals every semester.” Amy specifically stated, "I hope I can bring up my overall GPA to above a 3.0." Zack explained,

Starting about my sophomore year, I started setting goals. This was the year I joined a fraternity. It really helped to have guys with the same focus. Our fraternity has GPA standards, to join and to say in. Being in the fraternity has helped me set goals now, especially for grades and GPA.

Goal setting, more for the short term, rather than long term, is an activity demonstrated by many of the student participants. Other participants talked about their motivation to improve their grades and stay on track to graduation. Heather described, My motivation is to not go back to where I was my freshman year. I have come so far now, compared to where I was. I want to get good grades now. I want to do my best in each class.

Amy commented,

My advisor has been a big part of my motivation to finish. She is very supportive. She helps me stay on track with my requirements and make sure I follow the degree plan now. She knows how much I have struggled and how much work it has been. 
Axel stated, "My motivation now is to get a good job. I started looking recently." Similarly, Matthew advised, "I am nervous about getting a job now. I need to finish this semester with good grades." Taylor stated, "If I go on to a $\mathrm{PhD}$ program, I will need a really good GPA."

Many participants in this study did exhibit concepts of Grit Theory, such as selfmotivation and persistence. And many participants set personal short-term goals. Furthermore, from an academic perspective the participants were able to overcome the adversity of being place on academic probation after their first semester. However, all the participants had distinct personal experiences that contributed to their academic success. It was not grit alone that propelled them through this adversity. 
Drew Michael Burkeybile was born on November 27, 1981 in Kirksville, Missouri. Drew completed his K-12 education in Richmond, Missouri. After graduating from high school, Drew attended the University of Missouri- Columbia, earning a Bachelor of Science in Business Administration degree, with an emphasis in Management, and minor in Psychology. To continue his education, Drew completed a Master of Science degree in Criminal Justice from Central Missouri State University. While completing his graduate degree, Drew served as a graduate research assistant for the Criminal Justice department. This position entailed supporting faculty with research projects, grading papers, tutoring undergraduate students, and serving as a teaching assistant when needed. Drew had a very rewarding experience while completing his degree, through research projects, professional conference attendance, and leadership roles on campus.

Drew then entered the workforce, working full time in the field of law enforcement and insurance. After several years, Drew recognized his enjoyment of working in the academic environment. After some time, Drew was able to find a job working for a small, private community college in Lexington, Missouri. In the five years of employment at the institution, Drew served in various roles and completed several tasks. Duties completed included recruitment and admissions, academic advising, coordination of the dual credit program, enrollment management, and a promotion to Academic Assessment Coordinator.

Drew was then fortunate to return to his alma mater, now named University of Central Missouri, serving as an academic advisor for undergraduate students. During this 
time Drew also served as an instructor for first-year seminar classes, served on collegelevel and program-level curriculum committees, and chaired the campus wide all-advisor committee. It was also during this time when Drew fully recognized his passion for helping and serving students. To solidify his career in higher education, Drew decided to pursue his Doctor of Education degree, in Educational Leadership and Policy Analysis, from the University of Missouri- Columbia. Since the spring of 2017, Drew has served as the Assistant Director of Graduate Education and Research at UCM supporting graduate students and faculty. Drew looks forward to a career filled with new jobs and new people, supporting students' academic success. 